\title{
A COMPARISON OF IMPUTATION METHODOLOGIES IN THE OFFENSES-KNOWN UNIFORM CRIME REPORTS
}

\author{
BY \\ JOSEPH ROBERT TARGONSKI \\ B.A., University of Colorado at Boulder, 1999 \\ M.A., University of Illinois at Chicago, 2001
}

\section{THESIS}

Submitted as partial fulfillment of the degree requirements

for the degree Doctor of Philosophy in Criminology, Law and Justice in the Graduate College of the

University of Illinois at Chicago, 2011

Chicago, Illinois 


\section{ACKNOWLEDGEMENTS}

I would like to thank that National Institute of Justice for their support of this research though dissertation fellowship \#2004-90721-IL-IJ and the Bureau of Justice Statistics for their sponsorship of this research during the Quantitative Analysis of Crime and Criminal Justice Data summer workshop summer workshop at the University of Michigan.

I would also like to thank my wife, Marianne, for providing motivation and seeing me though the more stressful times of the research and writing phases.

I am greatly indebted to my committee members Dennis Rosenbaum, Sarah Ullman, Donald Hedeker, and Joseph Peterson for their support and feedback during all phases of the research. Most of all, I thank my chairman Michael Maltz, for his countless hours of mentoring, support, and dedication as my advisor. 


\section{TABLE OF CONTENTS}

CHAPTER

I. INTRODUCTION.

$\underline{\text { PAGE }}$

A. Statement of the Problem....................................... 1

B. Significance of Imputation.................................... 2

C. Research Goals and Objectives...................................... 4

D. Chapter Overview............................................. 5

II. LITERATURE REVIEW ....................................... 7

A. History of the Uniform Crime Reports ......................... 7

B. Components of the Uniform Crime Reporting Program............. 9

1. Offenses-Known............................................. 9

2. Age, Sex, Race and Ethnicity of Arrestees................... 11

3. Supplementary Homicide Reports............................ . 11

4. Law Enforcement Officers Killed or Assaulted ................ 11

5. Police Employment....................................... 12

6. Hate Crimes........................................... 12

7. Nation Incident Based Reporting System ................... 13

8. Summary................................................ 13

C. Coverage of the Uniform Crime Reports ....................... 14

D. Measurement Error in the Uniform Crime Reports ............... 14

1. Victim Nonreporting....................................... 14

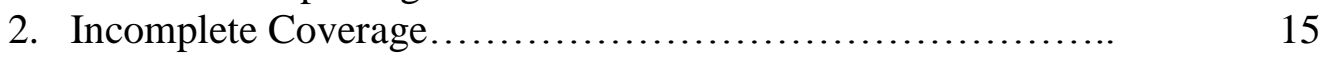

3. Imputation Issues......................................... 16

4. Hierarchy Rule.......................................... 16

5. Organizational Issues...................................... 17

6. Summary............................................ 18

E. Missing Data and Imputation............................... 18

1. Types of Missing Data...................................... 18

a. Missing Completely at Random............................ 19

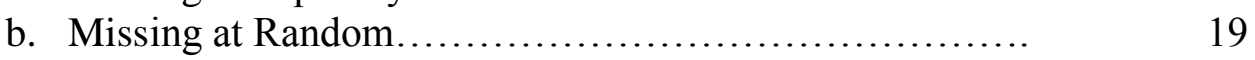

c. Missing Not at Random................................ 20

2. Approaches to Handling Missing Data...................... 20

a. Overview......................................... 20

b. Complete case....................................... 21

c. Weighting ........................................... 22

d. Single Imputation................................. 22

i. Hot Deck.................................... 23

ii. Mean Substitution................................... 23

iii. Historical/Longitudinal Imputation..................... 23

iv. Cold Deck........................................ 24

e. Multiple Imputation...................................... 24

F. Simulation Studies......................................... 25

G. Uniform Crime Reports and Missing Data...................... 26 


\section{TABLE OF CONTENTS (continued)}

CHAPTER

1. Background ............................................ $\frac{26}{26}$

2. Supplementary Homicide Reports Imputation................. 28

3. County-Level Data...................................... 30

4. National Archive of Criminal Justice Data Imputation.......... 31

5. Summary .............................................. 32

III. DATA AND METHODS ........................................ 33

A. Data Sources........................................... 33

B. Data Preparation.......................................... 34

C. Graphical Data Analysis...................................... 37

D. Data Cleaning.............................................. 38

1. Agency Name Checks.................................. 38

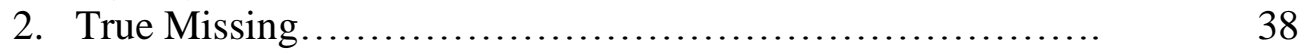

3. Aggregation of Months................................. 39

4. Covered-Bys........................................ 41

5. Non-Existent Agencies................................. 42

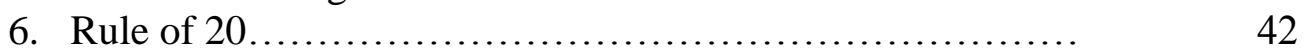

7. Negative Values...................................... 43

8. Outlier Values.......................................... 45

E. Current FBI Imputation Methodology.......................... 47

F. Longitudinal Imputation Method............................. 47

G. Simulation Data Set..................................... 50

1. Identify the Pattern of Missing Data....................... 50

2. Identify Full Reporting Agencies.......................... 51

3. Deletion of "Good" Data................................. 54

4. Running Imputations.................................. 56

IV. RESULTS ..................................................... 57

A. Introduction.......................................... 57

B. Descriptive Statistics of Missing Data........................ 57

1. New Definition of Missing Data Example.................. 57

2. Missing Data for Total United States....................... 58

3. Missing Data by Group................................. 58

4. Frequency of Missing Value Codes...................... 65

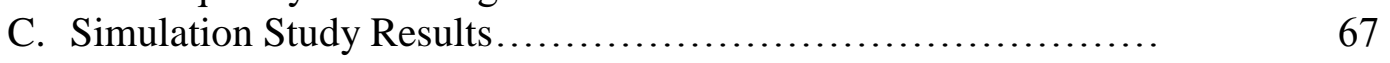

1. Absolute Value Differences............................ 67

2. Crime Index Level Accuracy........................... 72

V. DISCUSSION AND CONCLUSION................................ 76 


\section{TABLE OF CONTENTS (continued)}

CHAPTER $\quad \underline{\text { PAGE }}$

A. Discussion............................................ 76

B. Limitations of Research..................................... 79

C. Recommendations for Future Research...................... 80

D. Conclusion................................................... 81

\section{APPENDICIES}

Appendix A: FBI Forms........................................ 84

Appendix B: Data Preparation Steps............................. 87

Appendix C: Visual Basic Code for Imputation.................... 93

Appendix D: State Level Missing Data Charts....................... 104

CITED LITERATURE.............................................. $\quad 129$

VITA............................................................... 135 


\section{LIST OF TABLES}

$\underline{\text { TABLE }}$

$\underline{\text { PAGE }}$

I. MISSING DATA IN THE UNIFORM CRIME REPORTS......... 20

II. FBI GROUP TYPES ..................................... 26

III. VARIABLE TYPES ........................................ 35

IV. MONTHLY AGGREGATION MISSING VALUE CODES....... 40

V. SUMMARY OF MISSING VALUE CODES .................... 46

VI. FREQUENCY OF MISSING VALUE CODES, ALL ORIS,

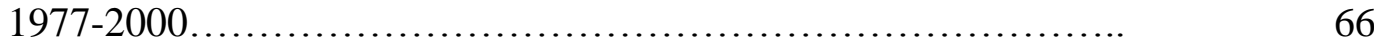

VII. SIMULATION RESULTS OF ABSOLUTE DIFFERENCES....... 69

VIII. SIMULATION RESULTS OF AVERAGE ABSOLUTE VALUE DIFFERENCES BY RUN LENGTH........................ 70

IV. SIMULATION RESULTS OF ABSOLUTE VALUE DIFFERENCES BY RUN LENGTH................................................ 71

X. COMPARISON OF CRIME COUNT TOTALS $\ldots \ldots \ldots \ldots \ldots \ldots \ldots \ldots \ldots$

XI. CRIME COUNT PERCENT ACCURACY TO ACTUAL............... 74 


\section{LIST OF FIGURES}

FIGURE

$\underline{\text { PAGE }}$

Figure 1. $\quad$ FBI Algorithm for Imputation........................ 27

Figure 2. Variable Naming................................. 34

Figure 3. Quarterly, Semiannual and Annual Reporting Example...... 39

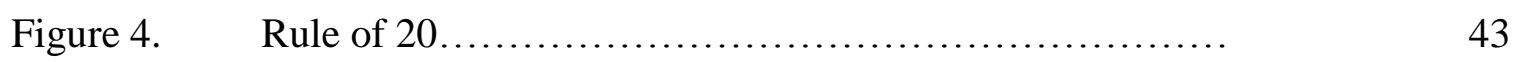

Figure 5. Negative Crime Values, 1977-2000................... 44

Figure 6. Outlier 9999 Value for Crime Index, Durango, CO......... 45

Figure 7. Longitudinal Imputation Example..................... 49

Figure 8. Missing Data Run Lengths for All ORIs................. 50

Figure 9. Number of ORIs that Qualify for Imputation by State...... 53

Figure 10. Percent of ORIs that Qualify for Imputation by FBI Group.. $\quad 54$

Figure 11. Screenshots of Simulated Data...................... 55

Figure 12. Percent of Missing Data All ORIs..................... 58

Figure 13. Percent of Missing Data Group I...................... 59

Figure 14. Percent of Missing Data Group II....................... 60

Figure 15. Percent of Missing Data Group III...................... 61

Figure 16. $\quad$ Percent of Missing Data Group IV ...................... 61

Figure 17. Percent of Missing Data Group V..................... 62

Figure 18. Percent of Missing Data Group VI..................... 62

Figure 19. Percent of Missing Data Group VII...................... 63

Figure 20. Percent of Missing Data Group VIII...................... 64

Figure 21. Percent of Missing Data Group IV...................... 64

Figure 22. Comparison of Crime Count Totals.................... 73 
Figure 23. Yearly Differences of Imputation Methods for Total US Base on the average of the five iterations............................... 


\section{LIST OF ABBREVIATIONS}

$\begin{array}{ll}\text { CIUS } & \text { Crime in the United States } \\ \text { FBI } & \text { Federal Bureau of Investigation } \\ \text { IACP } & \text { International Association of Chiefs of Police } \\ \text { ICPSR } & \text { Inter-university Consortium for Political and Social Research } \\ \text { LOCF } & \text { Last Observation Carried Forward } \\ \text { LEAA } & \text { Law Enforcement Assistance Administration } \\ \text { LEOKA } & \text { Law Enforcement Officers Killed and Assaulted } \\ \text { MAR } & \text { Missing at Random } \\ \text { MCAR } & \text { Missing Completely at Random } \\ \text { MI } & \text { Multiple Imputation } \\ \text { MNAR } & \text { Missing Not at Random } \\ \text { NACJD } & \text { National Archive of Criminal Justice Data } \\ \text { NCIC } & \text { National Crime Information Center } \\ \text { NPA } & \text { National Police Association } \\ \text { NVSS } & \text { National Vital Statistics System } \\ \text { NCVS } & \text { National Crime Victimization Survey } \\ \text { NIBRS } & \text { National Incident Based Reporting System } \\ \text { ORI } & \text { Originating Agency Identifier } \\ \text { SAC } & \text { Statistical Analysis Center } \\ \text { SHR } & \text { Supplementary Homicide Reports } \\ \text { SPSS } & \text { Statistical Package for Social Sciences } \\ \text { SSLEA } & \text { Sample Survey of Law Enforcement Agencies } \\ \text { UCR } & \text { Uniform Crime Reports } \\ & \end{array}$


VBA

Visual Basic for Applications 


\section{SUMMARY}

One of the most widely used and important sources of crime data for criminologists and criminal justice policy stakeholders is the Offenses-Known Uniform Crime Reports (UCR). However, it comes with many limitations, including missing data from non-compliant police agencies. The missing data are adjusted for by imputing data based on a cross-sectional methodology to maintain comparable trending analysis.

The purpose of this study was to reexamine and recode missing data in the UCR for the years 1977-2000 for all police agencies in the United States. With the newly cleaned dataset, a clearer picture of the UCR error structure would emerge and patterns of missing data could more accurately be described. The study found that there are more missing data than identified by the FBI's quality control.

The next phase of the project was to create a dataset with only full reporting agencies for a 10 year period, which would be used to test the cross-sectional method against a longitudinal method. This was done by creating simulation data sets that "punched out" the real crime values, thus artificially creating missing data. Each imputation method could then be tested by comparing the imputed value to the actual value. The overall results showed that in most circumstances, the longitudinal method was more accurate at estimating the missing crime data points. 


\section{INTRODUCTION}

\section{A. Statement of the Problem}

Academics, researchers, police chiefs, and policy analysts make extensive use of the FBI's Offenses-Known Uniform Crime Report (UCR) data. While these data are routinely used for important research and policy decisions, there are many gaps in the data that are filled in based on an imputation methodology developed in the 1950's when computing and data storage capabilities were limited. Although it is the nation's primary source for crime data, it has many weaknesses. The weakness most researchers have focused on is the so-called "dark figure" of crime, or crimes that are not reported to the police (Skogan 1977). While the UCR is a census of law enforcement agencies, that does not mean it is immune from the problem of non-compliance and missing data. This is an issue that has become more pronounced over time as funding and resources have been reduced for law enforcement agencies to support their UCR reporting (Maltz 1999).

Since 1958, the FBI has used an untested method to impute, or filled in the missing data for its yearly report, Crime in the United States. This method is based on cross-sectional data, which does not account for an agency's past reporting history, or issues such as seasonality and zero population jurisdictions. This dissertation will seek to 1) Identify the nature and extent of missing data in the Offenses-Known UCR, 2) Develop methods to clean the FBI's dataset, and 3) Test the FBI's current imputation methodology against an alternative longitudinal imputation method. 


\section{B. Significance of Imputation in the UCR}

Generating the UCR takes a great deal of time and effort, not only for the FBI, but for the over 17,000 police agencies that collect and transmit data their crime data to the $\mathrm{FBI}^{1}$. Considering the resources used in this endeavor, it is unfortunate that so little use is made of the data. In fact, they are used primarily to provide state, regional, and national trends. For this purpose, the current cross-sectional method of imputation was adequate. However, in recent years the uses of UCR data have expanded. UCR data sets are now more accessible since they are on the internet, the UCR has been used in determining allocation of federal funds, and researchers are using the data for smaller geographic units (Maltz 1999).

At the county level, UCR data have been used to investigate a number of policyrelated issues (Wilkinson 1984; Petee and Kowalski 1993; Petee, Kowalski et al. 1994; Kposowa, Breault et al. 1995). Several studies have recently examined the relationship between "right-to-carry" laws and violent crime using county-level data (Lott and Mustard 1997; Lott 1998; Lott 2000). Lott's books not only opened up research into the effect of these laws, it had the side benefit of popularizing county-level crime data in general. When examining crime rates at the county-level, imputation becomes even more important because those estimates are much more sensitive to missing data.

These county-level studies used either the FBI's annual "Crime by County" data sets or the annual county-level crime data set from the National Archive of Criminal Justice Data (NACJD) - which is based on the FBI's Crime by County file. Both of these

\footnotetext{
${ }^{1}$ Some police agencies report their data first to a state-level agency
} 
data sets have major flaws that are detailed in Maltz and Targonski (2002, 2003). That is, the imputation strategies used by both the FBI and NACJD have significant deficiencies.

With the advent of the internet, UCR data are being used more extensively. The results of any study of criminal justice policy that uses UCR data will only be as robust as the data it uses. However, as criminal justice researchers increasingly use UCR data for complex statistical studies, and at smaller and smaller levels of aggregation, there is a stronger need for a more sophisticated imputation method.

As noted above, the UCR has been used for the appropriation of federal anticrime funding. This occurred with the with 1994 reauthorization of the Omnibus Crime Control and Safe Streets Act of 1968. Funding to local agencies was allocated based on the number of violent crimes in the prior three years, using the unimputed data in the UCR. Maltz (1999) found that for the three years of data that was being used to disseminate these funds, $19 \%$ of police agencies did not provide even a single month of data. Such major federal policy decisions need to be made on the most accurate and reliable data possible. When police agencies fail to report their data to the FBI, scientifically sound imputation methods are the only way to make up for the missing values. As the UCR becomes more important in federal policy decision-making and fund allocation, the methods used to impute for missing data become even more critical.

The UCR is not the only criminal justice-related data source where imputation is a major factor. Imputation has also been an important issue in studies using the National Crime Victimization Survey (Ybarra and Lohr 2002) and the Sample Survey of Law Enforcement Agencies (SSLEA) (Dorinski 1998). Imputation is useful in government 
surveys because it allows for the creation of complete rectangular datasets that can easily be analyzed by researchers (Little 1988).

Given the importance of UCR data, many police chiefs and politicians have succumbed to manipulating the data for political gain. Examples have been documented of data tinkering in the District of Columbia and Philadelphia where offenses were downgraded to keep them out of the crime index (Seidman and Couzens 1974), and Maltz (1999) documented this practice in other cities. Most often, the manipulation is downward. Police and politicians want to show they are "doing something" about crime and that the result of their efforts is a reduced crime index.

\section{Research Goals and Objectives}

The purpose of this project is to develop a more accurate and reliable method of imputing crime data in the Uniform Crime Reports (UCR) and to provide a more complete understanding of UCR missing data and error structure. This will be accomplished by the following steps:

1) A thorough data cleaning of approximately 17,000 ORIs based on the Offenses-Known UCR data from 1977 to 2000. It is based on an agency-level data set that includes all Originating Agency Identifiers (ORIs), which are the FBI identification

codes for individual police agencies in the UCR system. This single data set includes all the crime data on a monthly basis between 1977-2000 for each police agency. It includes whether or not each month was reported, based upon the FBI definition of a missing data point and the quality control parameters designated by the researchers. In addition, it includes a host of new numerical codes for different types of missing data. 
2) Analysis of this cleaned dataset, to provide insight to the types of data errors and patterns of missing data in the UCR.

3) Development of a "simulation dataset" based on ORIs with complete reporting for data ten-year period. This complete reporting file will then have some of the real data points selectively deleted or also referred to as "punched out". That will allow the "real" values to be compared to the estimated values from both the current FBI imputation method and the longitudinal method.

As with any secondary analysis, this study is limited to the quality and completeness of the available data. The researcher did not have any involvement in the collection or original cleaning of the data. In the case of the UCR, many studies have examined the weakness of the data and limitations of its use. These weaknesses will be described in greater detail in the literature review.

For the data cleaning that was done for the project, all the analysis was done on the data as archived. Follow-up or input was not derived from the reporting agencies through any phone calls or in-person interviews. Given the scope of the project and the thousands of ORIs involved, such follow-up was not feasible.

\section{Chapter Overview}

Chapter two provides a comprehensive review of the literature. This includes the history of the UCR system, prior research on UCR weaknesses, and an overview of various imputation methods. Chapter three explains the methods used, including the sources, data cleaning steps, and new missing value codes. Chapter four describes the missing data in the UCR and the basis for the imputation dataset. Chapter five provides 
the results of the two imputation methods based on the simulation dataset. Chapter six includes the discussion and recommendations for future research on UCR imputation. 


\section{LITERATURE REVIEW}

\section{A. History of the UCR}

The Uniform Crime Reporting (UCR) system was developed in 1929 by the International Association of Chiefs of Police (IACP), which was originally the National Police Association (NPA) (Maltz 1977). At that time, there was no national collection of criminal statistics. The goal was to produce a data collection system that would have uniform definitions for crime and allow for cross-jurisdiction comparison. A crime data collection system would also provide a way to measure crime and would counter the efforts of journalists who would manufacture crime waves to sell newspapers (Maltz 1977). Several different methods of crime measurement were proposed, but ultimately the committee decided on measuring crimes recorded by the police. After consulting local police departments, a list of seven crimes, now known as the Crime Index or Part I crimes, were chosen. These seven crimes include murder, rape, robbery, assault, burglary, larceny and auto theft and still function as the Crime Index today ${ }^{2}$. They were chosen based on the fact that they were serious, prevalent and likely to be reported.

In addition to the Index Crimes, the UCR program began collecting data on lesser offenses where are referred to as the "Part II" crimes. Part II crimes include simple assault, fraud, vandalism, disorderly conduct and gambling ${ }^{3}$. The responsibility for collection and publishing the data became the task for the Bureau of Investigation, later known as the Federal Bureau of Investigation (FBI).

\footnotetext{
${ }^{2}$ Arson was added to the UCR in 1979, which became known as the Modified Crime Index. The Standard Crime Index is still reported without arson. The arson data was not included for this research project.

${ }^{3}$ For a complete list and detailed description of Part II crimes, see the Uniform Crime Reporting Handbook (FBI 1984)
} 
In the first two years of 1930 and 1931, the FBI published the crime data on a monthly basis. Over time, this was reduced to quarterly in 1932, semiannually in 1943 and finally went to annual reporting in 1958.

The UCR program did not receive a major overhaul until 1958. In the prior year, a committee was formed to evaluate the UCR program and recommend changes (FBI 1958). In addition to only releasing data annually, the committee recommended a number of changes to the way data were reported in the Crime Index. Negligent manslaughter was excluded, as were larcenies under fifty dollars, statutory rapes and simple assaults (FBI 1958). The biggest change related to this research was that the FBI began its imputation method that is still applied today ${ }^{4}$.

Through the 1960's and 1970's, the burden of collecting local agency data shifted to the states, which would serve as an intermediary between the local agencies and the FBI's UCR program. The rise in state-level agency reporting was directly related to funding by the Law Enforcement Assistance Administration (LEAA), which provided funding for states to develop Statistical Analysis Centers (SACs). Many states have the SACs serve as the clearinghouse for state-level UCR data, but some states delegate this task to their State Police. In 1999 there were 44 states that had state-level reporting agencies that met the FBI's requirements (Maltz 1999). However, of these 44 states, only 25 had state-level laws requiring their local police agencies to report their crime data (Riedel and Regoeczi 2004).

\footnotetext{
${ }^{4}$ This will be discussed in greater detail in Chapter four.
} 
In 1985, the FBI commissioned a study called Blueprint for the Future of the Uniform Crime Reporting Program (Poggio 1985), which outlined long-term changes to crime reporting in the United States. The focus of this report was shifting the system from the summary Crime Index to an incident-based system, now called the National Incident Based Reporting System (NIBRS). This would provide detailed victim, offender, and weapon information at the incident level for each crime recorded by the police. South Carolina was the first state to be NIBRS-compliant and as of 2007, 31 states are compliant, representing 6,444 police agencies (FBI 2011).

\section{B. Components of the Uniform Crime Reporting Program}

\section{Offenses-Known}

The primary data collection system of the UCR is the Offenses-Known data, which collects monthly crime tabulations. They are collected on what is known as the

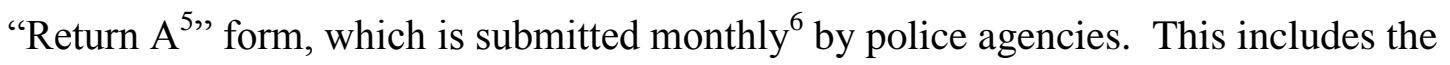
Crime Index, which encompasses murder, rape, robbery, aggravated assault, burglary, larceny, and motor vehicle theft (and arson, see Note 1). Part II offenses, which include lesser offenses such as gambling, liquor law violations, and prostitution are also collected but are not included in the official crime index. Data are collected on clearances of crimes providing an indication of the effectiveness of police investigations. The Return A also asks for data on "unfounded crimes," or incidents that are found to be false or baseless.

\footnotetext{
${ }^{5}$ For examples of the Return A and Supplementary Homicide Report forms, see Appendix A.

${ }^{6}$ While a majority of agencies report monthly data per the FBI guidelines, some jurisdictions report quarterly, semiannual, or annual data. This will be described in greater detail in chapter three.
} 
There is also the Supplement to the Return A, which collects information on value and type of property stolen and property recovered by the police. It also includes breakdowns of offenses such as the location of robberies, time and location of burglaries, and types of larceny.

An important step in tabulating the Offenses-Known data is the hierarchy rule. For each crime incident, no matter how many offenses are committed, only the most serious offense is to be counted on the Return A (FBI 1966; FBI 1984). The hierarchy rule is eliminated under NIBRS, which will be discussed in greater detail later.

Once submitted to the FBI, the data undergo scrutiny for reporting accuracy. The FBI looks for sharp rises or drops in crime trends to assess the accuracy of the data. ${ }^{7}$ If they find problems with the data, follow-up procedures are implemented as a quality control feature. The FBI holds training seminars for police departments on UCR reporting and provides them with the Uniform Crime Reporting Handbook (FBI 1984) that gives a detailed explanation of reporting procedures.

Once all the data are in, the FBI analyzes the data to assess crime trends. They also compute a crime rate, which is the number of crimes divided by the population of a given area. Each year, the FBI publishes Crime in the United States, which provides a detailed breakdown of police crime data to the public. The data from the UCR are also electronically archived for researchers to analyze.

\footnotetext{
${ }^{7}$ However, not all of the data anomalies are caught by the FBI.
} 


\section{Age, Sex, Race and Ethnicity of Arrestees (ASR)}

Arrest information is captured on the age, sex, race and ethnicity of offenders. This information is also collected monthly and is divided into adults and juveniles under the age of 18. Arrest information is collected for Part I and II crime, as well as curfew and runaway information for juveniles.

\section{Supplementary Homicide Reports (SHR)}

In addition to the summary homicide counts on the Return A, additional data are collected via the Supplementary Homicide Reports (SHR), which was added to the UCR system in 1961. The SHR is incident- rather than summary-based. The SHR collects additional data on each homicide, including information on the victim/offender relationship; age, sex, and race of victim and offender (if known); weapons; circumstance of the homicide ${ }^{8}$, and situation ${ }^{9}$. Coverage was minimal in the early years of the system, with data primarily coming from larger cities (Riedel 1990). The detailed information provides a rich description of homicide, which cannot be extracted from summary data. However, the SHR is not without its limitations. Problems have been identified with the coding of circumstances (Loftin 1986) and with missing data (Maltz 1999; Fox 2000).

\section{Law Enforcement Officers Killed and Assaulted (LEOKA)}

The FBI also collects information on police officers killed or assaulted in the line of duty. Law Enforcement Officers Killed and Assaulted (LEOKA) program collects data on a monthly basis for such incidents, along with details on the weapons used, type

\footnotetext{
${ }^{8}$ Examples of circumstances include rape, robbery, burglary, arson, prostitution, gambling, lover's triangle, argument over money, gangland killing, youth gang killing, sniper attack and unknown.

${ }^{9}$ Situations include Single Victim/Single Offender, Single Victim/Unknown Offender/Offenders, Single Victim/Multiple Offenders, Multiple Victims/Single Offender, Multiple Victims/Multiple Offenders, Multiple Victims/Unknown Offender or Offenders.
} 
of assignment, time of day, circumstance, as well as a text based narrative. The system also collects information on the circumstances related to officers killed or assaulted and arrest attempts. It includes details on assignment type, weapon used, and type of police activity

\section{Police Employment}

On an annual basis, the UCR program collects data on law enforcement employees. This provides details on number of officers, number of civilian employees, and gender composition.

\section{Hate Crime}

In the 1980's, the term "hate crime" was originally coined by Congresspersons John Conyers, Barbara Kennelly, and Mario Biaggi in the first appearance of the bill that would mandate federal collection of data on bias-motivated crime (Jacobs and Potter 1998). This led to increased usage of the phrase in the media to refer to crimes that were motivated by racial/ethnic or religious prejudice. The bill passed and became known as the Hate Crime Statistics Act of 1990.

Among the reporting states, each of their own statutes differs as to what constitutes a hate crime. To avoid this problem, the FBI has its own criteria that are used to standardize reporting. The FBI statute includes bias motivated crime for race, religion, disability, sexual orientation, or ethnicity/national origin and is defined as, "A criminal offense committed against a person or property which is motivated, in whole or in part, by the offender's bias against a race, religion, disability, sexual orientation, or ethnicity/national origin; also know as a Hate Crime (FBI 1999).” 
The incident level portion of the Hate Crime statistics reporting includes additional information on each incident, including type of bias, victim information, number of victims, and race and number of offenders.

\section{National Incident-Based Reporting System (NIBRS)}

While the summary UCR statistics provide an aggregate-level view of crimes reported, it provided little detail on individual crime incidents. To enhance the reporting of police crime statistics, the FBI developed the next generation of the UCR program with the National Incident-Based Reporting System (NIBRS). It is based on the guidelines and recommendations of the aforementioned report (Poggio 1985), it provides incident-level crime reporting, rather than only the summary reports found on the Return A. There are a number of other changes from the summary UCR, as described in (FBI 2000):

- Updated crime definitions

- Forcible rape could include male victims

- Abolition of the hierarchy rule

- Details on victim and offender characteristics

- Data on crimes against society (drug crimes, gambling, prostitution, etc)

\section{Summary}

Although the FBI collects all these various data sets, the one that is used and cited most frequently is the Crime Index, or Offenses-Known data. When journalists, politicians, or criminologists refer to police crime data or the crime rate, they are most 
often talking about the Part I Crime Index. As the data for the project focused on the Part I index crime, all references to "UCR" will pertain to the Offenses-Known segment of the UCR program.

\section{Coverage of the UCR}

The UCR encompasses all state and local law enforcement agencies, which submit data on a voluntary basis. The UCR is not a sample of agencies, but attempts to gather data from every state and local police agency. It attempts to take a census of law enforcement agencies, but is actually a "pseudo-census" because some members of the population are not reached (Maisel and Persell 1996). Each police agency is given an Originating Agency Identifier (ORI) code that is assigned by the FBI. The FBI originally began using the ORI code to identify agencies with computer terminal linked to National Crime Information Center (NCIC).

\section{Measurement Error in the UCR}

\section{Victim Nonreporting}

One of the greatest weakness is of the UCR is that it only counts crimes that are reported to the police (Skogan 1974; Skogan 1975; Skogan 1977; Schneider and Wiersema 1990; Mosher, Miethe et al. 2002). Crimes that occur but are not brought to the attention of the police are referred to as the "dark figure" of crime. Sometimes crimes such as shoplifting may go completely undetected (Schneider and Wiersema 1990).

Moreover, many citizens that either are victimized or witness a crime fail to report it. Many factors influence citizen reporting of crimes to the police. Thinking the police can do very little, lack of confidence in the police, and not knowing the procedures to 
report a crime may prevent a victim from reporting a criminal incident (Schneider and Wiersema 1990). Other studies have found that citizens are more likely to report a crime to the police if they had positive police interactions in previous victimizations that had been reported (Conaway and Lohr 1994), however, police do not always have a good track record of handling the psychological needs of victims (Rosenbaum 1987). Rape is one of the most underreported crimes, which is due to several factors. Rape is an emotionally disturbing crime, and victims often experience symptoms of posttraumatic stress (Ullman and Siegel 1994). The victim may even have to convince herself that she ${ }^{10}$ was victimized before she feels she can convince others (LaFree 1989).

Victim surveys, particularly the National Crime Victimization Survey (NCVS), data can be used as a comparison to measure the level of unreported crime to the police. Only $36.8 \%$ of all victimizations are reported to the police, with rates as low as $30.7 \%$ for rape and $28.4 \%$ for larceny (Ringel 1997). While the NCVS shows a clear level difference in the amount of crime compared to the UCR, the evidence is more mixed on whether the two systems agree or disagree on the trend in crime. Some researchers argue that the two systems trend similarly (O'Brien 1990; O'Brien 1991; Blumstein, Cohen et al. 1992) while others argue they do not (Menard 1991; Menard 1992). For a complete analysis of the UCR-NCVS trending debate, see Lynch and Addington (2007).

\section{Incomplete Coverage}

Federal collection of crime data has always had the problem of non-compliance by police departments. Claims of high reporting participation in the UCR are often

\footnotetext{
${ }^{10}$ While under many state statutes men can be victims of rape, the FBI UCR definition specifies that the victim is a woman.
} 
misleading, since an agency may be considered "participating" if it submits only one month of data for the entire year. Given the voluntary nature of the UCR program, the FBI does not have much leverage to get agencies to report their data.

The most comprehensive analysis regarding the extent of coverage and missing data in the UCR is found in Maltz (1999). Maltz found that UCR coverage had decreased over time, with less of the population being covered often due to the agencies' problems with conversion to NIBRS. In addition, factors such as budgetary constraints and natural disasters impede the ability of police agencies to keep accurate records of crime ${ }^{11}$. There is also a wide disparity between states, with states such as Illinois submitting unacceptable data resulting from state law defining rape in a gender-neutral way, while the FBI defines it as forcible intercourse between a man and a woman.

\section{Imputation Issues}

In the case of missing data, the FBI imputes data using a cross-sectional method. The imputation is only used for state and national estimates of crime and is not reported for individual agencies. The National Archive of Criminal Justice Data (NACJD) produces an imputed county-level dataset, which began with a different imputation method, and which has been criticized for undercounting crime in many counties (Maltz and Targonski 2002; Maltz and Targonski 2003).

\section{Hierarchy Rule}

\footnotetext{
${ }^{11}$ It is yet to be determined how state and municipal budget problems will impact crime reporting. Some cities have begun reductions in staffing for police agencies, most notably Newark, NJ, which has recently considered eliminating over 200 police positions (Queally and Giambusso 2010)
} 
The hierarchy rule provides another source of measurement error and under coverage. Since only the most serious offense is recorded in an incident, the crime rate will be biased downward. Related to the hierarchy rule is the "hotel rule." If a series of burglaries occurs in a dwelling with multiple residences, the burglary is scored as one offense rather than multiple (FBI 1984). The hotel rule does bias burglary rates because not all cities have the same proportion of transient or multi-family housing. For example, resort areas would have a burglary rate biased downward as compared to an area with primarily single-family homes.

\section{Organizational Issues}

Organizational issues can also influence police crime reporting (Kituse and Cicourel 1963; McCleary, Nienstedt et al. 1982). Police are decision makers, and factors such as complainant's social class and attitude toward the police have been found to influence crime reporting (Black 1970). Police turnover and organizational change can influence rates of reported crime. One study found that burglary rates can be influenced by changes in police management, making the crime rate more a function of organizational goals rather than an accurate measure of crime (McCleary, Nienstedt et al. 1982). Problems can also arise at the state reporting level, with overworked clerks unable to give the proper time for quality control (Brownstein 2000). The way crimes are classified and scored is also subject to measurement error. Misclassification of crimes, particular simple and aggravated assault, has been identified as an issue with UCR reporting (Nolan, Hass et al. 2006). 
Technological advancement can aid the process, but it can also be a hurdle. For example, conversion to NIBRS has disrupted summary UCR reporting in Vermont, New Hampshire, and Kansas (Maltz 1999).

\section{Summary}

Although the UCR is the primary source of data on crime, it does have many weakness and limitations. While some limitations are inherent to measuring crime from police reports, imputation is an area that researchers and the FBI have some control over. Testing and enhancing imputation methods are an important part of criminal justice research with UCR data that should not be overlooked.

\section{E. MISSING DATA AND IMPUTATION}

\section{Types of Missing Data}

Despite the best efforts of researchers, almost all datasets have missing data. The UCR and all criminal justice data are no exception. Whether it is UCR data or another source of crime data, criminologists too often rely on complete-case analysis as an approach to handling missing data (Brame and Paternoster 2003). This section will seek to summarize the different methods researchers have developed to handle missing data and how these methods have been applied to crime data.

When assessing and analyzing missing data trends, it is important to consider the missing data mechanisms. The underlying cause of the missing data can have an influence on which type of imputation method is selected. The three types of missing data, also referred to as "missingness," are described as being missing completely at 
random (MCAR), missing at random (MAR), and missing not at random (MNAR) (Little and Rubin 1987; Rubin 1987).

\section{a. Missing Completely at Random (MCAR)}

Data can be classified as missing completely at random when the probability of missing data for variable $\mathrm{X}$ is unrelated to itself or another other covariates in the data set. Thus, missing data are not correlated with any of the variables in the data set. This can be the most easily adjusted for type of missing data and is ideally suited for multiple imputation techniques (Little and Rubin 1987). Hypothetically, even listwise deletion would yield reliable results, because the complete cases would statistically be no different than the missing cases. However, the criteria for MCAR are difficult to meet because data are often correlated with other factors.

In the case of the UCR, an ORI's data could be considered MCAR only if the data were missing for some reason unrelated to crime, such as a natural disaster that prevented the agency from submitting UCR reports (Maltz 2007).

\section{b. Missing at Random (MAR)}

Data are Missing at Random (MAR) when the probability of missing data on a variable is non-random only in the bivariate case for measured variables. An example in homicide data is where the circumstance variable could be MAR if it was related to the victim-offender relationship, but not the circumstance itself (Wadsworth, Roberts et al. 2008).

Maltz (2007) identifies computer problems and noncompliance with UCR standards and examples of MAR for UCR data. Computer problems with UCR reporting 
stemmed from conversion to the National Incident Based Reporting System (NIBRS).

Some cities encountered software issues in the conversion, which left them without any way to report via NIBRS or the summary UCR system.

\section{c. Missing Not at Random (MNAR)}

A datum that is Missing Not at Random (MNAR) is missing when there is some underlying mechanism that is causing the data to be missing in a patterned fashion.

MNAR is therefore also referred to as non-ignorable missing data. Maltz (2007)

identifies other examples of UCR data being MNAR to include undercoverage, nothing to report, administrative problems, coding errors, and unrecorded crimes.

Table I: Missing Data in the UCR (Maltz 2007)

\begin{tabular}{|l|l|l|}
\hline MCAR & MAR & MNAR \\
\hline Natural Disaster & Noncompliance with UCR Standards & Undercoverage \\
& Computer Problems & Nothing to report \\
& & Administrative issues \\
& & Coding errors \\
& & Unrecorded crimes \\
\hline
\end{tabular}

Data that are MNAR are the most common and also the most difficult to handle. By definition, bias has been entered into the data by the missing data mechanism.

\section{Approaches to Handling Missing Data}

\section{a. Overview}

The ideal situation for any data collection is to have no missing data.

Unfortunately, this is rarely the case and missing data must be dealt with appropriately. There are three basic approaches to handle missing data: Complete cases analysis, 
weighting, and imputation. Each has its own pros and cons and is most appropriate depending on the type of data and type of missingness.

\section{b. Complete Case Analysis}

When faced with missing data, researchers face several options to adjust for the missing cells. The first approach is to ignore the cases with missing values and only analyze cases with no missing data, known as complete case analysis. Canned software packages will sometimes default to this method using what is called listwise deletion. Only cases that have every cell accounted for are kept for analysis. Of course, this introduces a bias into the analysis if the cases with missing data are not representative of the cases with complete data.

An example of this bias is identified by Maltz and Targonski (2002), which critiqued the methodology of More Guns, Less Crime (Lott 1998; Lott 2000). Using an example from Delaware County, Indiana, Maltz and Targonski show how the NACJD imputation methodology excluded the crime estimate for the ORIs, which led to a downward bias in the crime rate for that county. Delaware County was not an isolated example and some states had over half of their county-level data points with population coverage gaps of $30 \%$ or more. In addition, the states with the most missing data were skewed toward states that had more permissive right-to-carry guns laws, which introduces bias into evaluating the effect of those laws.

While this complete case analysis is very simple and yields only cases with complete data reporting, there are several drawbacks. If there is only a small amount of missing data and it is MCAR, listwise deletions may not have a severe impact on the 
results. However, as the number of missing data increases, fewer and fewer cases will be included for analysis. If these cases are either MAR or MNAR, more bias is introduced into the results. In addition, this is a very unforgiving method of handling missing data. In a large dataset with dozens of variables, listwise deletion will discard the entire case when it is missing only one of the variables. This is particularly true for longitudinal datasets with multiple waves of data, which increases the chances that at least one of the waves will be missing or incomplete.

\section{b. Weighting}

Weighting procedures are typically applied to larger amounts of missing data, such as unit nonresponse. The Supplementary Homicide Reports (SHR) use a weighting technique for both the victim and offender files (Maltz 1999; Fox 2004). Weighting methods work by applying a weight value to the non-missing cases to account for the missing cases. This is preferable to complete case analysis, but should only be applied to monotone patterns of missing data (Little and Rubin 1989).

It is important to note that the goal of imputation is to make inferences about an aggregate population, not to estimate or predict missing data for incomplete cases (Schafer and Graham 2002). Using the UCR as an example, the objective of imputation should be to attain national, state, and county crime estimates, not to predict the missing cells for incomplete reporting ORIs. Therefore, imputations at the ORI level should not be released as representing crime for that jurisdiction.

\section{c. Single Imputation}

\section{i. Hot Deck}


In hot deck imputation, missing values are borrowed from a "donor" case that most closely matches the missing case. The name traces its origins to the days of data processing when information was stored on cards and sorted in a manner that similar cases were clustered together. Hot deck can be performed using the "nearest neighbor" or on a set of independent variables that attempts to most closely match cases. Hot deck imputation is most appropriate for categorical variables or when there is substantial missing data (Yansaneh, Wallace et al. 1998). Hot deck imputation has been used to impute for the population census (Lillard, Smith et al. 1986) and has also been proposed in SHR imputation (Fox 2004).

\section{ii. Mean Substitution}

Perhaps the most basic of imputation methods is mean substitution, whereby the mean value for all reporting cases is imputed for the missing case. The advantage to this method is that it is very simple and straightforward to implement. However, it has its

obvious drawbacks, in particular skewing the distribution to concentrate values and create abnormal distributions. Thus, this method typically yields statistically invalid estimates (Rubin 1996).

\section{iii. Historical/Longitudinal Imputation}

Longitudinal imputation is a method whereby in a longitudinal dataset, data from prior responses of the same respondent (or case) is used to impute for the missing value. This method is also referred to as historical imputation, since it uses the past reporting history for a particular respondent. The most basic form of this method is known as Last Observation Carried Forward (LOCF). LOCF is where the most recent historical value is 
imputed for the missing value. For example in the UCR, if the Chicago Police Department was missing data on assault for December 2006, the assault data for Chicago in December 2005 would be substituted for the missing December 2006 value. This method has been used for the Sample Survey of Law Enforcement Agencies (SSLEA) (Dorinski 1998). The strength of this method is that a respondent's data are imputed from a respondent's own data, rather than trying to infer from similar cases. The downside is a decrease in variance, since the same datum is carried forward from wave to wave. A method that incorporates both a longitudinal and cross-sectional imputation methods was developed by Little and Su (1989). The strength of this method is that it can incorporate the influence of the individual and the trend of similar cases.

\section{iv. Cold Deck}

Unlike hot deck, cold deck imputes values from a different dataset. Often, this is a datum that was collected as part of a previous wave or similar survey. When a datum is used from a previous wave, the method is also a variation of historical imputation, since it derives the imputed value based on previously collected data.

\section{d. Multiple Imputation}

The methods described above can be classified as single imputation techniques, because the resulting dataset will contain a single value for the missing data points. An alternative method is multiple imputation (MI), which creates multiple possible values per missing data point (Little and Rubin 1987; Rubin 1987; Rubin 1996). The number of required iterations differs, but the more incomplete the dataset the more iterations that 
will be required. Each iteration produces a complete dataset, ready for standard statistical analysis.

While considered a major advancement in imputation, MI has several drawbacks. The first problem is that it can be difficult to implement and is more complex than the more straightforward single imputation methods. Second, by design, MI can produce slightly different results each time it is performed. This is good for producing error estimates, but complicates replication and can produce additional controversy among researchers, particularly for politically sensitive data such as the UCR.

\section{F. Simulation Studies}

When assessing the accuracy and validity of various imputation methods, statisticians can use a simulation study. This is a method where missing data are "simulated" from a data set of observed values. The known "true" values are selectively deleted to create the simulated missing data holes. The desired imputation technique is then applied to the simulated missing data. The imputed values are compared to the known values, and error ranges can be measured for the imputation method.

Simulation studies have been used to compare imputation methods for the Census Bureau's Survey of Income and Program Participation (SIPP) (Tremblay 1994; Williams and Bailey 1996). Williams and Bailey (1996) compared the random carryover, population carryover, longitudinal method, and flexible matching method. Using the monthly deviations, they found that the Little \& Su method estimated most closely to the actual values, while the random carryover showed the least accuracy. 


\section{G. UCR and Missing Data}

\section{Background}

Since 1958, the FBI has been using the same method to impute for missing data. The method is cross-sectional, therefore, it does not take into account the agencies past reporting behavior. Rather, it bases the imputed values on similar agencies based on population size, type of agencies and geographic location. The FBI's group classifications are found in table II.

\section{Table II: FBI Group Types}

\begin{tabular}{|l|l|}
\hline Group Number & Population Range or Type \\
\hline Group I & Cities over 250,000 \\
\hline Group II & Cities 100,000 to 250,000 \\
\hline Group III & Cities 50,000 to 100,000 \\
\hline Group IV & Cities 25,000 to 50,000 \\
\hline Group V & Cities 10,000 to 50,000 \\
\hline Group VI & Cities under 10,000 \\
\hline Group VII & Cities under 2,500 and Universities \\
\hline Group VIII & Rural and State Police \\
\hline Group IX & Suburban Counties \\
\hline
\end{tabular}

The FBI's imputation method has two variations, one for agencies reporting 0-2 months of data in a year, the other for agencies reporting 3-11 months in a year. If an agency reports less than 3 months of data, any reported months are ignored and the FBI imputes all the crime data, based on the similar agencies.

The similar agencies are ORIs located within the imputed ORI's state and in the same FBI group, but only ORIs that have reported 12 months of data for that year. A crime rate is calculated for the 12 month reporters and that crime rate (total crime divided 
by total population of these agencies, equivalized to the rate per 100,000) is multiplied by the population of the agency being imputed ${ }^{12}$.

If between 3 and 11 months are reported, the FBI will multiply the crime data for the reported months by 12 / (Number of Months Reported).

For example, assume an agency reports 57 index crimes for 3 months of reported data. The FBI method would use the following formula:

$57 \times 12 / 3=228$ index crimes.

As described above, the FBI's imputation algorithm is based only on crosssectional data and does not take into account year-to-year variation, or seasonal variation. In addition, it assumes that similar agencies will have comparable crime rates. This does not take into account agency level differences or the ORI's past reporting history.

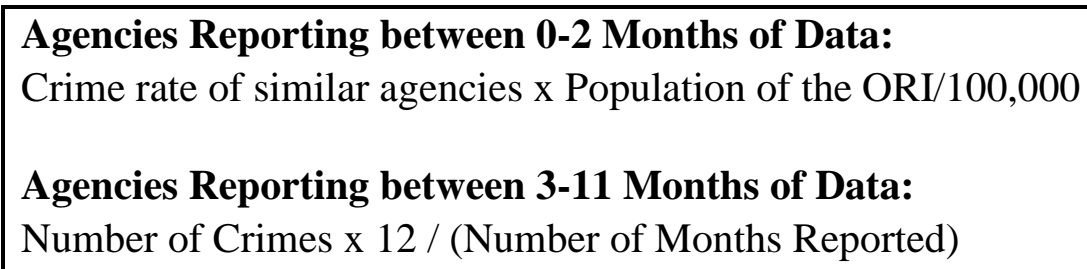

Figure 1. FBI Algorithm for Imputation

While the FBI's imputation is conducted at the ORI level, the imputed data are only reported for state level totals. The FBI will not release ORI (city) level crime counts that incorporate imputed data. This is consistent with imputation literature that recommends only using imputation to report aggregate totals.

\footnotetext{
${ }^{12}$ Maltz (1999) provides as example of an agency in Alabama with missing data with a population of 150,000 (FBI Group II). If the Group II assault rate in Alabama is 620.2 per 100,000 the estimated assault count for the missing agency would be $((620.2 * 150,000) / 100,000)=930.3$.
} 


\section{Supplementary Homicide Reports (SHR) Imputation}

Homicide data are often cited as being less immune to the problems of underreporting compared to the other index crimes, but the SHR does have its limitations. Since it is incident-based rather than summary-based, there is a great deal of additional detail collected, hence more opportunities for missing data to occur. Over the past few decades, the amount of missing data has increased as clearance rates for homicide declined, leaving more unknown offenders (Riedel and Regoeczi 2004). Other researchers have found missing SHR incidents when validated against the National Vital Statistics System (NVSS) mortality data (Van Court and Trent 2004; Loftin, McDowall et al. 2008).

There are two levels of missing data that can occur in the SHR file. The first is that the number of homicides reported in Return A summary data and the number in the SHR file may not be the same. The second level of missingness is that there may be missing pieces of data within a reported SHR incident, such as victim/offender relationship, circumstance, weapon used, offender/victim demographics, etc.

Maltz (1999) provides a detailed description of how the homicide counts between the Return A and SHR are synced. First, a weighting procedure is employed for both the victim and offender file. For the victim file, there is a Total US weight (wtus) and a state-level weight (wtst). The Total US weight is uniform across all SHR homicide records in a given year. This weight is calculated as the total homicides reported on the Return A by the number of victims in the SHR file. The calculation for the state-level is 
the same, except it is the total number of homicides on the Return A for a given state divided by the SHR total for a given state.

The offender file has slightly different weighting procedure. There is a national weight (wtimp) that estimates the unknown offenders for a given age/race/sex by creating a ratio victims killed by known offenders divided by unknown offenders. If for a given age/race/sex there were 100 victims and 80 were by known offenders, the wtimp weight would be $1.25(100 / 80)$.

To reconcile the discrepancy in victim count between the Return A and SHR, the offender file uses the weights wtimpus and wtimpst. For a given age/race/sex category, wtimpus is calculated as wtimp $*$ wtus $=$ wtimpus. This then accounts for both unknown offenders and missing SHR records. The wtimpst is the same calculation as the wtimpus, but it is calculated for each state.

As with the UCR system, SHR imputation has also been scrutinized for its weaknesses. Maltz (1999) points out that the offender weighting method operates under the assumption that age/sex/race of known offenders will be similar to that of unknown offenders. As an alternative, he suggests an imputation method based on circumstance of homicide rather than victim/offender demographics, which has been incorporated by other researchers (Flewelling 2004). A somewhat related idea is proposed by Fox (2004), which would use a hot-deck imputation method to fill in missing offender data based on similar cases where there is a known offender. The circumstance imputation is also not without its limitations, as the circumstance variable itself is often missing and the coding sometime ambiguous (Loftin 1986; Maxfield 1989). The conversion to NIBRS has not 
remedied the problem of missing data in homicide cases and in some instances made the problem worse (Addington 2004).

Wadsworth and Roberts (2008) go one step farther, by linking SHR data to other police homicide datasets, including the St. Louis Homicide Project, the Homicides in Chicago data file and police homicide records from Philadelphia and Phoenix. The additional homicide datasets had a longer lag time for collection than the SHR, which allowed them to have fewer missing data points for cases that had been solved after the SHR data had been submitted to the FBI. It then allowed the researcher to compare the missing data in the SHR files to more complete cases in the additional homicide data sets. The found that SHR data cannot assume to be MCAR and that all of the competing imputations for SHR were only moderately successful.

\section{County-Level Data}

As discussed in the introduction, the ease of access to and interpretation of the UCR has increased its use at more disaggregated levels of data. One dataset that has gained in popularity is county-level data. The appeal is understandable compared to state or national level data, as it allows researchers to control for variation across a state.

While county level data has many advantages, there are additional caveats to its use based on the method of imputation.

The FBI's imputation method is performed at the agency level; however, the imputed data are not published for city or county estimates. The imputed data are only used to produce state, regional and national estimates. This is consistent with standard 
practice for imputation, which states that imputed data should only be used to produce aggregate results. The FBI does produce a "Crime by County" file, which includes the crime count for each agency that submitted any data by county. For agencies that cross into two or more counties, their crime is distributed proportionately to each county based on its population.

\section{NACJD County-Level Dataset}

The main source for county-level UCR data can be found at the National Archive of Criminal Justice Data (NACJD), which is a subdivision of the Inter-University Consortium on Political and Social Research (ICPSR) at the University of Michigan-Ann Arbor. NACJD creates their data set based on the FBI's Crime by County file, which was discussed above. However, there are slight variations in how NACJD imputes missing data compared to the FBI's method. Between 1977 and 1993, NACJD would weigh the crime data for agencies reporting between 6-11 months by 12 / Number of months reported. However, there is one key difference to the FBI for the period of 1977 to 1993. If an agency reported five or fewer months of data, the entire agency's data would be dropped and not figured into the county totals. This procedure assumes that the crime rate for the non-reporting agency is the same as for the county, while also biasing down the crime count.

From 1993 on, NACJD switched to using the same imputation procedure as the FBI for county-level estimations. Use of the county level data should take note of this break in series - the consequences of not doing so are described by Maltz and Targonski (2002, 2003). Similar studies have identified the limitation of county-level due to the 
skewed regression results from a large percentage of counties having zero homicides in a given year, as well as data quality issues (Pridemore 2005).

\section{Summary}

The FBI's cross-sectional imputation method has been adequate for state and national estimates. Given the limited computing capabilities when the imputation methodology was developed in the 1950's it is understandable how it would not have been feasible to drawn upon the longitudinal history of thousands of police agencies. However, as UCR data are increasingly used for analysis of smaller and smaller geographies and as modern computers become more powerful, it is necessary to test and examine more sophisticated imputation techniques. 


\section{DATA AND METHODS}

\section{A. Data Sources}

The primary data sources were the UCR files maintained by the National Archive of Criminal Justice Data, (NACJD), part of the University of Michigan's Inter-university Consortium for Political and Social Research. The files were from the Return A files, part of the FBI's Uniform Crime Reports (UCR) (FBI 2002). The Return A files contain the UCR data on Offenses-Known, unfounded crimes, police agency information, crimes cleared and population. NACJD receives the raw data file from the FBI, and then generates the appropriate syntax statements so the file can be read into either SPSS or SAS. For this research, SPSS was the chosen software package.

However, there were some problems with the NACJD version of the 1994 data set. Some of the variables of interest had corrupted values that were needed for this study. This was determined after consulting with the NACJD staff, which confirmed that the data set did contain errors. To obtain usable data for 1994, we requested and received the data directly from the FBI.

The publicly available raw UCR data files are not in a ready-to-use format for performing statistical analysis. The Offenses Known data sets are in a separate file for each year, the variables do not have descriptive headings, and the datasets are subject to coding errors and outlier values. The first step was to clean all of the files, merge them into one master dataset, and save it in a format that can be analyzed by users with various software packages. Below I describe in detail each step taken to create such a dataset. 


\section{B. Data Preparation}

The first step was merging all the agency level Return A files from 1977-2000 using ORI (ORiginating Agency Identifier, i.e., police agency identifier used by the FBI) as the key variable, to create a single longitudinal data set $^{13}$. Each ORI is supposed to be a unique identifier; however, this is not always the case. Some have been reused (i.e., one agency disappears and its ORI is no longer in use and, some years later, another agency begins reporting to the FBI and is assigned the "recycled" ORI).

The raw data were stored as a text file and then imported into SPSS using a syntax file. Variables unnecessary for imputation analysis (e.g., unfounded crime, clearances) were eliminated from the agency-level files from 1977-2000. This reduced the size of the data sets, making them easier to handle. All of the variables for 1977-2000 were renamed (so they are not the SPSS defaults, v1, v2, etc.) to a user-friendly format. Each new variable name contains an eight-character code corresponding to the variable type, the year, and the month.

mu.97.01

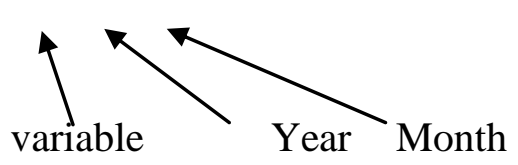

$(\mathrm{mu}=$ murder, year=1997, month=January)

Figure 2. Variable Naming

\footnotetext{
${ }^{13}$ For a complete list of all the SPSS syntax used in this study, see Appendix B.
} 
Table III : Variable Types

\begin{tabular}{|l|}
\hline $\mathrm{IN}=$ month included in \\
\hline $\mathrm{UP}=$ date last update \\
\hline $\mathrm{CI}=$ crime index total \\
\hline $\mathrm{MU}=$ murder \\
\hline $\mathrm{RA}=$ rape \\
\hline $\mathrm{RO}=$ robbery \\
\hline $\mathrm{AS}=$ assault \\
\hline $\mathrm{BU}=$ burglary \\
\hline $\mathrm{LA}=$ larceny \\
\hline $\mathrm{MV}=$ motor vehicle theft \\
\hline
\end{tabular}

In addition, several other variables had to be calculated to match the index crime counts in the FBI's Crime in the United States. The first calculation was for aggravated assault. The variable for the assault total in the Return A file includes simple assault, which must be excluded to get the aggravated assault total. To calculate aggravated assault, the totals for assault with gun, assault with knife, assault with hands/feet, and other assault were added together.

Population totals also had to be recalculated. The Return A files contain three population figures for each ORI. This is because a separate population count is recorded for each of the (up to) three counties in which an ORI is located ${ }^{14}$. To find the total population, the three population figures were added together as a new variable.

The agency-level files from 1977-2000 were merged using the ORI as the key variable to create a longitudinal data set. This produces the data in a panel style format, with each ORI as the unit of analysis. The longitudinal SPSS file was then converted into

${ }^{14}$ An ORI may straddle more than three counties, but the FBI records only the three largest. 
50 Microsoft Excel workbooks, one for each state. Each state workbook contained a total of 18 worksheets. The first worksheet contained the identified reporting errors and a plot of monthly crime data for each ORI. The second sheet contained the descriptive information about an ORI including name, population count, data updated (for identifying missing months), county, SMSA code, FBI population group, "covered by" status ${ }^{15}$, and reporting history. The remaining 16 worksheets contained the crime data for each ORI. The monthly index crime required two worksheets, since Excel 2003 can only hold 256 columns and each ORI contains 288 monthly crime data points (24 years x 12 months $=288$ ). This also includes two additional worksheets for the month-by-month sum of the index crimes.

Exporting the data into Excel was done to facilitate the charting of data and to allow for programming the imputation algorithms in Visual Basic for Applications (VBA), which are included in Appendix C. As described above, a worksheet was created to graph the ORI level crime data. This was done using a VBA macro to pull the monthly index crime totals for the entire 1977-2000 time period. This allowed the inspection of each of the over 17,000 ORIs individually. While this process was timeconsuming, it allowed for the human eye to detect anomalies that may go uncovered by an algorithm. In addition, this process uncovered several patterns and types of missing data that might have gone undetected.

\footnotetext{
${ }^{15}$ This is explained in Section 3 below.
} 


\section{Graphical Data Analysis}

The primary analysis tool for this project was the use of graphical methods to analyze the UCR Offenses-Known data. Early adopters of this method have applied it to a range of data types (Tufte 1983; Tufte 1990; Cleveland 1993; Cleveland 1994; Tufte 1997). Graphical analysis have also been used by criminologists to analyze homicide data (Maltz 1998; Shon and Targonski 2003) and are a significant part of crime mapping research and application.

Most researchers use graphs as means to display data, but graphs can also offer insights and serve as an analytic tool (Maltz 1998). They become more applicable as datasets become larger and standard statistical tests designed for samples become more limited in their usefulness (Maltz 1998, 2009). UCR data are no exception, since it is already quite large and will only expand with agencies converting to NIBRS.

The first step for this project will be to use graphical analysis for the data cleaning and outlier detection. They will also be used to report the results of the data cleaning and provide examples of data anomalies that were detected. Graphical analysis will also be incorporated into the simulation results and to show the trends in missing data over time by FBI group and state.

\section{Data Cleaning}

Despite the efforts of the FBI's quality control mechanisms ${ }^{16}$, data anomalies and errors were found in the UCR files that had to be addressed before any imputation

\footnotetext{
${ }^{16}$ For a detailed description of the FBI's quality control mechanisms, see User Technology Associates (1999) and Akiyama and Propheter (2005).
} 
analysis was conducted. The following subsections detail the types of the anomalies and outliers that were detected.

\section{Agency Name Checks}

After the files were merged, the first data-cleaning task performed was to check the sequence of agency names over the 24-year period. This was done to ensure the ORI code for each year refers to one and only one agency and to determine the years in which the ORI existed.

\section{True Missing}

There is no stated flag code in the Return A file indicating if an ORI had submitted valid data for a given month. However, after consulting with FBI staff, it was determined that it was possible to identify if an agency had submitted data for a particular month. Each month a Return A file is submitted to the FBI, the date the form was received is recorded in the DATE LAST UPDATE field. If no Return A file was received, the value is left blank. The Return A variable DATE LAST UPDATE can then serve as a proxy for whether or not that month's crime data are missing. Any month with a missing value for DATE LAST UPDATE was recoded as a "true missing" value, with a code of -99 .

Without the DATE LAST UPDATE variable, it would not be possible to distinguish a zero value as meaning "no crime" or "no report submitted." As was observed during the data cleaning, this is not a perfect indicator and there are many exceptions. The following examples describe these exceptions and how they were recoded. 


\section{Aggregation of Months}

While crime data are supposed to be submitted on a monthly basis, not all agencies adhere to this policy. The most common exceptions are reporting crime on a quarterly, semiannual, or annual basis. Birmingham, AL (Figure 3) provides a good example, because it used all three in reporting data between 1990 and 2000:

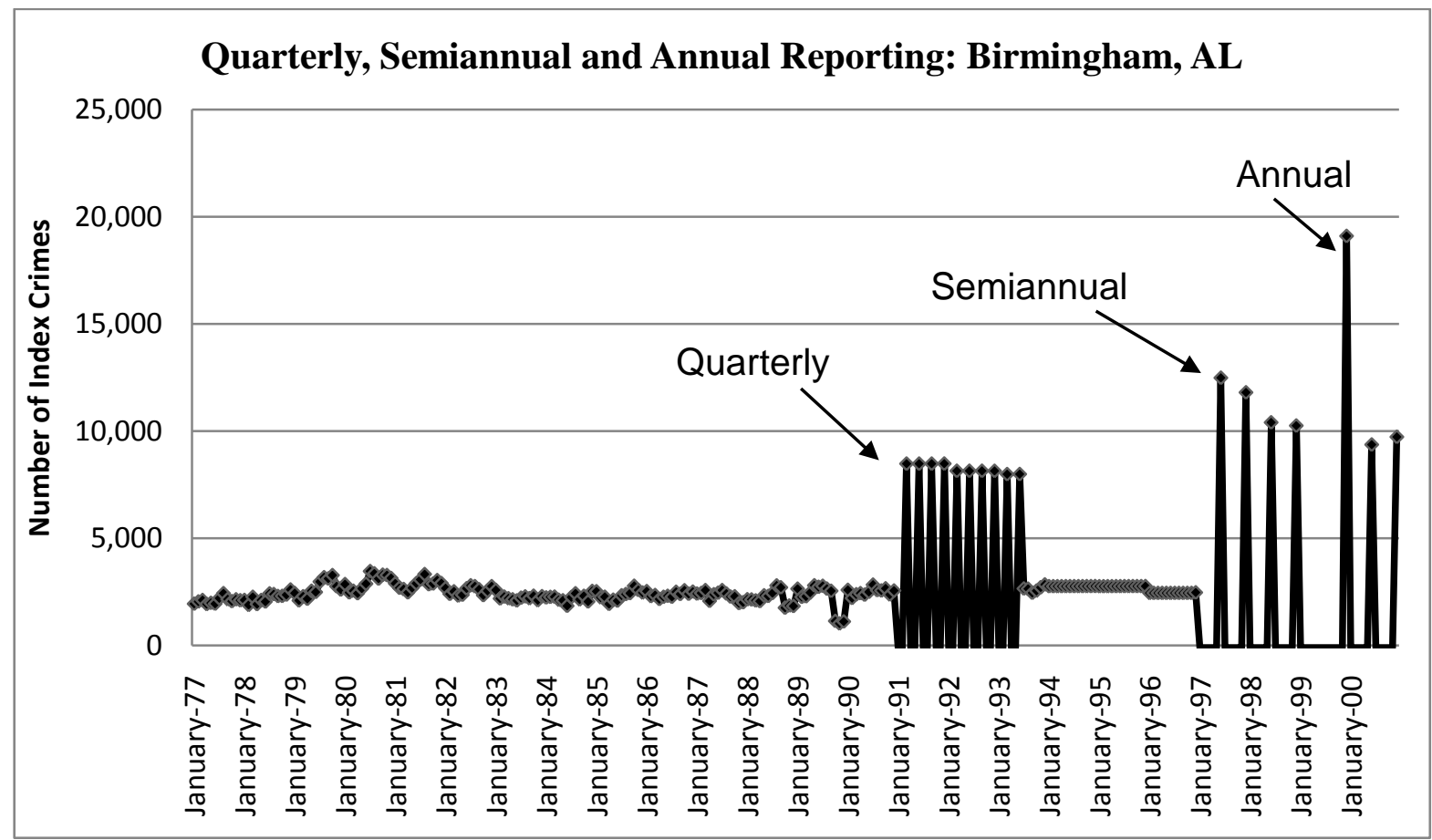

Figure 3. Quarterly, Semiannual and Annual Reporting Example

In addition, from 1994 to 1996 Birmingham reported data for all months, but the annual total was distributed (approximately) equally to all months.

Aggregate reporting complicates accurately coding missing months, since the system is set up for monthly reporting. For example, an annual reporter will report zero index crimes for January through November and then have a high crime count in December. 
In this example, the difficulty in accounting for missing data is how they code January through November. Often, the DATE LAST UPDATE will show missing values for those months (but not when the crimes are uniformly distributed). That does not accurately represent the agencies reporting, because they did submit twelve months of data. To accurately account for the number of months reported, a macro was written to detect quarterly, semiannual and annual patterns. The months that were flagged as missing by the DATE LAST UPDATE were recoded using the following system:

Table IV: Monthly Aggregation Missing Value Codes

\begin{tabular}{|l|l|}
\hline Month & Code \\
\hline Aggregated to February & -102 \\
\hline Aggregated to March & -103 \\
\hline Aggregated to April & -104 \\
\hline Aggregated to May & -105 \\
\hline Aggregated to June & -106 \\
\hline Aggregated to July & -107 \\
\hline Aggregated to August & -108 \\
\hline Aggregated to September & -109 \\
\hline Aggregated to October & -110 \\
\hline Aggregated to November & -111 \\
\hline Aggregated to December & -112 \\
\hline
\end{tabular}

\section{Covered-Bys}

Some smaller agencies choose to report their UCR data through a larger neighboring agency, rather than report directly themselves to the FBI or state-reporting agency. This is a "covered by" situation, whereby the larger agency acts as the "covering" agency. This situation may occur if a small agency may not want the administrative expense of UCR reporting, particularly if they have little crime to report. 
If a small agency is covered by another agency, then its crime data are reported though the larger agency. Often, the smaller agency will submit a report, but report no crime at all, as its crime is aggregated into the covering agency. If an agency is "covered by" another agency, then its data should not be considered missing.

The DATE LAST UPDATE may also indicate non-reporting for the covered-by agency. For the analysis of missing data, the "covering" agency's missing data status is used and not the "covered-by" (smaller) agency. The missing value code of -85 was assigned to months in which the agency was covered by another agency.

There was an issue with raw data files in 1980 and 1995, where the covered-by variables were not in the raw ICPSR data file. To address this gap, some assumptions were made to fill in the missing years. If an agency was covered by the same "covering" agency in the years surrounding the missing year (1979 and 1981 for 1980; 1994 and 1996 for 1995), and the agency had no crime in the missing year, then it was assumed the same agency was covering in the missing year. This took care of virtually every case of missing covered-by data.

\section{Non-Existent Agencies}

Not every ORI existed every year between 1977 and 2000. For the years an ORI was not in existence, a new code was needed to account for this status. Otherwise, it would have been considered a missing value and would overstate the missing data. An imputation algorithm might also try to impute for values in which an agency did not exist. The missing value code of -80 was assigned to months in which the agency did not exist. 


\section{Rule of 20}

As described earlier, the main method to determine a true missing data point was based on the DATE LAST UPDATE variable. There were some cases where an ORI submitted a Return A report for that month, but the crime count was zero. For many small agencies with low crime, it is possible to not have any index crimes for a month. However, there were instances of ORIs that consistently reported many index crimes, the DATE LAST UPDATE indicated a Return A form was submitted, but the index crime for the month was zero. Figure 4 illustrates an example for the Bay State MI Police. The red circle shows a gap where no index crimes were reported. However, during those months the Bay State MI Police were reporting 12 months of crime data per year according to the DATE LAST UPDATE variable.

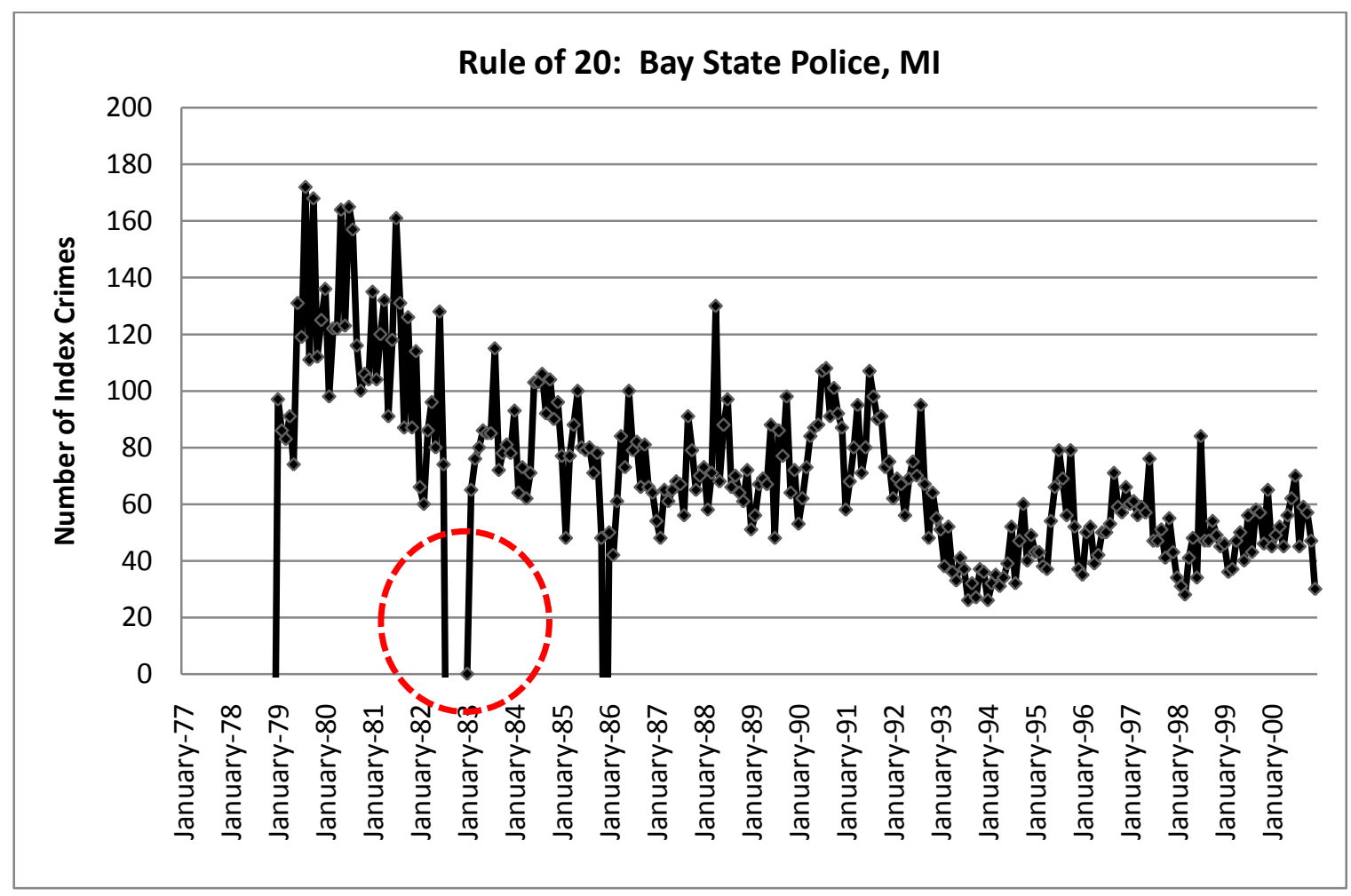

Figure 4. Rule of 20 
To account for such ORIs, a rule was established that an ORI with an average of 20 or more index crimes per month could not have zero index crimes in a month, if the DATE LAST UPDATE flagged the Return A as being submitted. These instances were coded as missing with a value of $-90 .{ }^{17}$

\section{Negative Values}

During the data screening, a number of negative values for index crime counts were discovered. The FBI does allow for adjustments for instances where in from prior months crimes had been over-reported, such as cases that were later determined to be false (unfounded) reports, or for reclassification (FBI 1984).

However, some of the negative values were obviously out of range and are most likely data entry errors. In the entire dataset, 5081 negative values were found. Only 142 were lower than -3 and were reassigned to be missing values (-99). The cutoff for determining what was a "true" negative number and a "real" negative number could not be done with exact precision. However, the cutoff of -3 was based on logical grounds of reporting and average crime counts. In order to have 4 unfounded crimes, it would likely have to have an average of at least 10 crimes a month, which is a very conservative estimate. To arrive at monthly value of -4 , it would require, for example, 2 actual crimes and 6 unfounded, which would be a very unlikely occurrence.

\footnotetext{
${ }^{17}$ In addition to these cases, there were some instances of agencies with average crime counts that were less than 20 showing zero crime and a date for the DATE LAST UPDATE. These were, in the researcher's judgment, data points that were missing.
} 


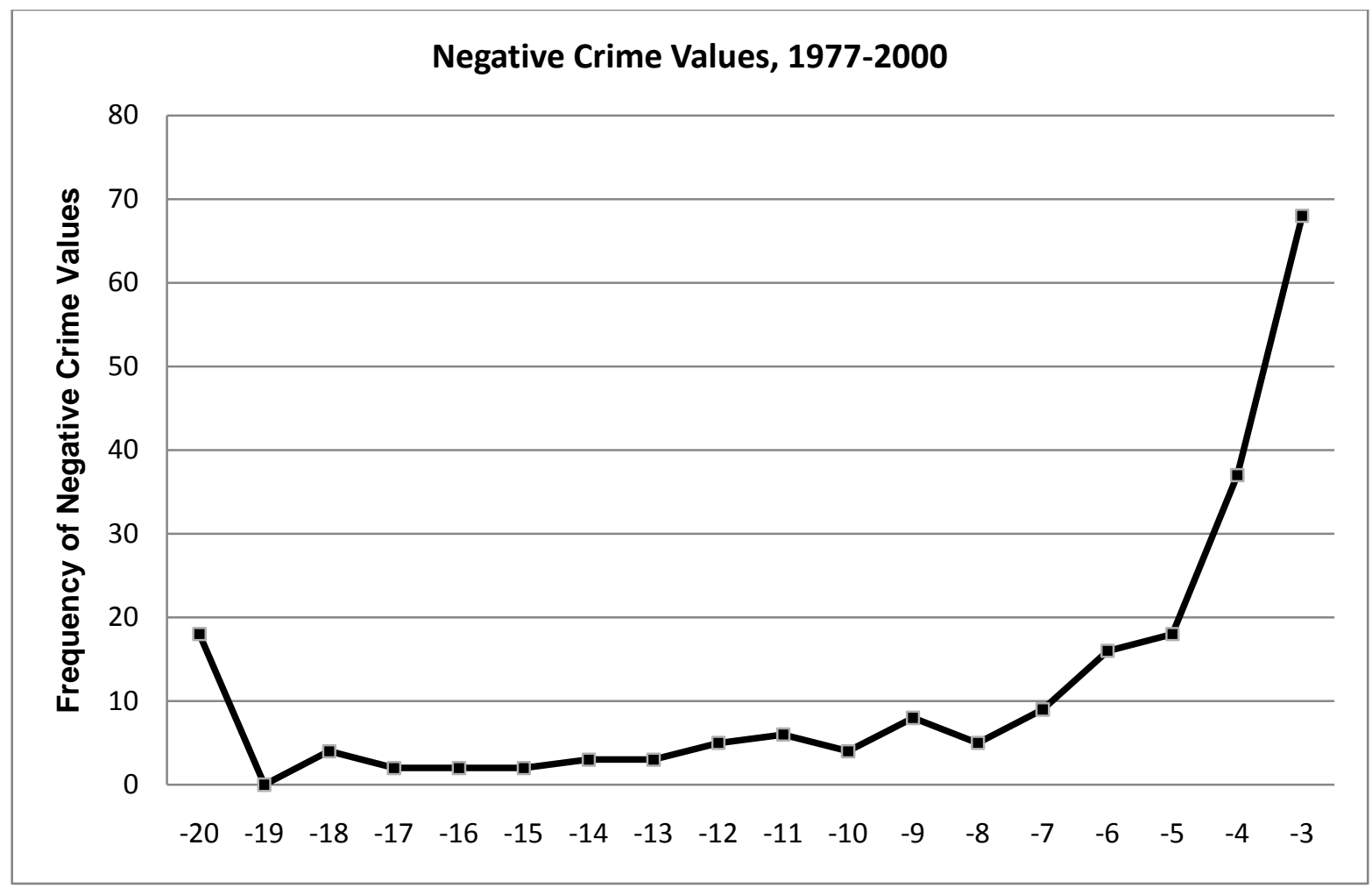

Figure 5. Negative Crime Values, 1977-2000

For the purpose of screening outliers, -4 was determined as the cutoff for legitimate values. Any values less than -4 were recoded as missing values (-99), since they were most likely data entry errors.

\section{Outlier Values}

As part of the data screening process, each ORIs trend was examined graphically. In the process, outliers were detected for the crime index. To prevent these values from skewing the imputation results, the outlier values were recoded as -90 . In a separate Excel sheet, the old values were retained if they needed to be accessed.

A subtype of outlier values were the "999," "9999," and "99999" crime counts. Below in figure 6 is an example from Durango, CO: 


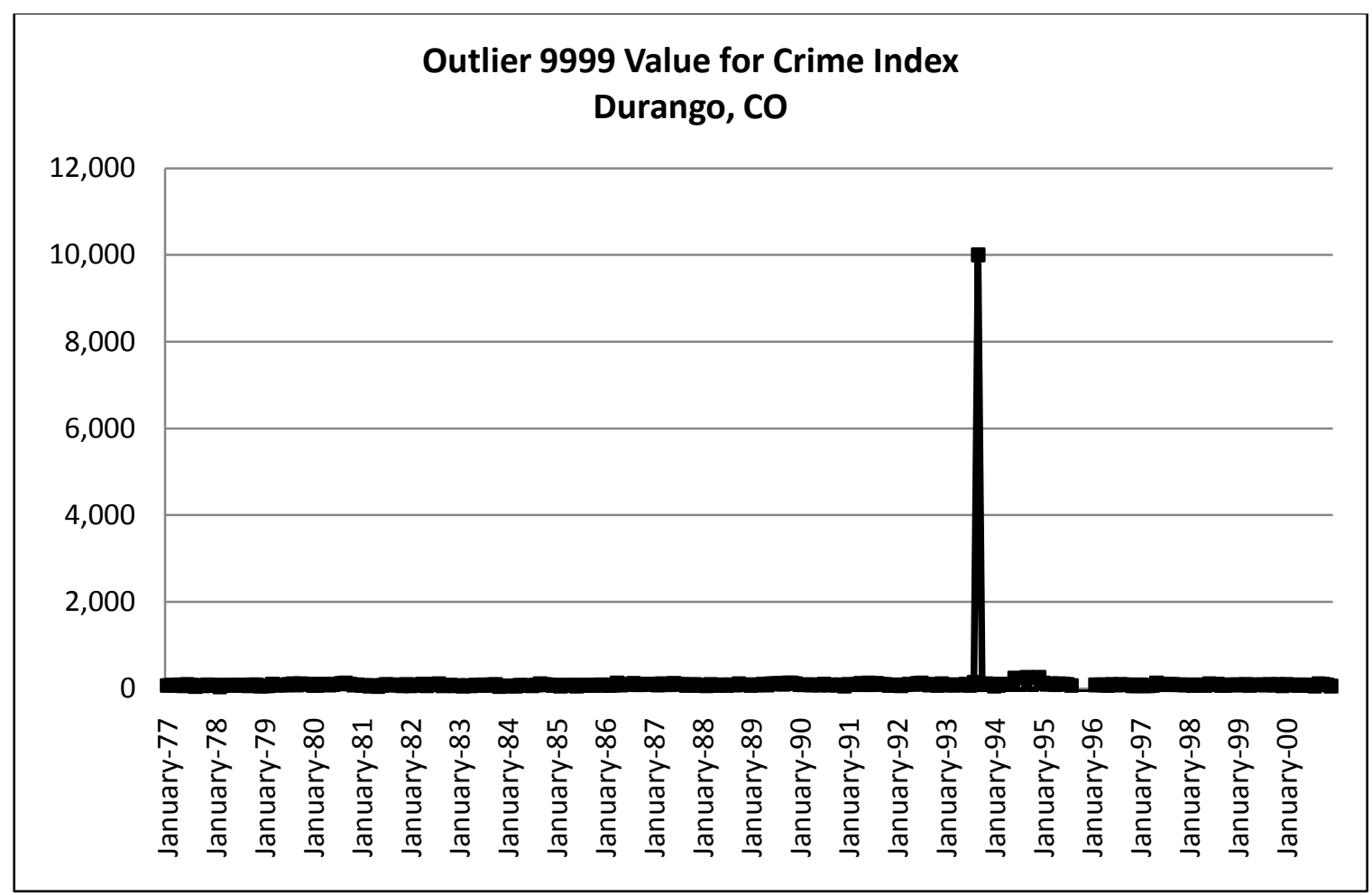

Figure 6. Outlier 9999 Value for Crime Index, Durango, CO

In September 1993, Durango reported 9999 assault cases, which pushed the crime index to 10,002 . This was an obvious outlier value and would have caused many problems when trying to impute for Durango including such a value in the crime index. In situations where a single crime was responsible causing the missing crime index, a separate code was created for each crime, $-9 \mathrm{x}$ for the $\mathrm{x}$-th index crime missing. Thus, the totality of all codes used for individual crimes are as follows: 
Table V: Summary of Missing Value Codes

\begin{tabular}{|l|l|}
\hline Type of Value & Code \\
\hline Aggregated to December & -112 \\
\hline Aggregated to November & -111 \\
\hline Aggregated to October & -110 \\
\hline Aggregated to September & -109 \\
\hline Aggregated to August & -108 \\
\hline Aggregated to July & -107 \\
\hline Aggregated to June & -106 \\
\hline Aggregated to May & -105 \\
\hline Aggregated to April & -104 \\
\hline Aggregated to March & -103 \\
\hline Aggregated to February & -102 \\
\hline No data reported (True Missing) & -99 \\
\hline More than one index crime missing & -98 \\
\hline Motor vehicle theft missing & -97 \\
\hline Larceny missing & -96 \\
\hline Burglary missing & -95 \\
\hline Assault missing & -94 \\
\hline Robbery missing & -93 \\
\hline Rape missing & -92 \\
\hline Murder missing & -91 \\
\hline Researcher assigned missing value & -90 \\
\hline ORI was covered by another agency & -85 \\
\hline Agency did not exist during this period & -80 \\
\hline & \\
\hline
\end{tabular}

\section{E. Current FBI Imputation Methodology}

As described in chapter II, the FBI's imputation algorithm is based only on crosssectional data and does not take into account an individual ORI's history. In addition, it 
assumes that similar agencies will have comparable crime rates. This does not take into account agency level or geographic differences.

\section{F. Longitudinal Imputation Method}

As an alternative, a longitudinal method was explored for imputing an agency's crime data. This takes into account an agency's past reporting behavior, account for seasonality, and allows for crime estimates at more granular levels, such as ORI and county levels. For agencies reporting less than 3 months of data, the imputation algorithm will take the group crime rate for that ORI in the current year divided by the group rate in the prior year, to arrive at the change estimate. This change estimate is then multiplied by the data reported in the prior year.

As with the FBI method, the group consists of those agencies in the same state and same population range that provide crime reports for the full 12 months. However, this method uses the group rates for the change estimate, rather than for the index crime level estimate.

For an agency reporting 3-11 months of data, the longitudinal imputation formula is based on that agency's year-to-year increase for the months reported. That is, it assumes that the agency has the same seasonal trajectory in both years, so it multiplies the agency's missing months' data with the percent change factor from the FBI group.

If $\{\mathrm{X}\}_{\mathrm{t}}$ is the set of months for which agency $\mathrm{A}$ reported crime in year $\mathrm{t}$ and $\{\mathrm{Y}\}_{\mathrm{t}}$ is the set of months for which it did not report crime. Then 


$$
\begin{aligned}
R C(t) & =\sum C_{i} \quad \text { is the sum of reported crime in year } t \\
& i \text { in }\{X\}_{t}
\end{aligned}
$$

and

$$
\begin{gathered}
\mathrm{RC}(\mathrm{t}-1)=\sum \mathrm{C}_{\mathrm{i}} \text { is the sum of reported crime for the same months in year } \mathrm{t}-1 \\
\mathrm{i} \text { in }\{\mathrm{X}\}_{\mathrm{t}-1}
\end{gathered}
$$

The year-to-year increase for those months, then, is $\mathrm{K}=\mathrm{RC}(\mathrm{t}) / \mathrm{RC}(\mathrm{t}-1)$. We then apply this increase to every month in $\{\mathrm{Y}\}_{\mathrm{t}-1}$ for which there are no reports in year $\mathrm{t}$, so now they experience the same year-to-year increase as the reported months. If $\mathrm{MC}\left(\mathrm{t}_{\mathrm{i}}\right)$ is the imputed value of crime for month $\mathrm{i}$ in year $\mathrm{t}$, then we have, for each month in $\{\mathrm{Y}\}_{\mathrm{t}}$,

$$
\mathrm{MC}\left(\mathrm{t}_{\mathrm{i}}\right)=\mathrm{K} \times \mathrm{C}_{\mathrm{i}}(\mathrm{t}-1) \text {, for } \mathrm{i} \text { in }\{\mathrm{Y}\}_{\mathrm{t}}
$$

This algorithm will identify the missing months, find the matching months from the prior year, and impute based on the crime rate change. The example below illustrates how the algorithm would work for an agency reporting 12 months in 1998, but only 9 months of data in 1999: 


\begin{tabular}{|c|c|c|c|c|c|c|c|c|c|c|c|c|}
\hline & Jan & Feb & Mar & Apr & May & June & July & Aug & Sept & Oct & Nov & Dec \\
\hline \multicolumn{13}{|l|}{ Year } \\
\hline 1998 & 6 & 8 & 2 & 1 & 4 & 9 & 2 & 3 & 8 & 2 & 7 & 1 \\
\hline Year & & & & & & & & & & & & \\
\hline 1999 & 4 & 2 & 9 & 3 & & 6 & & 2 & & 4 & 8 & 7 \\
\hline
\end{tabular}

Figure 7. Longitudinal Imputation Example

Matched months: Previous Year $=6+8+2+1+9+3+2+7+1=39$

Matched months: $\quad$ This Year. $=4+2+9+3+6+2+4+8+7=45$

$$
\mathrm{K}=45 / 39=1.1538
$$

New values for May, K x $4=4.62$; July=2.31; September $=9.23$

By attempting to use the matching months for an agency's past reporting crime values, seasonality can be preserved. If the imputation were based solely on the total number of months, the crime rate would be inflated or deflated depending on the months that were missing in each year. A resort community, for example, might neglect to report crime during the off-season. The FBI imputation method would fill these months with the high-season crime rate.

\section{G. Simulation Data Set}

With the imputation algorithms determined, the centerpiece of the analysis was conducting a simulation study, whereby imputation is performed on a simulated data set 
with real values that are "punched out" to become missing values. The imputed results are compared to the known values, allowing the calculation of error estimates. The imputation method that has the least amount of variation between the known values and the imputed values is considered the more accurate method. To prepare the simulation study, the following steps were performed:

\section{Identify Patterns of Missing Data}

After the data had been thoroughly cleaned, the patterns of missing data needed to be determined from the complete dataset. This was accomplished by examining the run lengths, which represent the consecutive months of missing data. This method has been used in other UCR missing data studies to examine patterns of missingness (Maltz 2006).

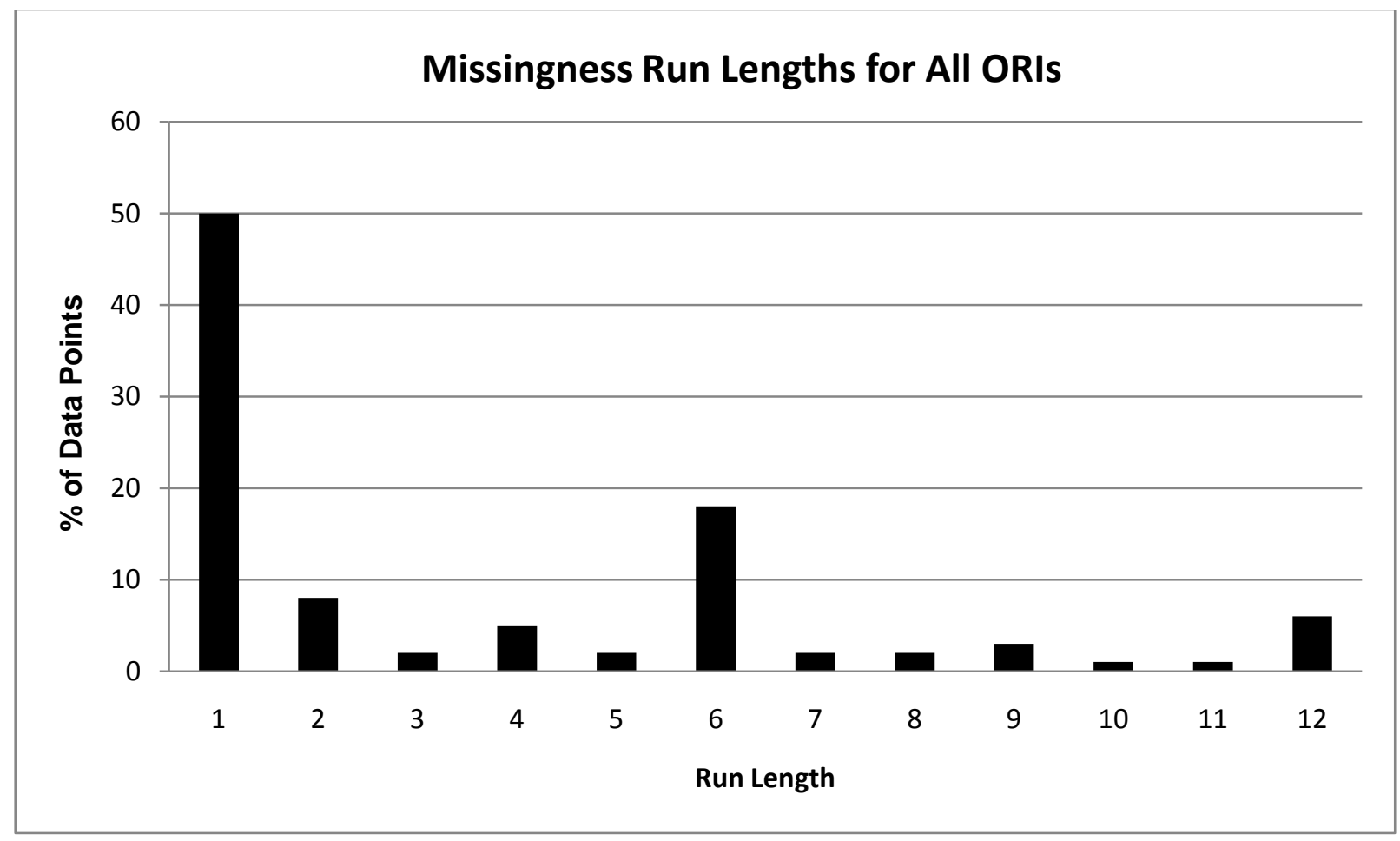

Figure 8. Missing Data Run Lengths for All ORIs 
The results of the run length analysis reveal a skewed distribution of data points, with $50 \%$ of the data missing for only one consecutive month. There is another increase when we get to six months of consecutive months missing, which may be driven by agencies reporting for half the year. Finally, $6 \%$ of the data points are missing run lengths of 12 months, which represents the percentage of agencies that reported zero months of data.

\section{Identify Full Reporting Agencies}

The next step was to identify all ORIs that had full reporting for years 1989 to 1999. The time frame was narrowed from the original dataset, to allow for more ORIs to be included in the study. There were a total of 4,765 ORIs that met this criterion and served as the basis for the simulation study sample. A breakdown of these ORIs by FBI state and group can be found in figures 9 and 10. Note that Group I has the fewest such ORIs, since there are very few ORIs in this group, which represents the most populous cities. 


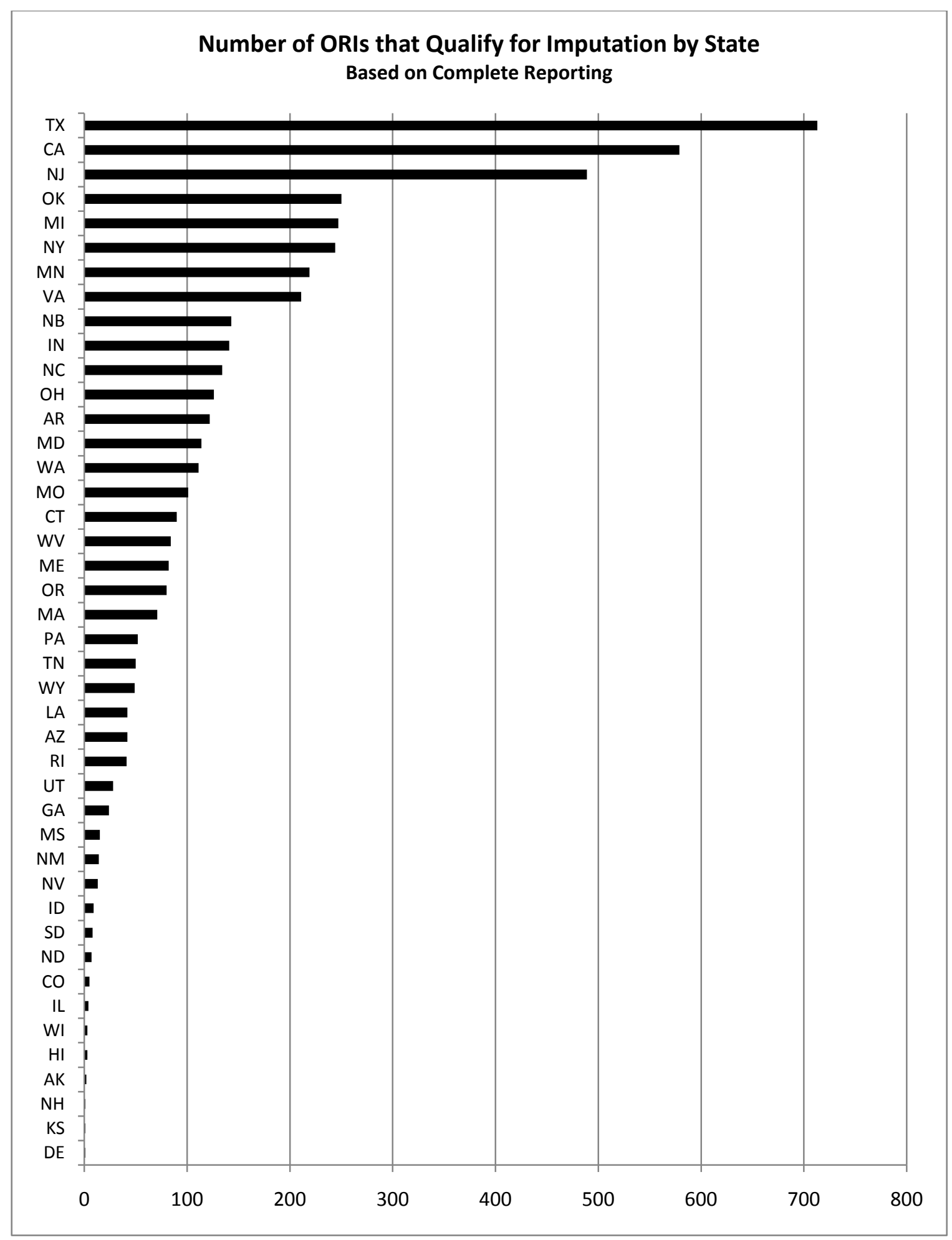

Figure 9. Number of ORIs that Qualify for Imputation by State 


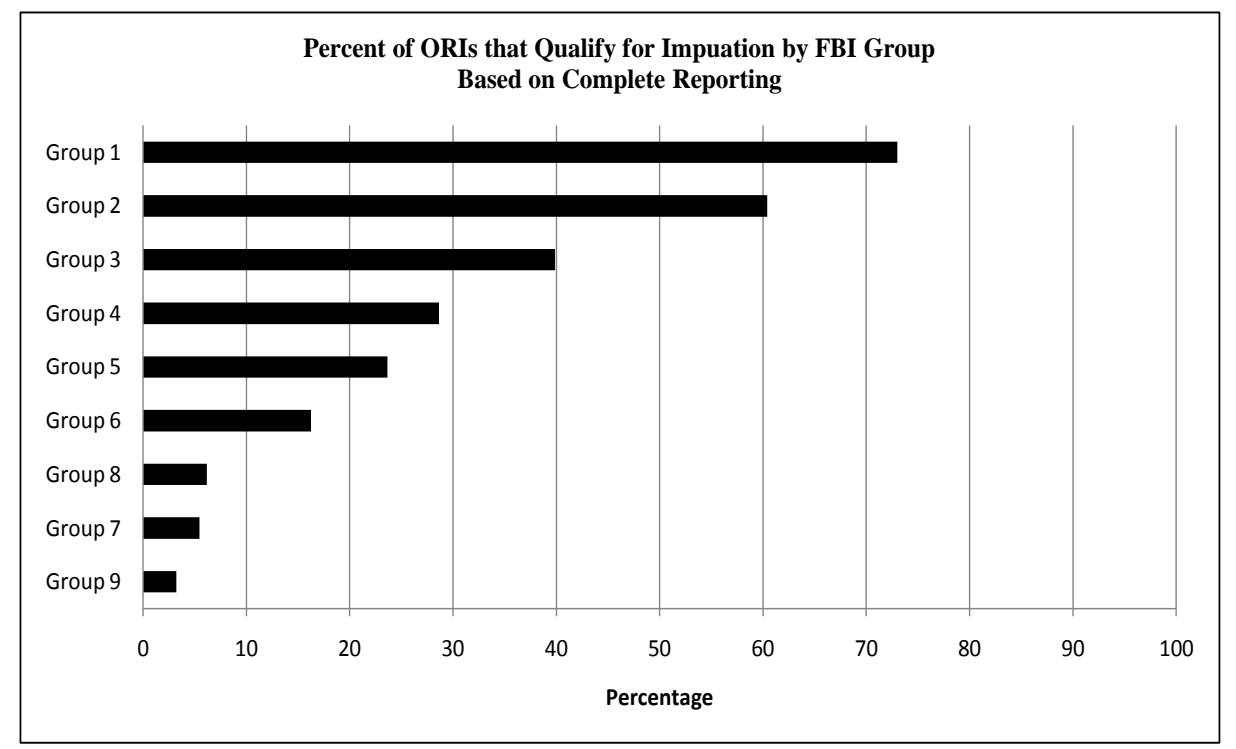

Figure 10. Perentage of ORIs that qualify for imputation by FBI group

\section{Deletion of "Good" Data}

Using the new data set of full reporting ORIs, a macro was run to randomly delete the "good" data based on the patterns in step 1 and figure 8 . The number of deletions was three times the number of ORIs for each state and FBI group, so that they would experience on average three missing runs in the ten-year period. This deletion of the "good" data points created the simulation data sets, which now how have "punched out" values in the cells that were selected for deletion. In figure 11, the first screenshot shows part of the original data set. The second is the same set of data, but with green cells representing data points that had been deleted and then replaced with an imputed value. 


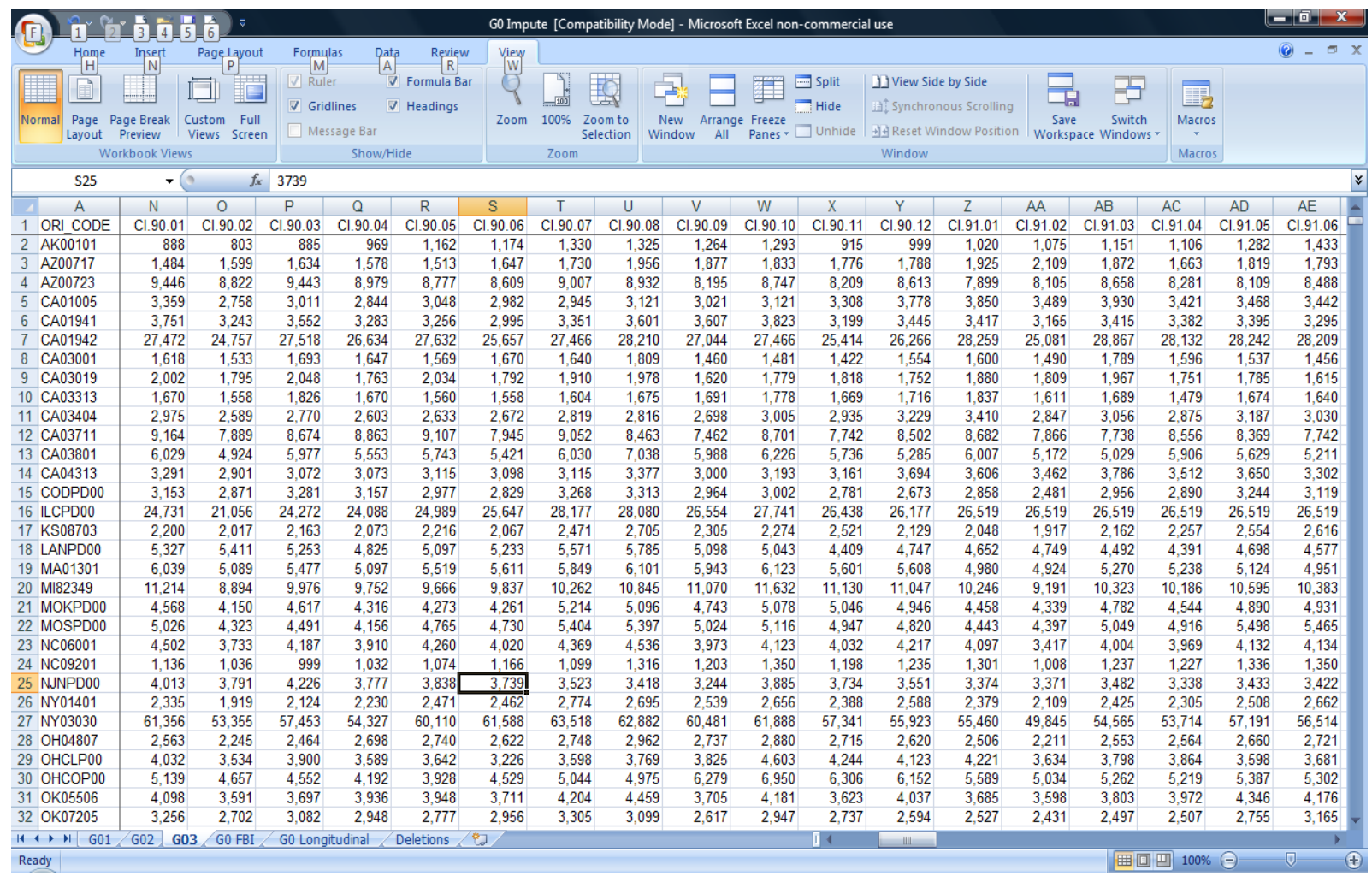

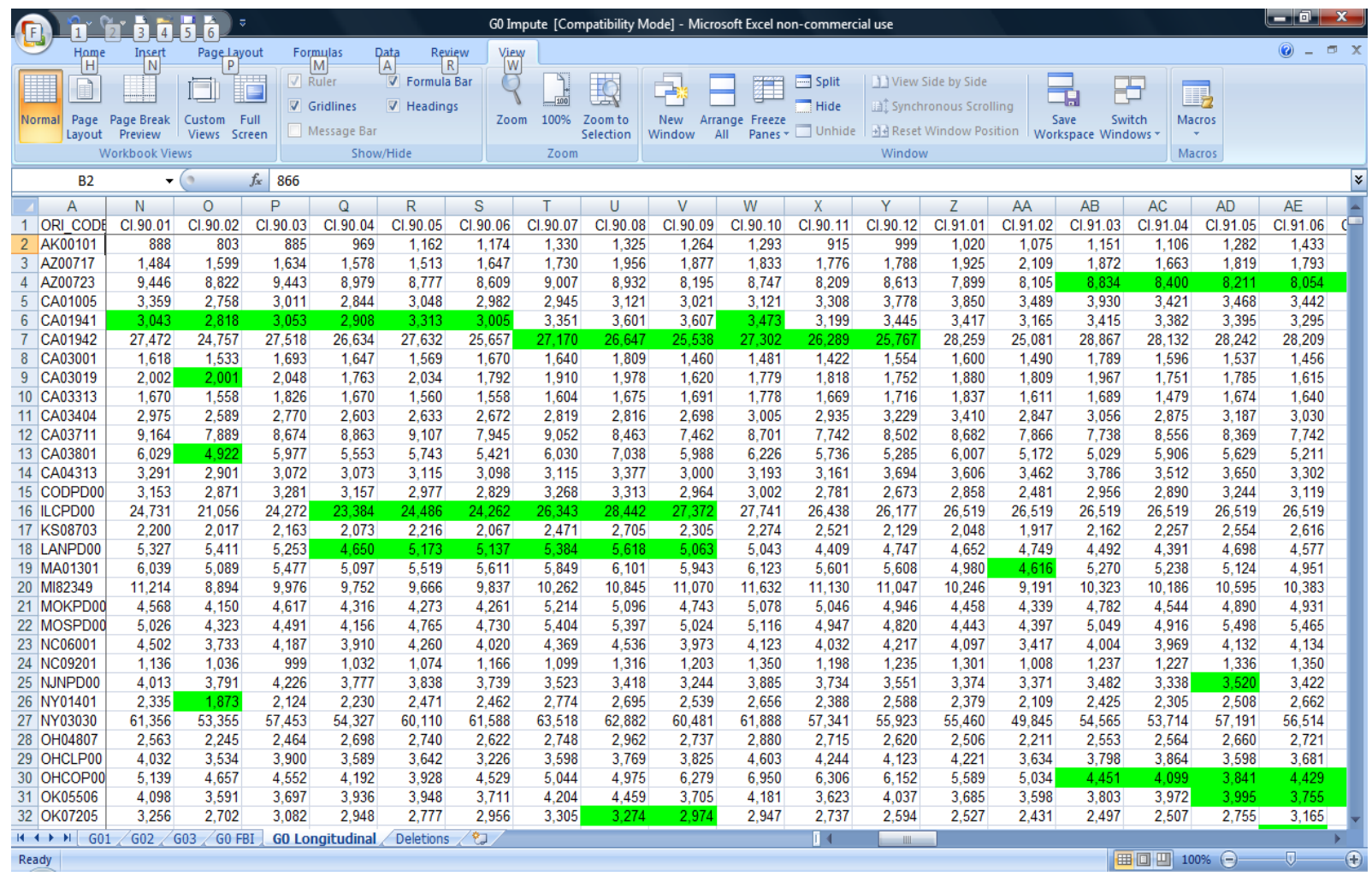

Figure 11. Screenshots of Simulated Data 
The leftmost column is the ORI code and the rest of the columns represent the monthly

crime data. The variables in the first column are for each month, with "CI" standing for "Crime Index," followed by the two-digit year and then two-digit month.

There were a total of 60 test files created, one for all the ORIs, one for each of the nine FBI groups, and one for each state. This was done to permit comparisons by FBI group and state.

\section{Running Imputations}

Each imputation method was run and the imputed values were compared to the actual values. Comparisons were based on the absolute difference and root mean square difference. The analysis based on the yearly crime totals, as well as the aggregate of all the years. The Visual Basic code used in the Excel analysis can be found in Appendix C. 


\section{RESULTS}

\section{A. Introduction}

After the data are cleaned, the next step is to analyze the patterns and levels of missing data. This was performed by using the new missing value codes that were applied during the data cleaning. Missing data was disaggregated and analyzed by the total United States, FBI group, and state. The simulation data sets are then run and also analyzed by total United States, FBI Group, and run length.

\section{B. Descriptive Statistics of Missing Data}

\section{New Definition of Missingness}

As part of the yearly CIUS, the FBI publishes the population coverage of the UCR. However, for an agency to be considered "covered" for its population, the FBI only requires that it submit one month of data. In a case where an agency only submits one month, the FBI would have to impute for the remaining 11 months of data. This can result in an underestimate of the missing data.

For this study, the amount of missing data is based on the new missing value codes. Therefore, it accounts for all the data issues described in Chapter III including outlier values, covered-by agencies, aggregated reporting, and incorrect negative values. 


\section{Missing Data for the Total United States}

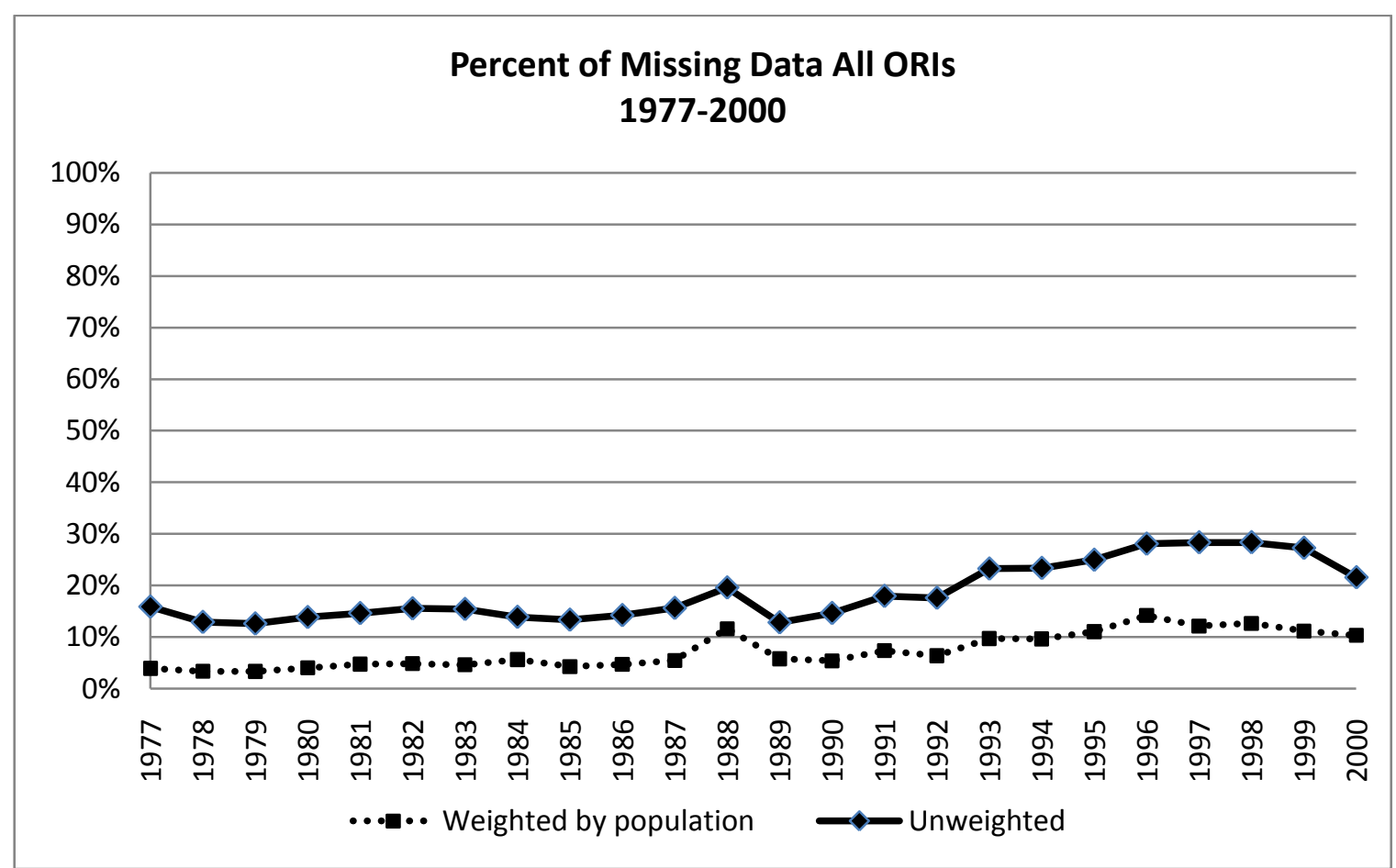

Figure 12. Percent of Missing Data All ORIs, 1977-2000

Between 1977 and 1987, the level of missing data held fairly consistent around $15 \%$ for the raw count and $5 \%$ of the population. In 1988, there is a spike at the national level, which was the result of state-level problems with Florida and Kentucky. Both states reported $100 \%$ missing data for that year, due to data quality issues (FBI 2007). The number of missing data then began to increase through the late 1990s, with a slight decrease in 2000 .

\section{Missing Data by Group}

While missingness at the total US level provides insight to overall trends, it is necessary to disaggregate to lower level geographies to get a better understanding of 
missing data. The next lower level that is more important is missing data by the different FBI group designations. The importance of the groups is that they provide insight to differences in missing data across various size and types of police agencies. In addition, the groups are a basis for both the FBI and longitudinal imputation method.

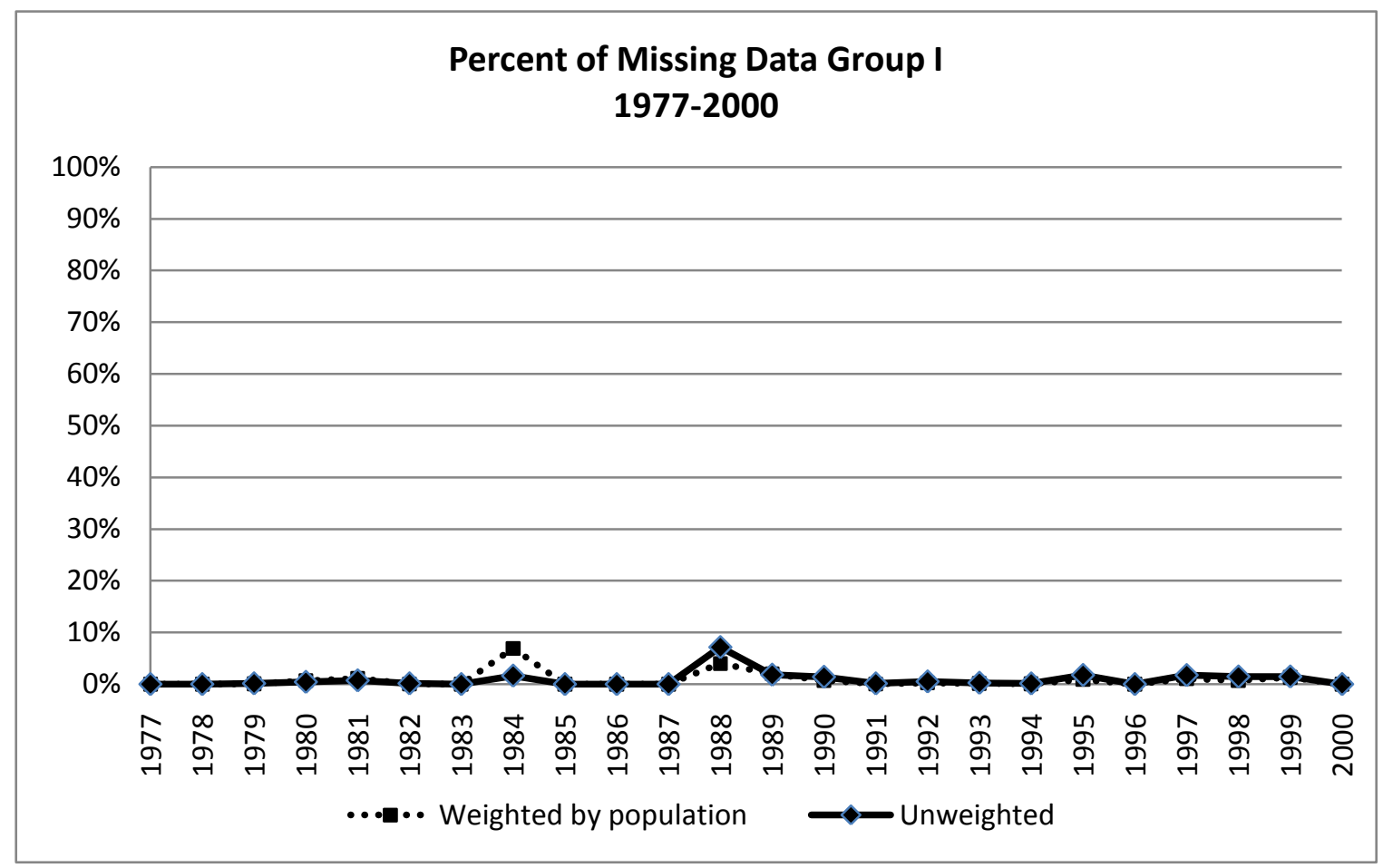

Figure 13. Percent of Missing Data Group I, 1977-2000

Group I displays the most consistent reporting over time. Group I represents the largest agencies, with populations over 250,000. If non-response occurs with these agencies, they are more rigorously followed-up by the FBI to supply their crime data for the year.

There are two years that Group I has missing data: 1988 and 1985. The missing data in 1988 is the result of state-level problems with Florida and Kansas. The jump in 
missing data for 1984 was the result of the Chicago Police not reporting 12 months of data.

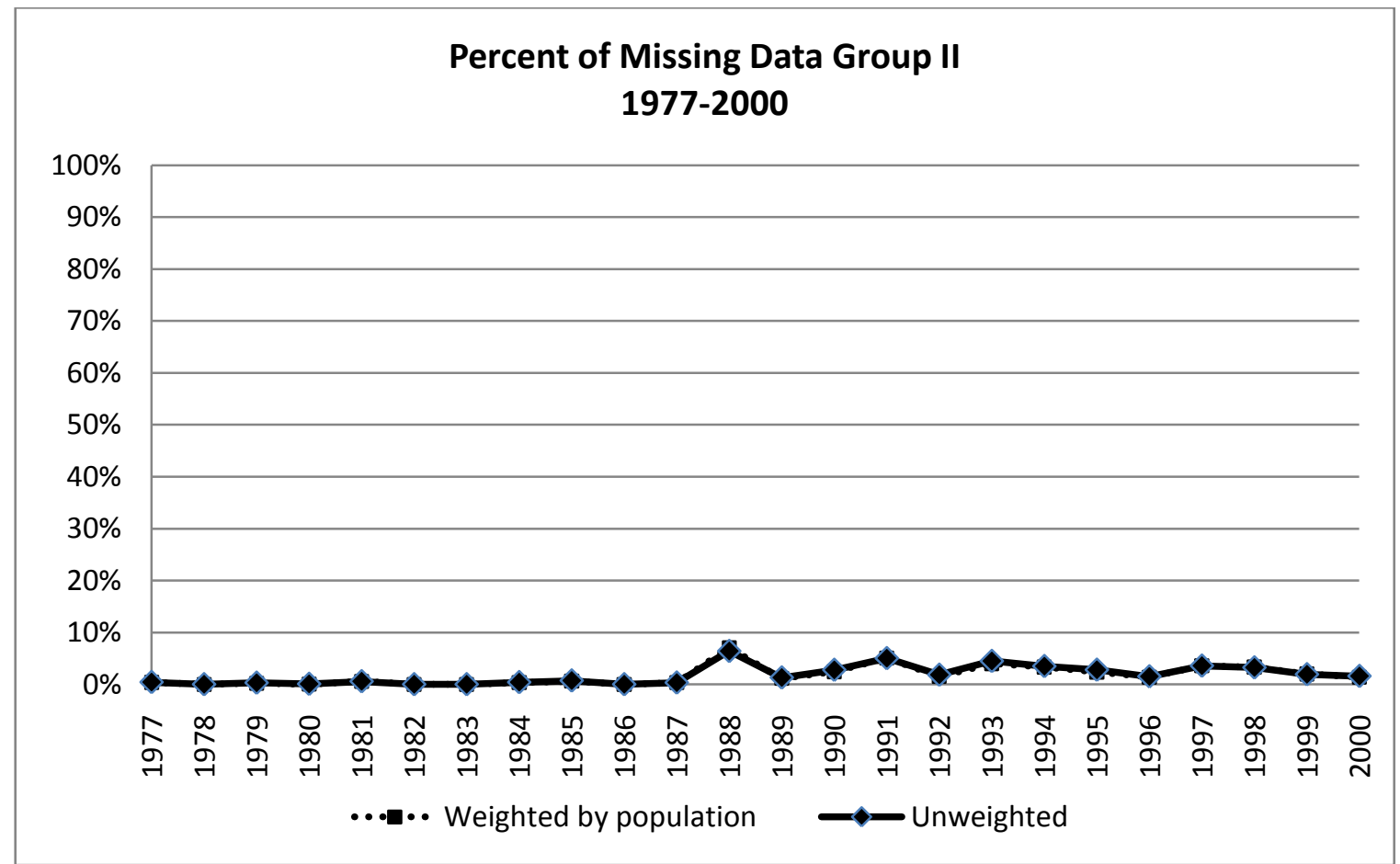

Figure 14. Percent of Missing Data Group II, 1977-2000 


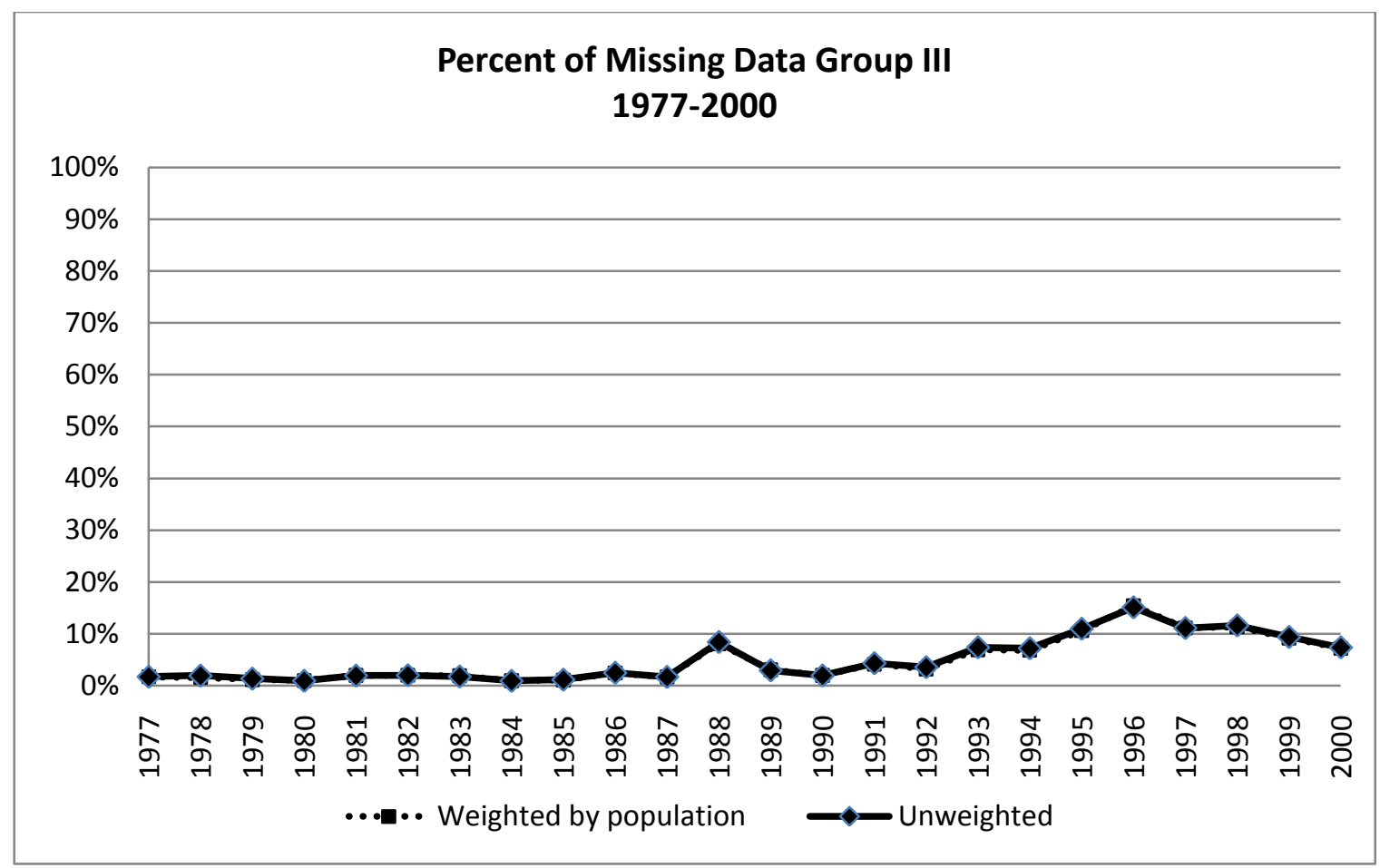

Figure 15. Percent of Missing Data Group III, 1977-2000

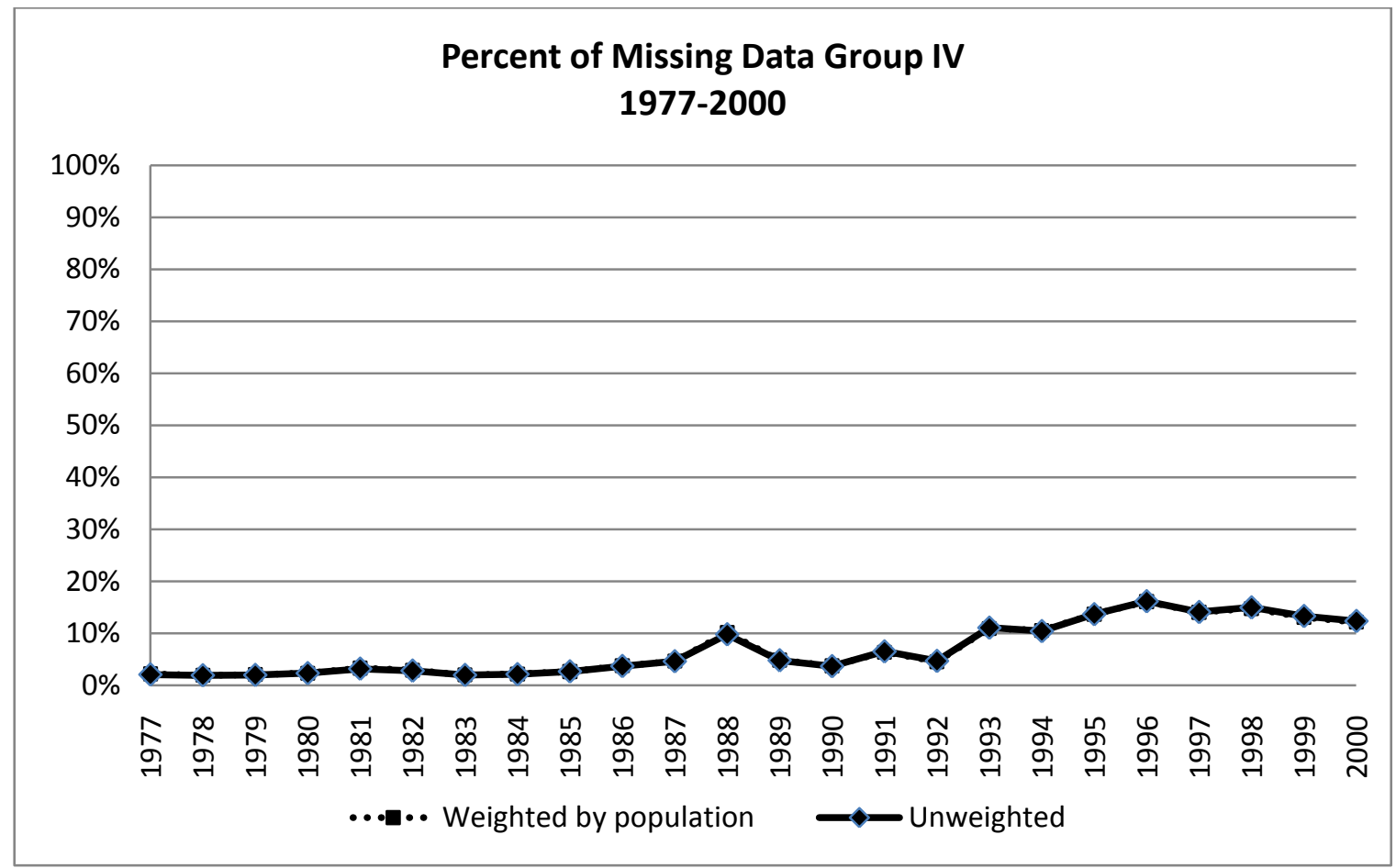

Figure 16. Percent of Missing Data Group IV, 1977-2000 


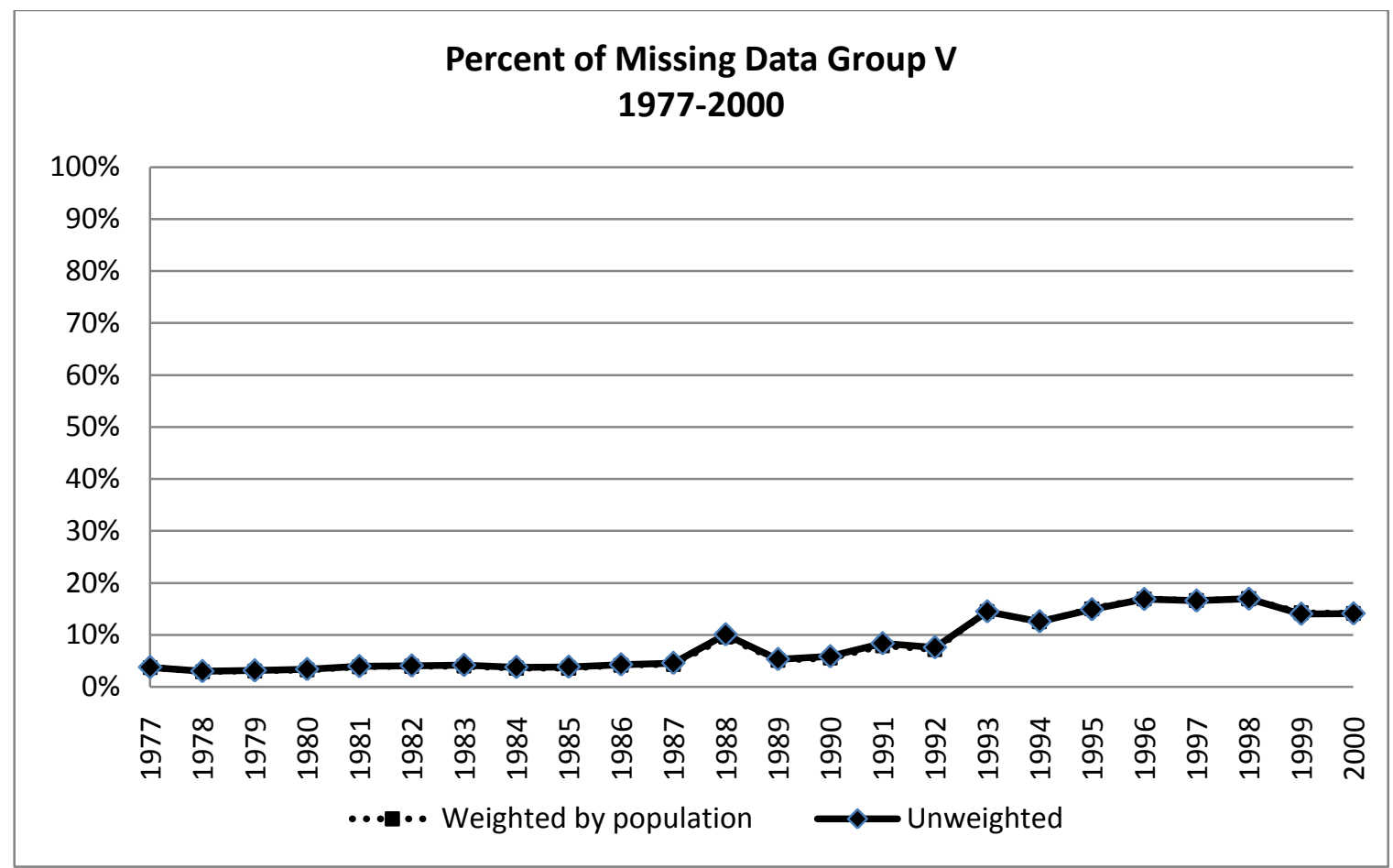

Figure 17. Percent of Missing Data Group V, 1977-2000

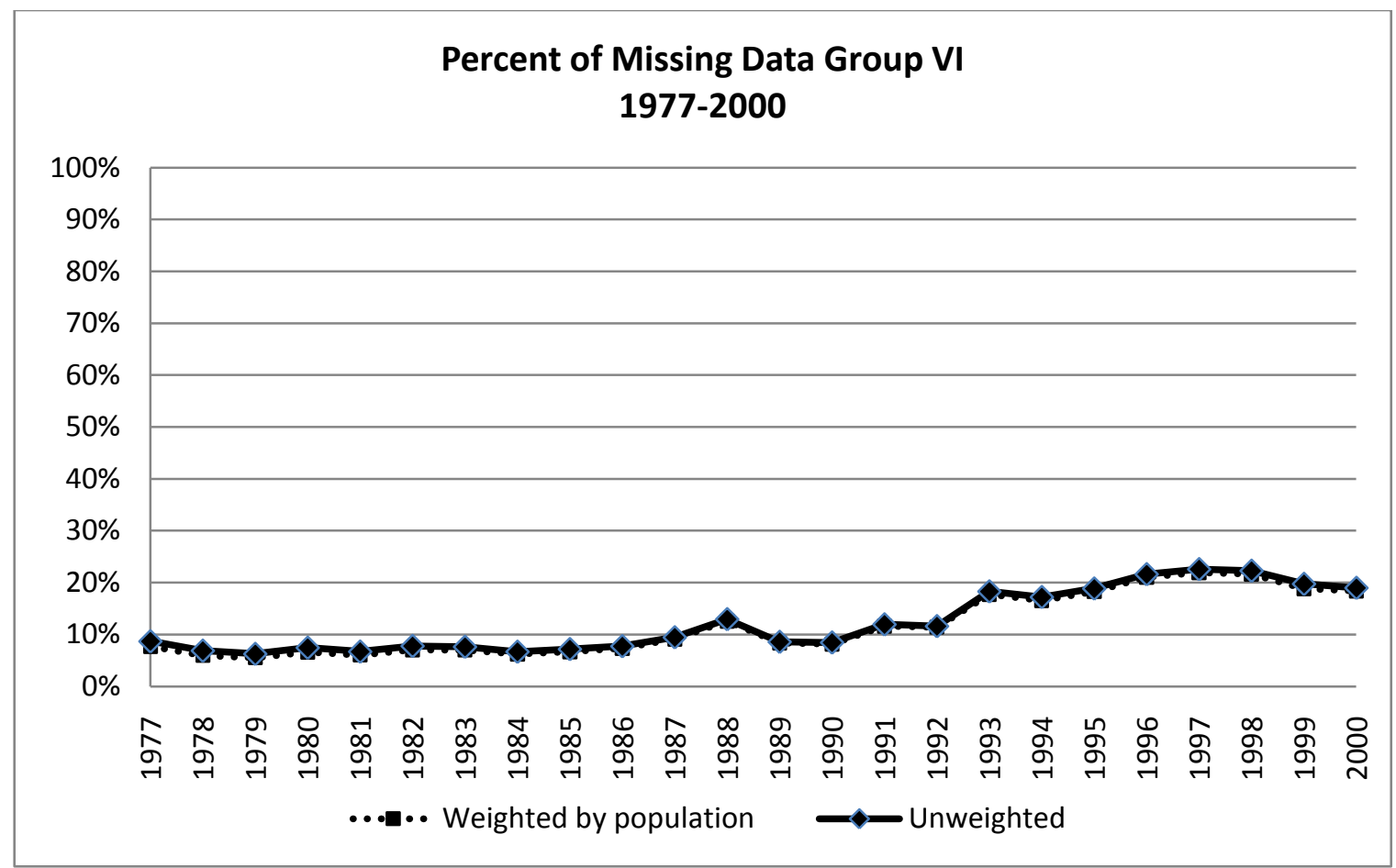

Figure 18. Percent of Missing Data Group VI, 1977-2000 


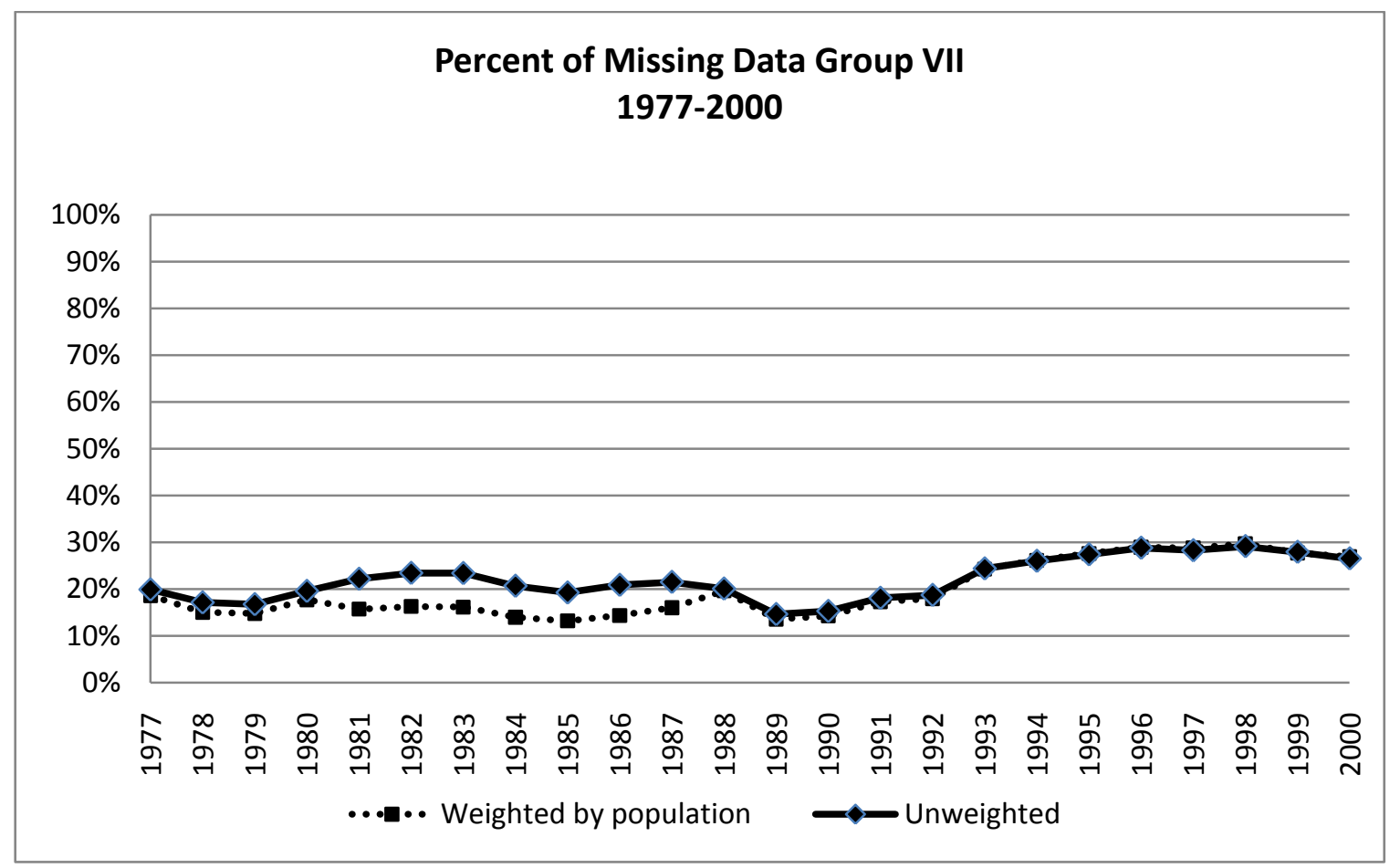

Figure 19. Percent of Missing Data Group VII, 1977-2000

Groups II through VII all show a similar pattern, with small amounts of missing data between 1977 and 1992. The level of missing data becomes slightly higher as the group numbers get larger, with the population of the agencies becoming smaller. From 1993 through 2000, there is an overall upward trend in missing data across groups. 


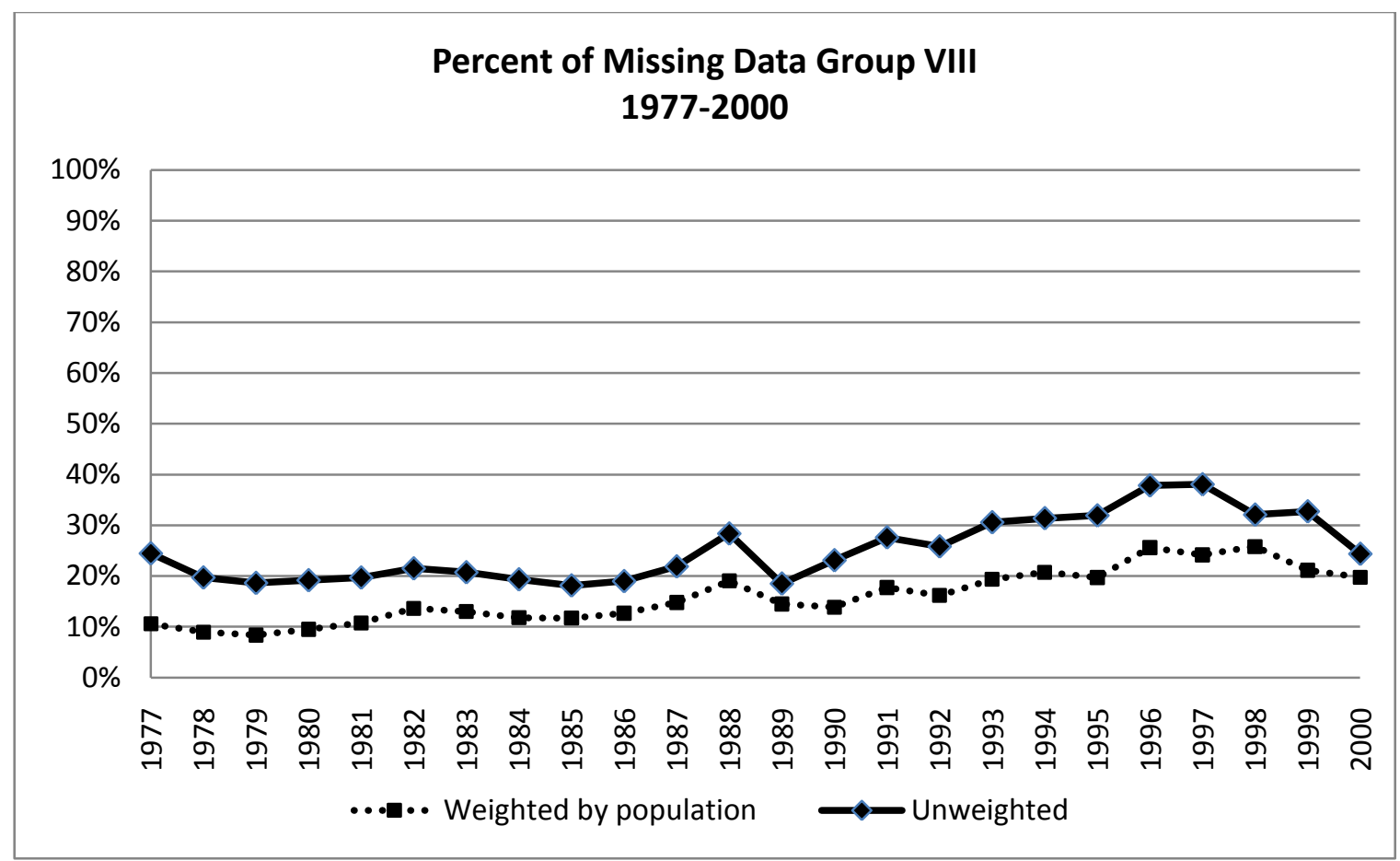

Figure 20. Percent of Missing Data Group VIII, 1977-2000

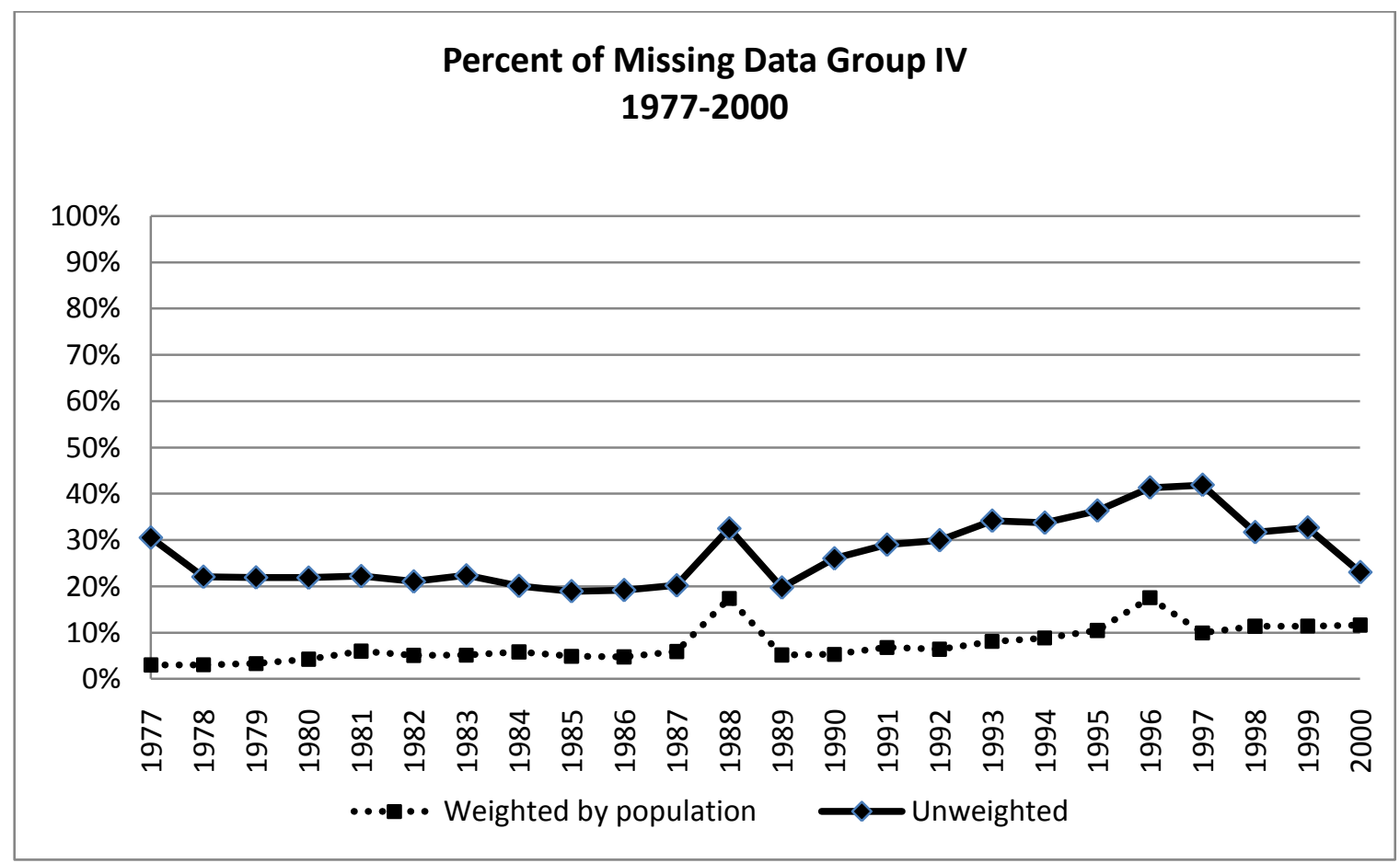

Figure 21. Percent of Missing Data Group IV, 1977-2000 
Group IV, which represents Suburban Counties, including State Police with no population, saw the highest level of unweighted missing data of all the groups. When weighted by population, the missing data level drops, since the agencies are some of the smallest in terms of population coverage. For charts of the missing data for all 50 states, please see Appendix D.

\section{Frequency of Missing Value Codes}

The complete dataset for $1977-2000$ contains a total of 5,779,295 cells. $62.5 \%$ represent valid data points with crime values, including true zero values. 943,982 $(16.3 \%)$ were identified as missing values using the "DATE LAST UPDATE" variable on the raw Return A file. In between is a combination of aggregated reporting, nonexistent ORIs, missing values we assigned, and individual missing crimes. Identifying the missing values monthly Return A form using the "DATE LAST UPDATE" variable is an all or nothing proposition. If the month had a date and was considered a valid reporting month, there is no special FBI code to indicate missing values on the individual crimes. Therefore, any missing values for the individual crimes were identified by the researcher. That makes a total of $11,241(0.19 \%)$ of the total data points that were deemed to be missing even though they had a data reported for the "Date Updated" variable. While this is a very small percentage, the scale to which the values were outside the norm could severely skew an imputation algorithm or other statistical analysis. For example, some agencies reported values such as "99999." These likely represent a code for a missing value, but treating them as a valid data point could severely skew statistical results. 
Table VI: Frequency of Missing Value Codes, All ORIs, 1977-2000

\begin{tabular}{|l|l|l|l|}
\hline Type of Value & Code & $\begin{array}{l}\text { Number of Data } \\
\text { Points }\end{array}$ & \% of Total \\
\hline Aggregated to December & -112 & 76,222 & $1.3 \%$ \\
\hline Aggregated to November & -111 & 91 & $0.0 \%$ \\
\hline Aggregated to October & -110 & 23 & $0.0 \%$ \\
\hline Aggregated to September & -109 & 271 & $0.0 \%$ \\
\hline Aggregated to August & -108 & 84 & $0.0 \%$ \\
\hline Aggregated to July & -107 & 18 & $0.0 \%$ \\
\hline Aggregated to June & -106 & 545 & $0.0 \%$ \\
\hline Aggregated to May & -105 & 27 & $0.0 \%$ \\
\hline Aggregated to April & -104 & 4 & $0.0 \%$ \\
\hline Aggregated to March & -103 & 219 & $0.0 \%$ \\
\hline Aggregated to February & -102 & 3 & $0.0 \%$ \\
\hline No data reported (True Missing) & -99 & 943,982 & $16.3 \%$ \\
\hline More than one index crime missing & -98 & 9,825 & $0.2 \%$ \\
\hline Motor vehicle theft missing & -97 & 56 & $0.0 \%$ \\
\hline Larceny missing & -96 & 79 & $0.0 \%$ \\
\hline Burglary missing & -95 & 59 & $0.0 \%$ \\
\hline Assault missing & -94 & 103 & $0.0 \%$ \\
\hline Robbery missing & -93 & 48 & $0.0 \%$ \\
\hline Rape missing & -92 & 144 & $0.0 \%$ \\
\hline Murder missing & -91 & 1 & $0.0 \%$ \\
\hline Researcher assigned missing value & -90 & 926 & $0.0 \%$ \\
\hline ORI was covered by another agency & -85 & 421,500 & $7.3 \%$ \\
\hline Agency did not exist during this period & -80 & 312,056 & $12.3 \%$ \\
\hline Negative Value & -1 & 131 & $0.0 \%$ \\
\hline Negative Value & -2 & $3,612,862$ & $0.0 \%$ \\
\hline Negative Value & -3 & $0.0 \%$ \\
\hline Negative Value & -4 & $0.0 \%$ \\
\hline Non-Missing Value & Reported Value & $6 \%$ \\
\hline & & & \\
\hline
\end{tabular}




\section{Simulation Study Results}

\section{Absolute Value Differences}

The imputation methods were evaluated by comparing the actual reported UCR value to the imputed value using both the FBI imputation procedure and the longitudinal method. As described in Chapter III, the simulation data set of the full 12 month reporting ORIs had its valid data points selected to be "punched out" based on the missingness run lengths. The two imputation methods run were then run to estimate for the "punched out" values. The original valid reported crime data points are considered "truth" against which the imputed estimate is tested. The absolute value differences are then calculated at the ORI level, for each imputation method, and summed up to national and group rates to assess the accuracy of the imputations. The simulation was run in five iterations, to reduce the chance that one particular set of simulation results was an outlier and the results arrived at by chance.

At the national level, the longitudinal method proved to yield more accurate results across all five iterations (see table VII). Overall, the FBI method had an absolute difference from the actual values by an average of 817,542 index crimes, while the longitudinal method differed by an average of 587,542. In percentage terms, the longitudinal method showed a $28.1 \%$ improvement over the FBI method for national estimates.

At the group level, the longitudinal method was more accurate for all FBI group types, with the average improvement ranging from $8.8 \%$ to $34.1 \%$. At $8.8 \%$ Group VI showed the smallest improvement, followed by Group VIII with 11.5\%, Group V with 
$21.7 \%$, Group IV at $27.4 \%$, Group III at $28.3 \%$, Group II at $30.0 \%$, Group IV at $30.3 \%$, Group VII at $33.1 \%$ and Group I at $34.1 \%$. 
Table VII: Simulation Results of Absolute Differences

\begin{tabular}{|c|c|c|c|c|c|c|c|c|c|c|c|}
\hline & Iteration 1 & & Iteration 2 & & Iteration 3 & & Iteration 4 & & Iteration 5 & & \\
\hline & $\begin{array}{l}\text { FBI } \\
\text { Method }\end{array}$ & LNG Method & $\begin{array}{l}\text { FBI } \\
\text { Method }\end{array}$ & $\begin{array}{l}\text { LNG } \\
\text { Method }\end{array}$ & $\begin{array}{l}\text { FBI } \\
\text { Method }\end{array}$ & LNG Method & $\begin{array}{l}\text { FBI } \\
\text { Method }\end{array}$ & LNG Method & $\begin{array}{l}\text { FBI } \\
\text { Method }\end{array}$ & LNG Method & $\begin{array}{l}\text { Average } \\
\text { Improvement } \\
\text { Across Simulations }\end{array}$ \\
\hline Total US & 877,447 & 640,570 & 807,403 & 607,861 & 809,683 & 556,381 & 786,880 & 571,468 & 806,296 & 561,431 & $28.1 \%$ \\
\hline Group I & 146,798 & 99,103 & 179,280 & 128,210 & 209,584 & 121,665 & 155,259 & 94,289 & 173,078 & 125,951 & $34.1 \%$ \\
\hline Group II & 82,062 & 69,651 & 112,177 & 65,914 & 82,702 & 62,512 & 94,072 & 68,088 & 119,626 & 77,089 & $30.0 \%$ \\
\hline Group III & 95,953 & 60,413 & 88,506 & 64,232 & 80,978 & 64,172 & 88,645 & 61,396 & 81,962 & 62,737 & $28.2 \%$ \\
\hline Group IV & 77,379 & 57,783 & 88,059 & 58,341 & 87,420 & 64,211 & 88,644 & 67,751 & 86,453 & 62,446 & $27.4 \%$ \\
\hline Group V & 84,256 & 66,397 & 93,762 & 69,792 & 75,462 & 61,418 & 82,434 & 68,792 & 83,193 & 61,575 & $21.7 \%$ \\
\hline Group VI & 60,112 & 55,190 & 64,884 & 56,748 & 62,070 & 57,435 & 59,695 & 55,197 & 61,479 & 56,569 & $8.8 \%$ \\
\hline Group VII & 31,148 & 21,558 & 30,229 & 20,706 & 31,950 & 23,334 & 35,560 & 21,676 & 34,239 & 21,925 & $33.1 \%$ \\
\hline Group VIII & 41,720 & 37,591 & 48,246 & 40,534 & 42,808 & 39,463 & 44,287 & 38,945 & 42,398 & 37,717 & $11.5 \%$ \\
\hline Group IV & 126,180 & 96,705 & 123,489 & 85,984 & 124,847 & 76,471 & 113,856 & 81,931 & 124,587 & 85,900 & $30.3 \%$ \\
\hline
\end{tabular}


In addition to measuring the absolute value accuracy by FBI group number, the same analysis was conducted by the missing data run length. This allows a different drill down of the analysis, to see how the accuracy varied by amount of missing data the method was imputing for in the simulation data set (see tables VIII and IX below).

Table VIII: Simulation Results of Average Absolute Value Differences by Run Length

\begin{tabular}{|l|l|l|l|}
\hline \multicolumn{2}{|c|}{ Average Across the Five Iterations } & \\
\hline $\begin{array}{l}\text { Run } \\
\text { Length }\end{array}$ & $\begin{array}{l}\text { FBI Imputation } \\
\text { Method }\end{array}$ & $\begin{array}{l}\text { Longitudinal } \\
\text { Imputation Method }\end{array}$ & $\begin{array}{l}\% \text { Improvement with } \\
\text { the Longitudinal }\end{array}$ \\
\hline 1 & 101,299 & 111,905 & $-10.5 \%$ \\
\hline 2 & 31,473 & 32,426 & $-3.0 \%$ \\
\hline 3 & 9,615 & 9,589 & $0.3 \%$ \\
\hline 4 & 30,372 & 27,540 & $9.3 \%$ \\
\hline 5 & 15,672 & 18,759 & $-19.7 \%$ \\
\hline 6 & 183,165 & 174,142 & $4.9 \%$ \\
\hline 7 & 22,813 & 23,507 & $-3.0 \%$ \\
\hline 8 & 28,051 & 25,664 & $8.5 \%$ \\
\hline 9 & 49,411 & 57,422 & $-16.2 \%$ \\
\hline 10 & 34,928 & 11,768 & $66.3 \%$ \\
\hline 11 & 35,500 & 11,621 & $67.3 \%$ \\
\hline 12 & 275,242 & 83,200 & $69.8 \%$ \\
\hline Total & 817,542 & 587,542 & $28.1 \%$ \\
\hline
\end{tabular}


Table IX: Simulation Results of Absolute Value Differences by Run Length

\begin{tabular}{|c|c|c|c|c|c|c|c|c|c|c|}
\hline & Iteration 1 & & Iteration 2 & & Iteration 3 & & Iteration 4 & & Iteration 5 & \\
\hline $\begin{array}{l}\text { Run } \\
\text { Length }\end{array}$ & FBI Method & LNG Method & FBI Method & LNG Method & FBI Method & LNG Method & FBI Method & $\begin{array}{l}\text { LNG } \\
\text { Method }\end{array}$ & FBI Method & LNG Method \\
\hline 1 & 97,877 & 111,890 & 102,158 & 107,158 & 103,762 & 114,027 & 102,850 & 117,037 & 99,846 & 109,413 \\
\hline 2 & 37,528 & 38,269 & 43,434 & 39,812 & 24,154 & 30,254 & 25,325 & 26,004 & 26,924 & 27,791 \\
\hline 3 & 9,384 & 9,079 & 10,033 & 10,050 & 5,115 & 6,334 & 10,849 & 13,133 & 12,694 & 9,349 \\
\hline 4 & 40,589 & 34,066 & 29,533 & 25,353 & 31,702 & 27,687 & 25,274 & 25,880 & 24,763 & 24,713 \\
\hline 5 & 13,411 & 16,246 & 20,757 & 33,750 & 12,026 & 13,027 & 13,195 & 14,061 & 18,973 & 16,709 \\
\hline 6 & 209,301 & 210,932 & 162,178 & 163,008 & 199,670 & 158,973 & 159,724 & 157,700 & 184,955 & 180,095 \\
\hline 7 & 23,782 & 22,436 & 25,487 & 30,731 & 24,382 & 20,694 & 28,038 & 26,608 & 12,376 & 17,068 \\
\hline 8 & 37,001 & 31,472 & 24,937 & 19,714 & 29,124 & 26,059 & 24,566 & 22,403 & 24,625 & 28,672 \\
\hline 9 & 61,631 & 68,039 & 34,781 & 57,518 & 50,901 & 50,393 & 61,387 & 65,448 & 38,355 & 45,713 \\
\hline 10 & 21,185 & 6,966 & 47,962 & 18,505 & 20,199 & 7,657 & 35,813 & 8,572 & 49,482 & 17,139 \\
\hline 11 & 31,482 & 9,224 & 30,155 & 13,215 & 39,045 & 13,191 & 38,453 & 10,961 & 38,364 & 11,512 \\
\hline 12 & 294,278 & 81,951 & 275,987 & 89,047 & 269,603 & 88,084 & 261,405 & 83,660 & 274,938 & 73,258 \\
\hline Total & 877,447 & 640,570 & 807,403 & 607,861 & 809,683 & 556,381 & 786,880 & 571,468 & 806,296 & 561,431 \\
\hline
\end{tabular}


While the overall improvement with the longitudinal method was $28.1 \%$ versus the FBI method, the results varied depending on the missing run length. The longer run lengths of 10,11, and 12 months showed significant improvement with the longitudinal method. This should be expected, since the FBI imputation for these run lengths is not based on the agency's own data, but on "similar" agencies (12-month reporters in the same state and population group).

The 10-month run length improved by $66.3 \%, 11$ months by $67.3 \%$, and 12 months by $69.8 \%$. For the remaining run lengths, the results were varied. Some showed moderate improvement, such as run length $4(9.3 \%)$, run length $6(4.9 \%)$, and run length $8(8.5 \%)$. Run length 3 showed only marginal improvement with $0.3 \%$ improvement. For run lengths $1,2,5,7$, and 9, the FBI method proved to be more accurate. For these the improvement with the longitudinal method was $-10.5 \%$ (run length 1 ), $-3.0 \%$ (run length 2), $-19.7 \%$ (run length 5), $-3.0 \%$ (run length 7), and $-16.2 \%$ (run length 9).

\section{Crime Index Level Accuracy}

The absolute value differences provide a view of how accurate each method is against the actual values, but it does not show the impact to overall crime level estimates. To do this, the crime totals of the simulation data set were summed for all years. From 1989-1999, the 4,765 full reporting ORIs in the simulation data set had 90,025,341 total index crimes. Across the five iterations, the FBI method estimates ranged from $89,799,028$ to $89,913,536$ for an average of $89,857,809$. The longitudinal method estimates ranged from $89,999,605$ to $90,049,393$ for an average of $90,026,838$ (see table $\mathrm{X})$. 
Table X: Comparison of Crime Count Totals

\begin{tabular}{|l|l|l|l|l|l|l|}
\hline & Iteration 1 & Iteration 2 & Iteration 3 & Iteration 4 & Iteration 5 & Average \\
\hline Actual & $90,025,341$ & $90,025,341$ & $90,025,341$ & $90,025,341$ & $90,025,341$ & $90,025,341$ \\
\hline FBI & $89,834,855$ & $89,894,019$ & $89,799,028$ & $89,913,536$ & $89,847,604$ & $89,857,809$ \\
\hline Lng & $90,049,393$ & $90,035,895$ & $90,030,660$ & $89,999,605$ & $90,018,638$ & $90,026,838$ \\
\hline
\end{tabular}

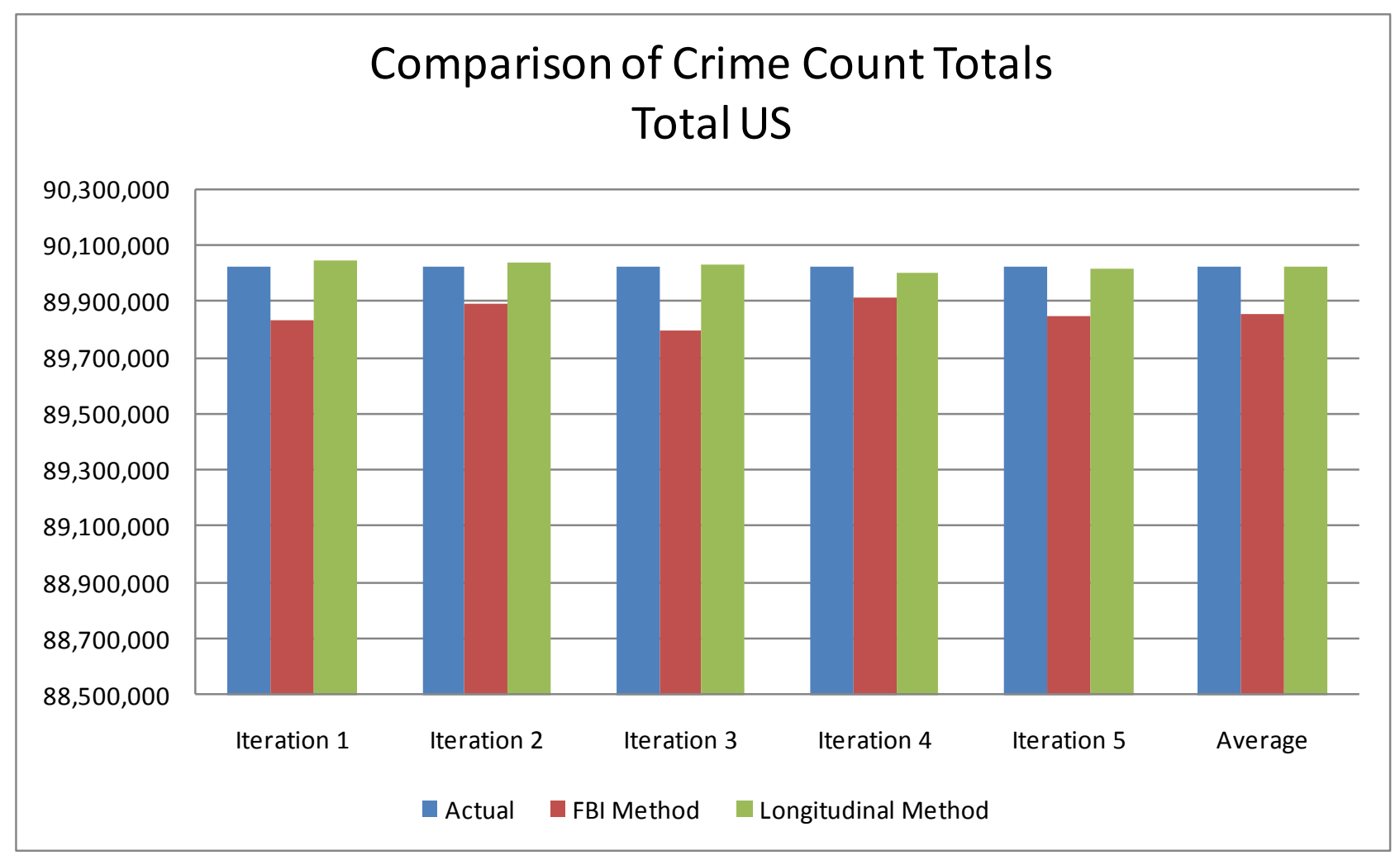

Figure 22. Comparison of Crime Count Totals

Across all five iterations, the FBI method consistently underestimated the level of crime compared to the actual. The greatest underestimation was in iteration 3 with $-0.25 \%$, followed by iteration 1 with $-0.21 \%$ (see table XI). The closest estimate for the 
FBI method was iteration 4 with $-0.12 \%$. Across all five iterations, the average for the FBI method was $-0.19 \%$.

The longitudinal method overestimated the actual totals in the first three iterations and underestimated it in the last two. The least accurate iterations were 1 and 4 , with iteration 1 reporting an overestimate of $0.03 \%$ and iteration 4 reporting -0.03 . The iterations 2, 3 and 5 all were tied for the most accurate with iterations 2 and 3 at $0.01 \%$ and iteration 5 with $-0.01 \%$. The average across all five iterations was $0.001 \%$. The reason the average was more accurate than the individual iterations is because the over and underestimations cancelled themselves when averaged together.

Table XI: Crime Count Percent Accuracy to Actual

\begin{tabular}{|l|l|l|l|l|l|l|}
\hline & Iteration 1 & Iteration 2 & Iteration 3 & Iteration 4 & Iteration 5 & Average \\
\hline FBI Method & $-0.21 \%$ & $-0.15 \%$ & $-0.25 \%$ & $-0.12 \%$ & $-0.20 \%$ & $-0.19 \%$ \\
\hline $\begin{array}{l}\text { Longitudinal } \\
\text { Method }\end{array}$ & $0.03 \%$ & $0.01 \%$ & $0.01 \%$ & $-0.03 \%$ & $-0.01 \%$ & $0.00 \%$ \\
\hline
\end{tabular}

When examined on a yearly basis for the total United States, the longitudinal method performed better in each year (see figure 23 below). There is no difference in 1989, since all of the imputations began in 1990. The longitudinal method performed the best in absolute terms in 1998, when it was only $0.01 \%$ different from the actual values. The longitudinal method was weakest in absolute terms in years 1990 and 1993, when it was off in by $0.12 \%$ and $-0.12 \%$.

The FBI method was the most accurate in absolute terms in 1996, when it differed from the actual by $-0.08 \%$. It was the least accurate in 1993 at $-0.33 \%$, followed by - 
$0.29 \%$ in $1994,-0.27 \%$ in $1998,-0.26 \%$ in $1990,-0.23 \%$ in 1997 and $1999,-0.18 \%$ in 1991 and 1992 , and $-0.16 \%$ in 1995.

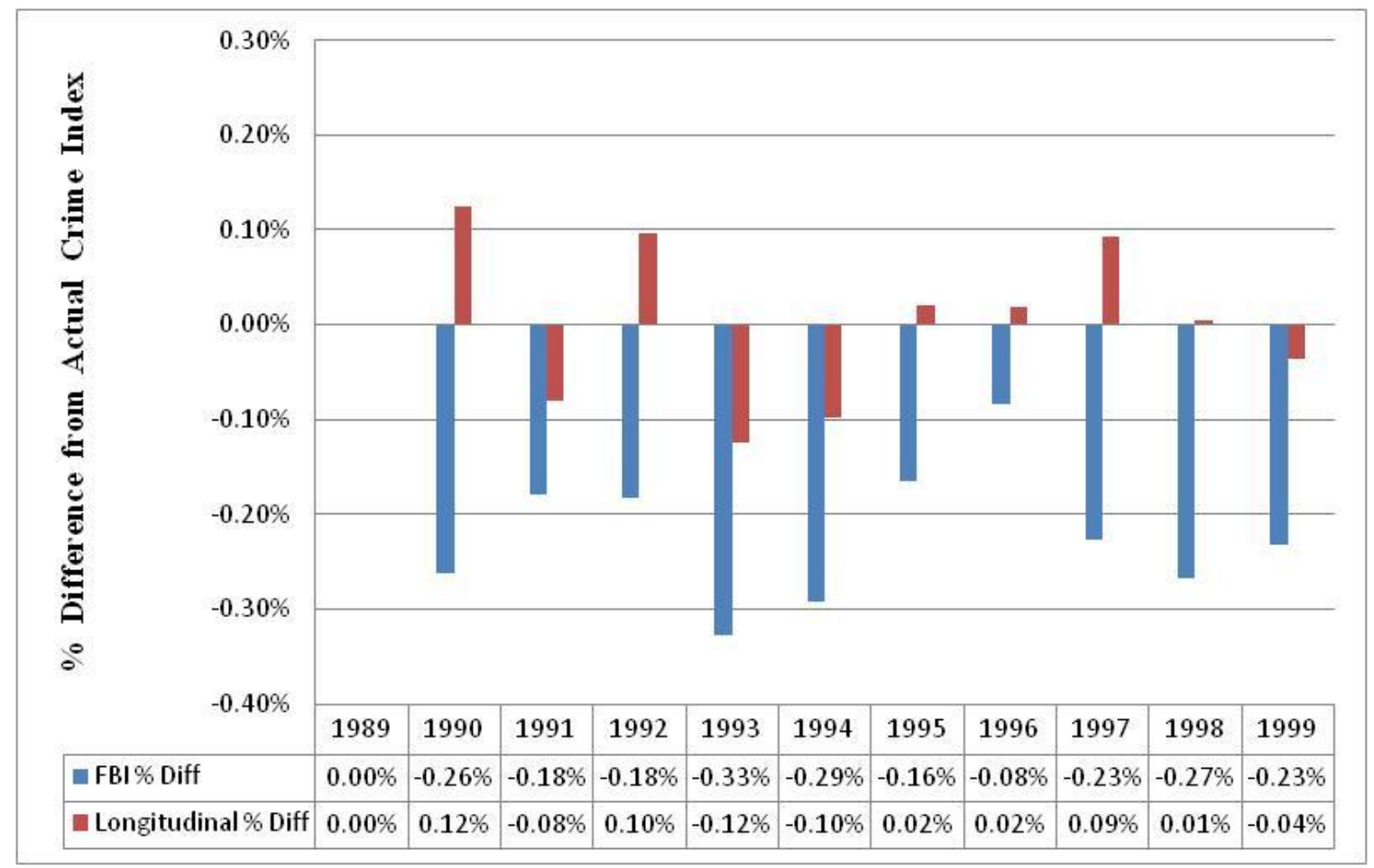

Figure 23. Yearly differences of imputation methods for Total US based on the average of the five iterations 


\section{DISCUSSION AND CONCLUSION}

\section{A. Discussion}

The purpose of this research was to 1) Clean the Offenses-Known UCR agency level files and create a single longitudinal data set; 2) Analyze the type and extent of data errors to determine patterns of missing data; and 3) Use a simulation data set of complete reporting ORIs to determine the accuracy of the FBI cross-sectional imputation methodology against a competing longitudinal method.

The missing data analysis found that there was an upward trend in the amount of missing data in the UCR program beginning in the late 1980s through the ends of the 1990s. The growth in missing data was not consistent among the different FBI population groups, with group I showing consistent reporting over time and group II with only a slight increase in the 1990s. The remaining groups III-IV, which constitute the smaller agencies, saw larger increases in missing data over time. A similar pattern was present for the level of missing data, with groups I and II having the strongest reporting, while groups III-IV reporting higher levels of missing data.

The data cleaning process revealed a number of unusual data artifacts, which required recoding to properly analyze the missing data. Some of these artifacts were a known issue in UCR data; others had not been documented and were ones not anticipated. The aggregation of data into quarterly, semiannual and annual reporting had been a known issue that was quantified as part of the analysis. However, what was more unusual were agencies that aggregated data outside of those patterns. There were 250 data points (<.01\% of the total) that reported aggregated data in the months of February, April, May, July, August, October or November. These don't fit into the quarterly, semiannual, or annual reporting months patterns. It is possible 
to see how this could happen for agencies that were reporting data late and might send two months of data in a single monthly report.

Negative values are another known possibility in UCR data that can be legitimate values. Police agencies can submit negative values as an accounting mechanism to adjust for unfounded crimes. What was not expected was that some ORIs have reported negative values below -20. While some negative values were to be expected, it seemed reasonable to set a cut off of -4 and deem any value lower than that to be a missing value.

Outlier values were also present in the UCR crime index data. These typically were either "999," "9999," or "99999." The most likely explanation for these is that police agencies were using these as their own missing value codes. However, the ICPSR data files do not contain missing value codes in their codebook, so an unobservant researcher might unknowingly plug these values into an analysis without realizing the impact it could have on the results. For the purposes of analyzing missing data, these values were coded as missing.

The overall results confirmed the hypothesis from Maltz (1999) that a longitudinal imputation method would be a more accurate imputation method than the FBI's cross-sectional method. This hypothesis was based on other criminology research that has shown "all crime is local" (Sherman, Gottfredson et al. 1997) and that crime rates and patterns will vary substantially across police jurisdictions. With the exception of any major changes to the jurisdiction (large population shift, natural disaster, major crime wave, etc) the past crime reporting history of the jurisdiction would be similar to the more recent missing year. Therefore, the hypothesis would predict that the past crime reporting behavior would be a better predictor for missing values than using the crime rate of agencies of similar size. For the total United States over the ten year 
history, the average improvement across the iterations was $28.1 \%$ for the longitudinal method compared to the FBI method. This is a significant improvement, especially considering that there was improvement across all FBI population groups.

The results across the different missing data run lengths were more mixed, but have important implications for understanding the value of the different imputation methods. The missing data run lengths of 10,11 , and 12 months all showed $60 \%+$ improvement with the longitudinal method. Therefore, when the largest amounts of data were missing, the longitudinal method was much more accurate. The significance of this finding is that under the FBI's imputation method, any ORI with 12,11 , or 10 months of missing data are completely scrapped and the FBI imputes entirely based on the cross-sectional rate of "similar" agencies. For ORIs with a missing run lengths between 9 and 1 months, the FBI method takes the reported crimes multiplied by $12 / \mathrm{N}$ ( $\mathrm{N}$ is the number of months for which valid monthly crime reports existed). Therefore, when the cross-sectional imputation method is relying solely on estimates based on "similar" jurisdictions, the estimates significantly drop off in accuracy.

Two important findings come from this observation. When partial data are used for the estimation, as it is for the 9 to 1 month missing data run lengths, the results don't show a consistent pattern of improvement over the longitudinal. Second, the findings show how much lower the accuracy is for crime estimates when only based on ORIs of similar size and geography. There is a caveat to this finding, which is that the simulation data set used in this analysis was designed so that there would always be some historical data from which the longitudinal method could impute from. In reality, there are some ORIs that are chronic nonreporters and might have very little or no history to impute from. Given the voluntary nature of the UCR program, some agencies will place very low priority on submitting their data to the FBI 
or state-level UCR program. Since the longitudinal method needs some history from which to base its estimates, chronic non-reports would still require some form of cross-sectional imputation.

For estimating crime rate totals at the national level, the FBI method on average underestimated the crime level by $0.19 \%$, while the longitudinal method was within $<0.01 \%$. While neither method had a major impact on level estimates, it should be noted that these are at the highest aggregate level. I did not break down the crime level impact at lower level geographies, but it is possible there could be more variation. This would be especially true at the county level, in which a single ORI could make a significant contribution to the crime level.

The data cleaning process also illustrated the importance of visually inspecting the data using graphical methods to detect errors and anomalies. The classic approach of researchers to data is to not inspect them graphically and treat them as a "black box" (Maltz 1998; Maltz 2009). The justification for such an approach is often that the researchers not become biased in the examination of the data. However, there is a risk to this approach whereby data issues can be overlooked. For example, the "999," "9999," and "99999" values, as well as the unusually low negative crime values, were identified by visual inspection of ORI plots. Without manually assigning these to be missing values, ORIs reporting those values could have been eligible as a complete reporting agency for the simulation data set. Therefore, researchers should be thorough in their data cleaning and using graphical methods are one powerful tool that can be used.

\section{B. Limitations of the Research}

There are several limitations to this study that one should consider when interpreting the results. The analysis was performed on the crime index as a whole, rather than on the individual 
crimes. The disadvantage to such an approach is that larceny, which makes up a large percentage of the index crime count, can have a disproportionate affect on the crime rate trend and hence the imputation results.

Second, only one competing imputation method was tested against the FBI crosssectional method. While the longitudinal method was carefully chosen based on prior research recommendations, other imputation methods might provide useful insights to the handling of missing data.

Third, the data has become dated since the initial data cleaning and research project began. There is always a lag time of approximately two years, since it takes the FBI and ICPSR a significant amount of time to archive the UCR files. However, UCR reporting is an evolving system and trends in reporting and missing data can change over time.

Fourth, the study was limited to secondary data collected by official statistical agencies and police departments. This study is subject to all of the limitations of the UCR program described in Chapter II and cannot be remedied with any imputation method. While every effort was taken to exclude statistical outliers and data entry errors, the same problems with the collection and possible measurement error still exist. The simulation data set of complete reporting ORIs were used to represent "truth," when these statistics are subject to various layers of measurement error before being archived at ICPSR.

\section{Recommendations for Future Research}

Future research should consider disaggregating the crime index by different types of crimes, to prevent the limitation having larceny possibly drive the total crime index trend and influence the imputation algorithms. To achieve this, it may not even be necessary to 
disaggregate by each individual crime, but instead to separate property crimes (larceny, burglary, and motor vehicle theft) from violent crimes (murder, rape, aggravated assault, and robbery).

As the NIBRS programs grows, so too will the need to examine the effects of missing data and imputation methods. Rather than simply having to determine an estimated crime count for missing values, NIBRS will produce missing data on victim/offender characteristics, location codes, arrestee information, and property type. Understanding the scope and causes of missing data in NIBRS will be just as important to researchers examining crime trends as it will to police administrators. Since it is analogous to the SHR system, a hot-deck approach might be more appropriate for NIBRS data (Fox 2004).

Finally, future research should examine missing data outside the context of the reported UCR data. All inferences made during the course of my research were based on examining the reported UCR data, but more can be learned from a more in-depth examination of why certain agencies non-report their UCR data. For example, a follow-up survey of non-reporting agencies can yield additional insights to why an agency failed to report their data (Lynch and Jarvis 2008). This would obviously have its challenges, since an agency that failed to report their UCR data may also be likely to non-respond to a phone survey or in-person interview.

\section{E. Conclusion}

The handling of missing data for many social scientists and criminologists is an afterthought, even though missing data are found in nearly every data set. The Offenses-Known UCR data are no exception and its impact goes beyond the needs of criminological research. UCR data have political implications for both law enforcement and politicians. Therefore, how the missing data are handled should be examined and tested to meet the robust statistical 
standards. The current FBI cross-sectional method was adequate and sensible when it was developed in the pre-modern computing days of the 1950's. However, given the changes in the use of UCR data and modern computing technology, the imputation methods must also be revisited.

A longitudinal method shows promise for providing more accurate estimates of crime. Incorporating some aspects of longitudinal imputation to aggregate reporting could provide more accurate estimates of crime level and trend. This is particularly true at the county level, given the limitations of the NACJD imputation procedures (Maltz and Targonski 2002; Maltz and Targonski 2003).

As discussed earlier in this chapter, the longitudinal method is limited to agencies with some reporting history. One possible solution is to employ the longitudinal method for agencies that meet the criteria of having sufficient history from which to base the imputed values. If an agency is a chronic non-reporter, the cross-sectional method can still be used. However, as suggested by Maltz (1999), chronic non-reporters should be followed up on using other possible sources to determine how accurate the cross-sectional methods are. This could be a on a sampled basis, possibly using its annual report to the municipal or county government.

Missing data may be viewed as a nuisance to social science research and government reporting, but they cannot be ignored. The use of UCR data for funding appropriations, subnational use for county level reporting, and conversion to NIBRS only increase the importance that should be given to how missing data are handled in the UCR system. Enhancements and testing of the imputation methods used will help better serve researchers, policy makers, local politicians, and police administrators with more accurate and useful crime data. 
RETURN A - MONTHLY RETURN OF OFFENSES KNOWN TO THE POLICE

This repert is anthocired by law Title 28, Section 534, U.S. Code. Your cooperatioe in consplecing thin form will assist the FBI, in compaling timely comprobeusive, and accurato data. Plesse submit this form mouthly, by the seronth dry affer the close of the month, med any questioes to the FBI, Crimiesl Jestice Informstion Services Division, Atseztion: Uniform Crime Roports/Modtale E-3, 1000 Custar Hollow Road, Clurksburg, Wost Virginia 26306; tolephone 304-625-4830, faccimile 304-625-3566. Under the Paperwork Redaction Act, you are not required to complace this foem unloss it coetains 2 valid OMI coutrol member. The form takes approximstely 10 minutes to coemplete. Instructious for propering the form appesir oe the roverse side

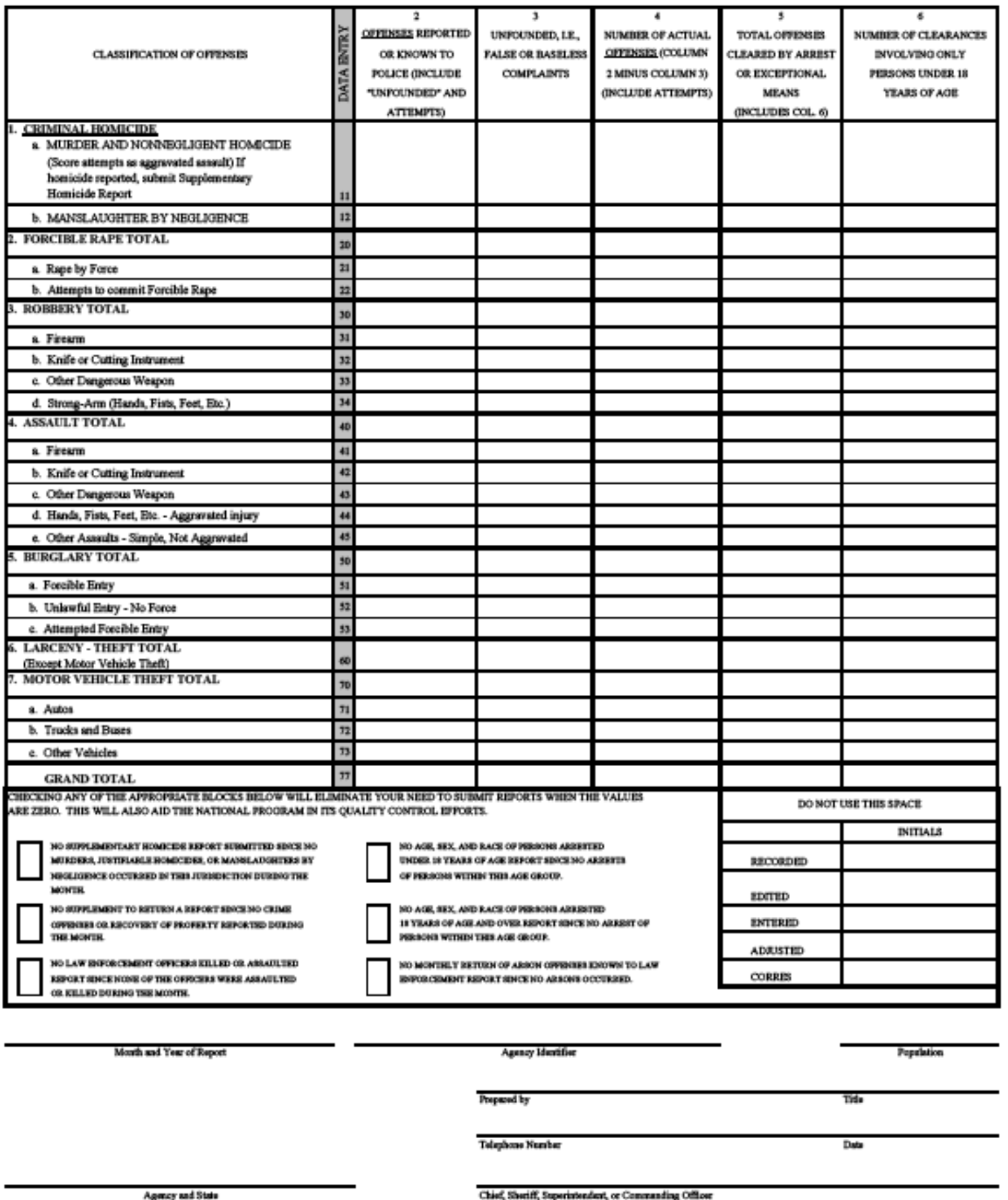




\section{SUPPLEMENT TO RETURN A \\ $1-206(0 \times 2,28006$ CME Na. $1110-4601$ MONTHLY RETURN OF OFFENSES KNOWN TO THE POLICE \\ Expines 61-38-10}

This report is authonzed by law Title 28, Section 534, U.S. Code. Your cooperation in completing this form with the Return $A$ will assist the FBI in compiling timely, comprehensive, and accurate data. Please submit this form monthly, by the seventh day after the close of the month, and any questions to the FBI, Criminal Justice Information Services Division, Attention: Uniform Crime Reports/Module E-3, 1000 Custer Hollow Road, Clarksburg, West Virginia 26306; telephone 304-625-4830, facsimile 304-625-3566. Under the Paperwork Reduction Act, you are not required to complete the form unless it contains a valid OMB control number. The form takes approximately 11 minutes to complete.

This form deals with the nature of crime and the monetary value of property stolen and recovered. The total offenses recorded on this form, page 2, should be the same as the number of actual offenses listed in Column 4 of the Return $A$ for each crime class. Include attempted crimes on this form, but do not include unfounded offenses. If you cannot complete the report $m$ all areas, please record as much mformation as is avallable. Tally sheets will be sent upon request.

\begin{tabular}{|c|c|c|c|}
\hline \multicolumn{4}{|c|}{ PROPERTY BY TYPE AND VALUE } \\
\hline \multirow{2}{*}{$\begin{array}{c}\text { Type of Property } \\
\text { (1) }\end{array}$} & \multirow{2}{*}{ 列| } & \multicolumn{2}{|c|}{ Monetary Value of Property Stolen in Your Jurisdiction } \\
\hline & & $\begin{array}{l}\text { Stolen } \\
\text { (2) }\end{array}$ & $\begin{array}{c}\text { Recovered } \\
\text { (3) }\end{array}$ \\
\hline (A) Currency, Notes, Etc. & 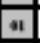 & \$ & $\$$ \\
\hline (B) Jewelry and Precious Metals & $n$ & & \\
\hline (C) Clothing and Furs & - & & \\
\hline (D) Locally Stolen Motor Vehicles & 4 & & \\
\hline (E) Office Equipment & st & & \\
\hline (F) Televisions, Radios, Stereos, Etc. & 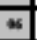 & & \\
\hline (G) Firearms & $n$ & & \\
\hline (H) Household Goods & -1 & & \\
\hline (I) Consumable Goods & 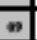 & & \\
\hline (J) Livestock & it & & \\
\hline (K) Miscellaneous & 萡 & & \\
\hline TOTAL & $\infty$ & s & s \\
\hline & & I & 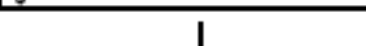 \\
\hline & & $\begin{array}{l}\text { The total of this collumn should } \\
\text { agree with the } \\
\text { Crand Total (DATA ENTRY Th) } \\
\text { thowe an page 2. }\end{array}$ & 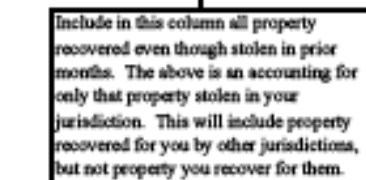 \\
\hline
\end{tabular}

Telephone Number Date

Chief, Sbeniff, Supenintendent, or Commanding Officer

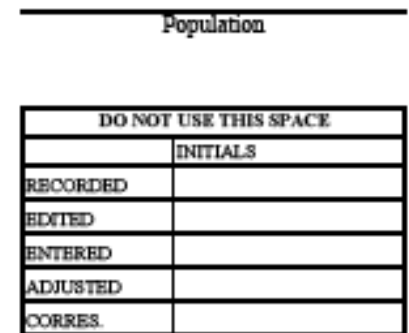


This report is authorized by law Title 28, Section 534, United States Code. While you are not required to respond, your cooperation in using this form to list data pertaining to all homicides reported on your Return A will assist the FBI in compiling comprehensive, accurate data regarding this important classification on a timely basis. Any questions regarding this report may be addressed to the Federal Bureau of Investigation, Criminal Justice Information Services Division, Attention: Uniform Crime Reports/Module E-3, 1000 Custer Hollow Road, Clarksburg, West Virginia 26306; telephone 304-625-4830, facsimile 304-625-3566. Under the Paperwork Reduction Act, you are not required to complete the form unless it contains a valid OMB control number. The form takes approximately 9 minutes to complete.

1a. Murder and Nonnegligent Manslaughter

List below specific information for all offenses shown in item la of the monthly Return A. In addition, list all justifiable killings of felons by a citizen or by a peace officer in the line of duty. A brief explanation in the circumstances column regarding unfounded homicide offenses will aid the national Uniform Crime Reporting Program in editing the reports.

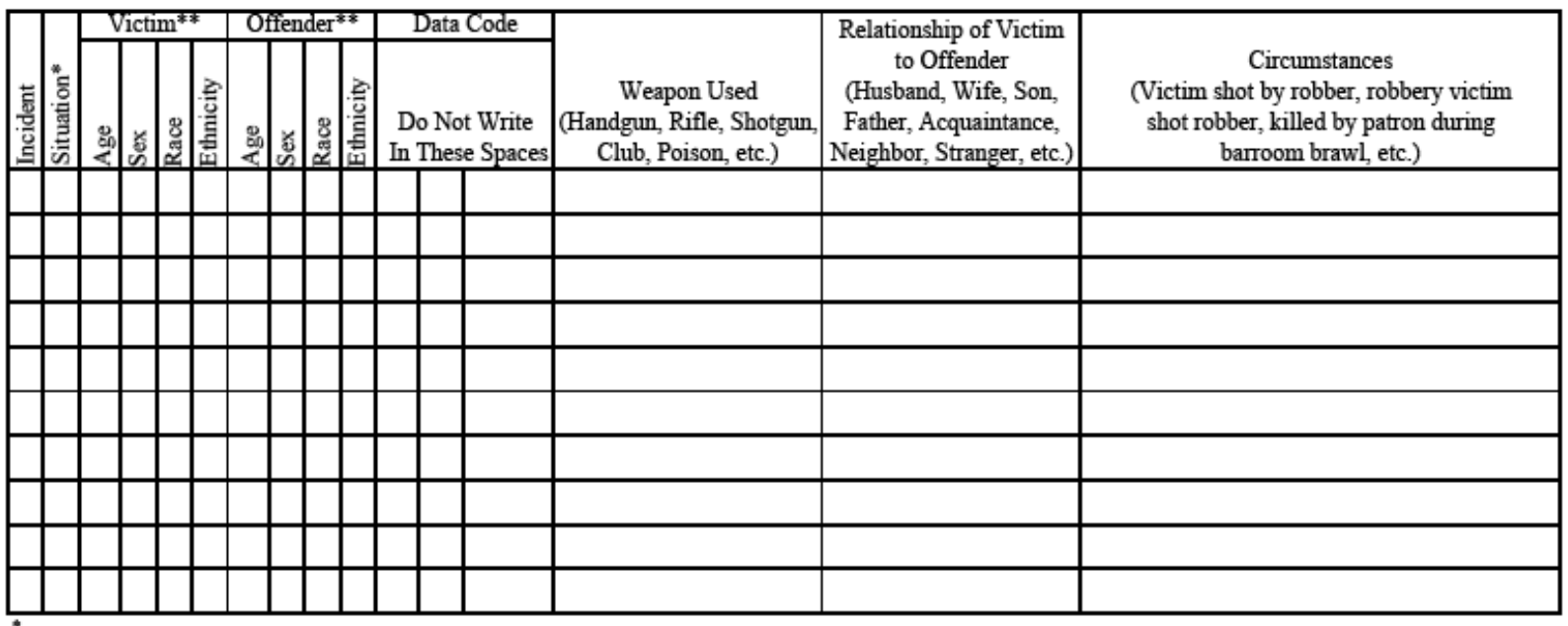

** - See reverse side for explanation

Month and Year

Agency
Agency Identifier

State
DONOT WRTE HERE

Recorded

Edited

Punched

Verified

Adjusted 


\section{APPENDIX B: DATA PREPARATION STEPS}

\section{Conversion Steps for ICPSR 9028 SPSS Files}

1. Calculate aggravated assault. Do not use the total, which includes simple assaults. Add up assault with gun, with knife, with hands/feet, and other.

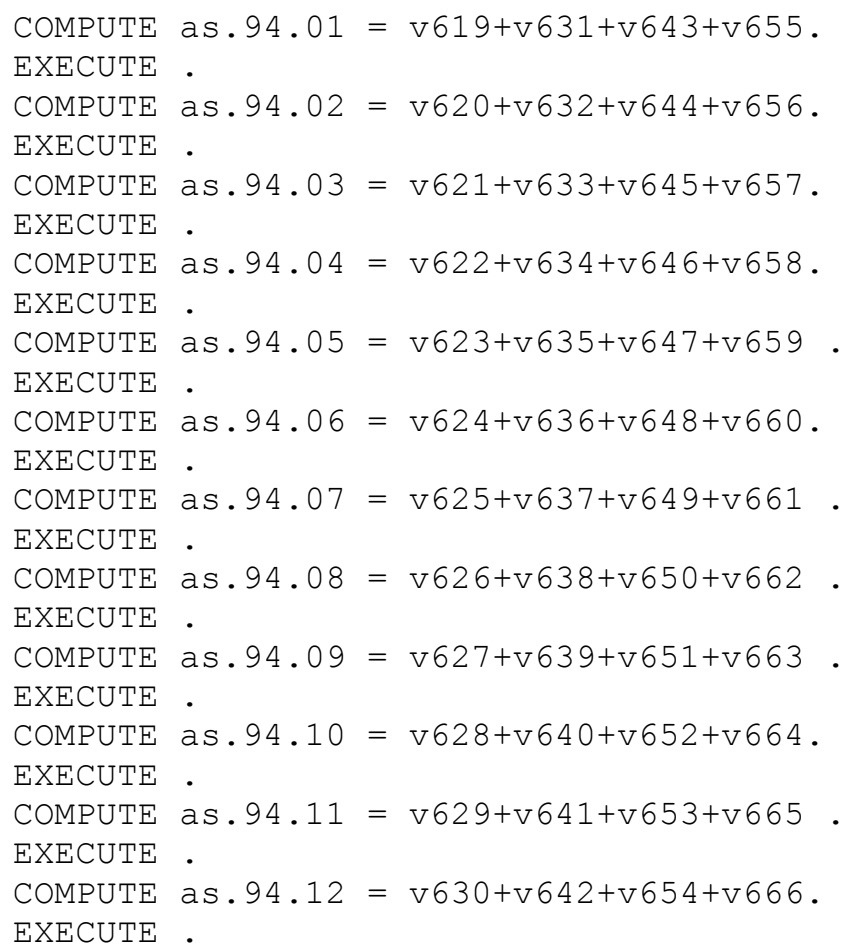

Other crimes are as follows:

Murder: use the total without manslaughter

Rape: use rape total

Robbery: robbery total

Burglary: burglary total

Larceny: larceny total

Motor vehicle theft: MV theft total

2. Calculate the total population for the agency by adding up the first 3 populations. 
COMPUTE pop4.94=pop1.94+pop2.94+pop3.94.

EXECUTE .

3. Calculate the number of months reported for the year.

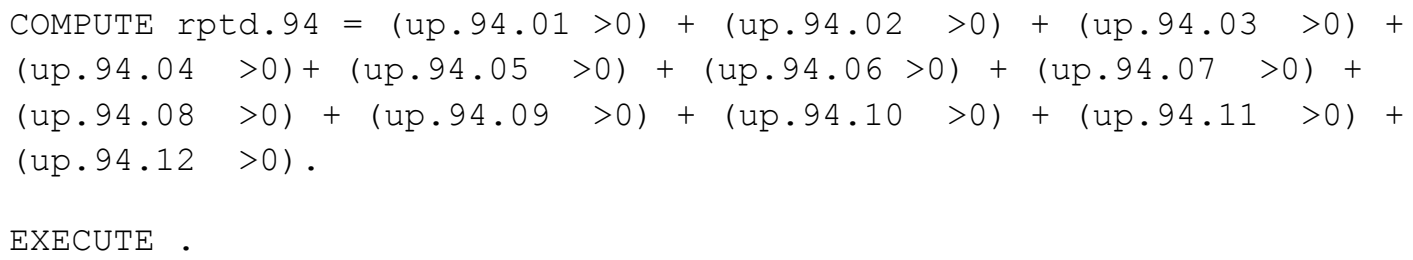

4. Merge all yearly files to a single longitudinal file:

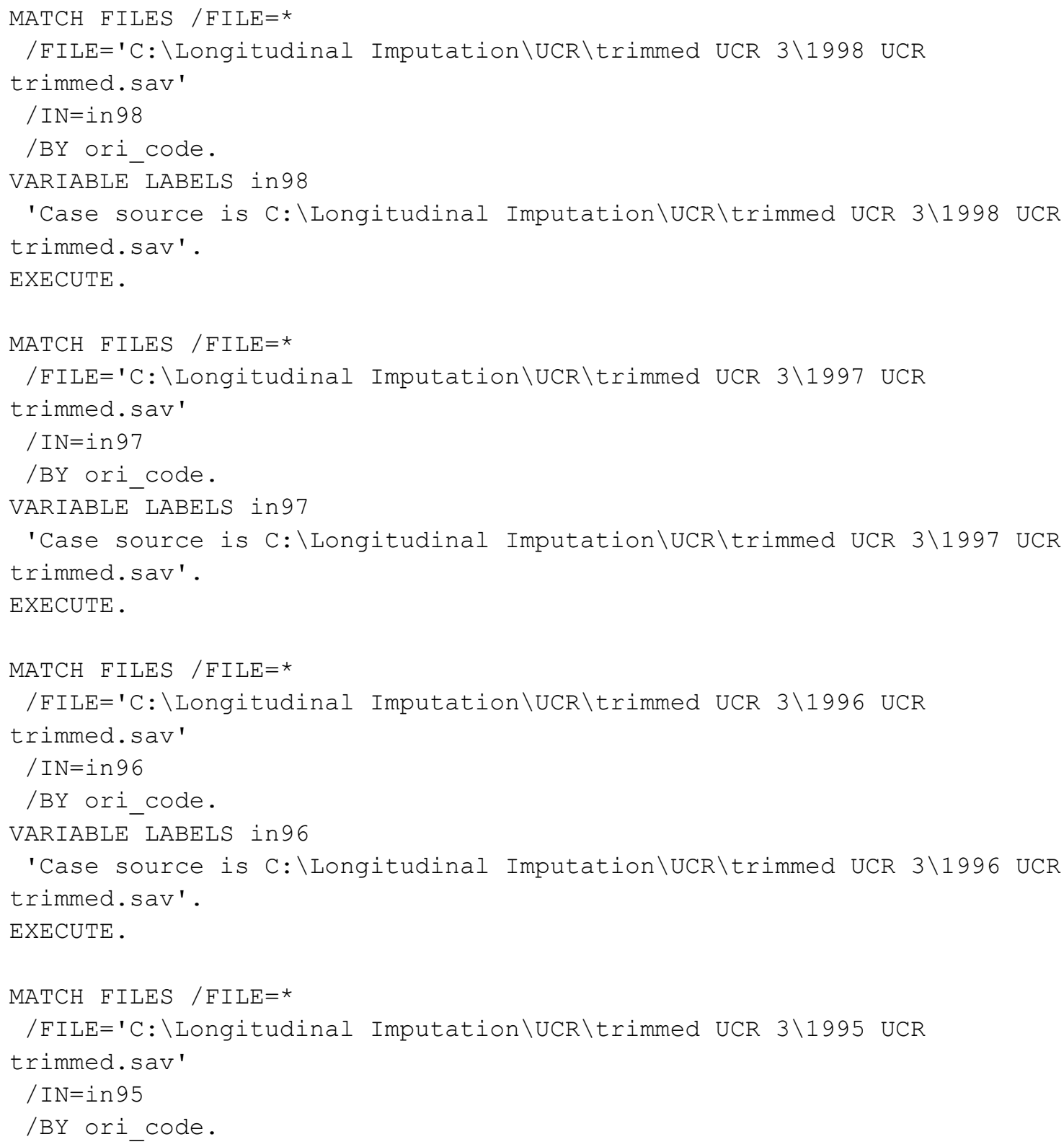




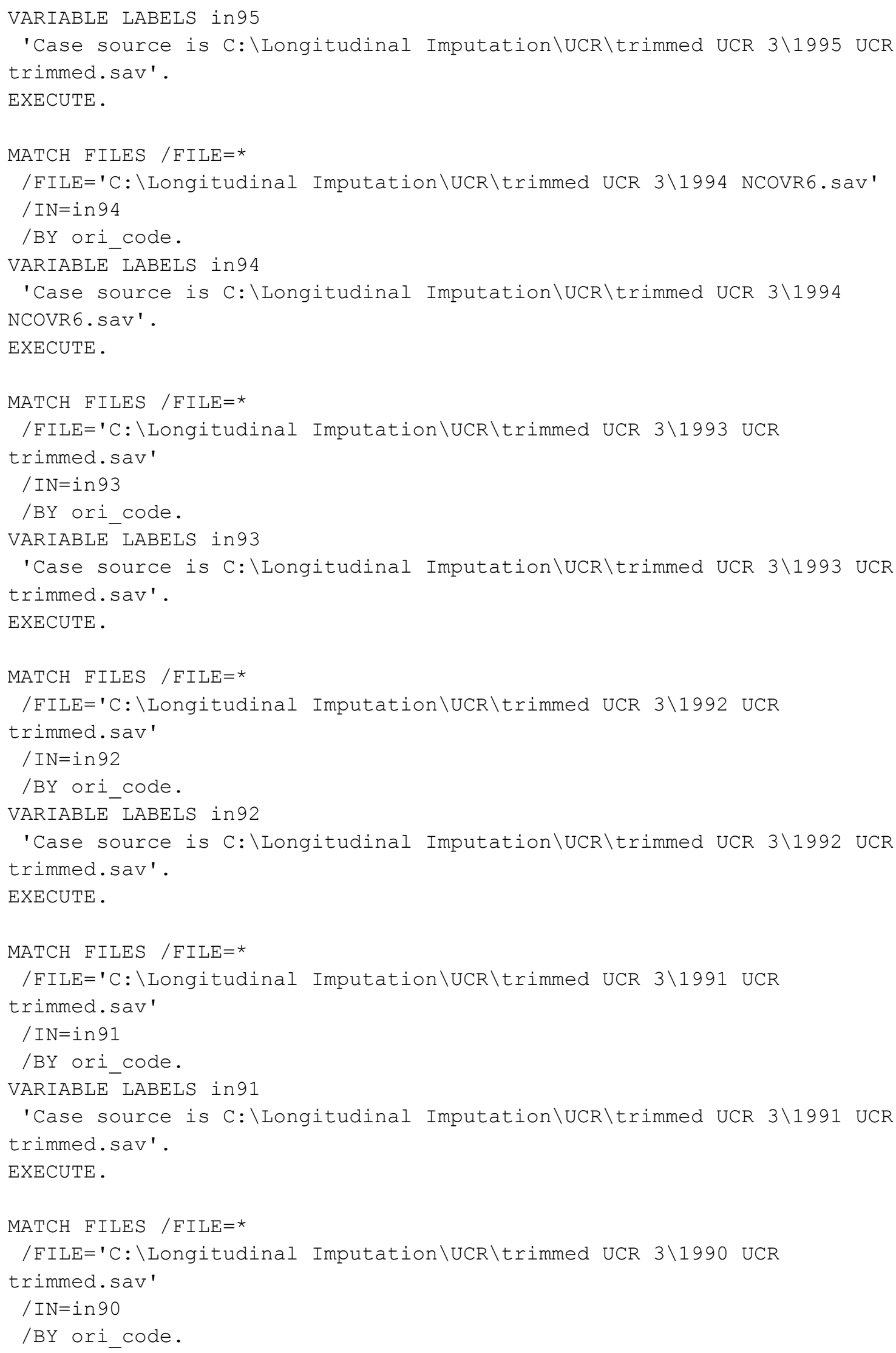




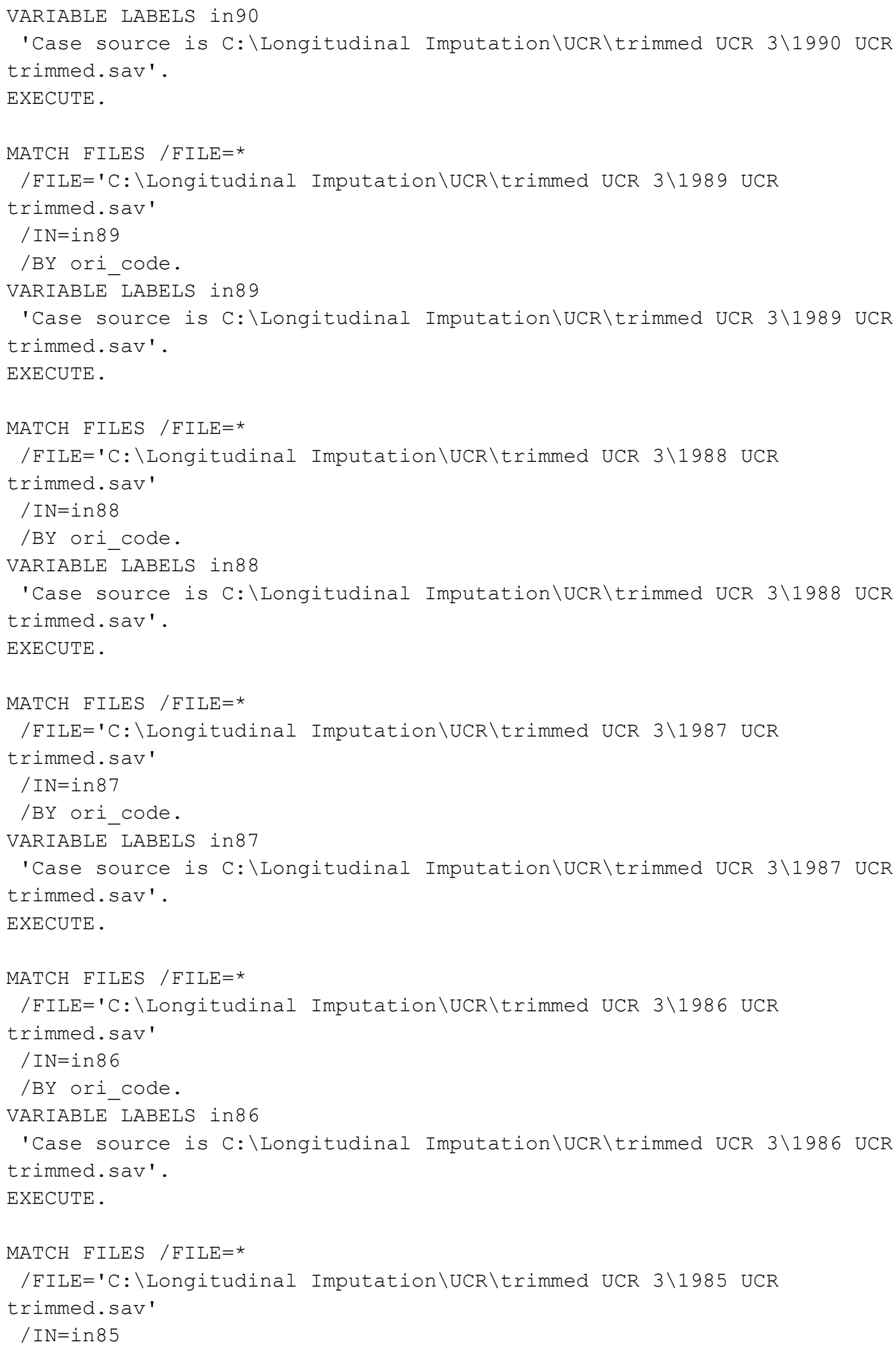




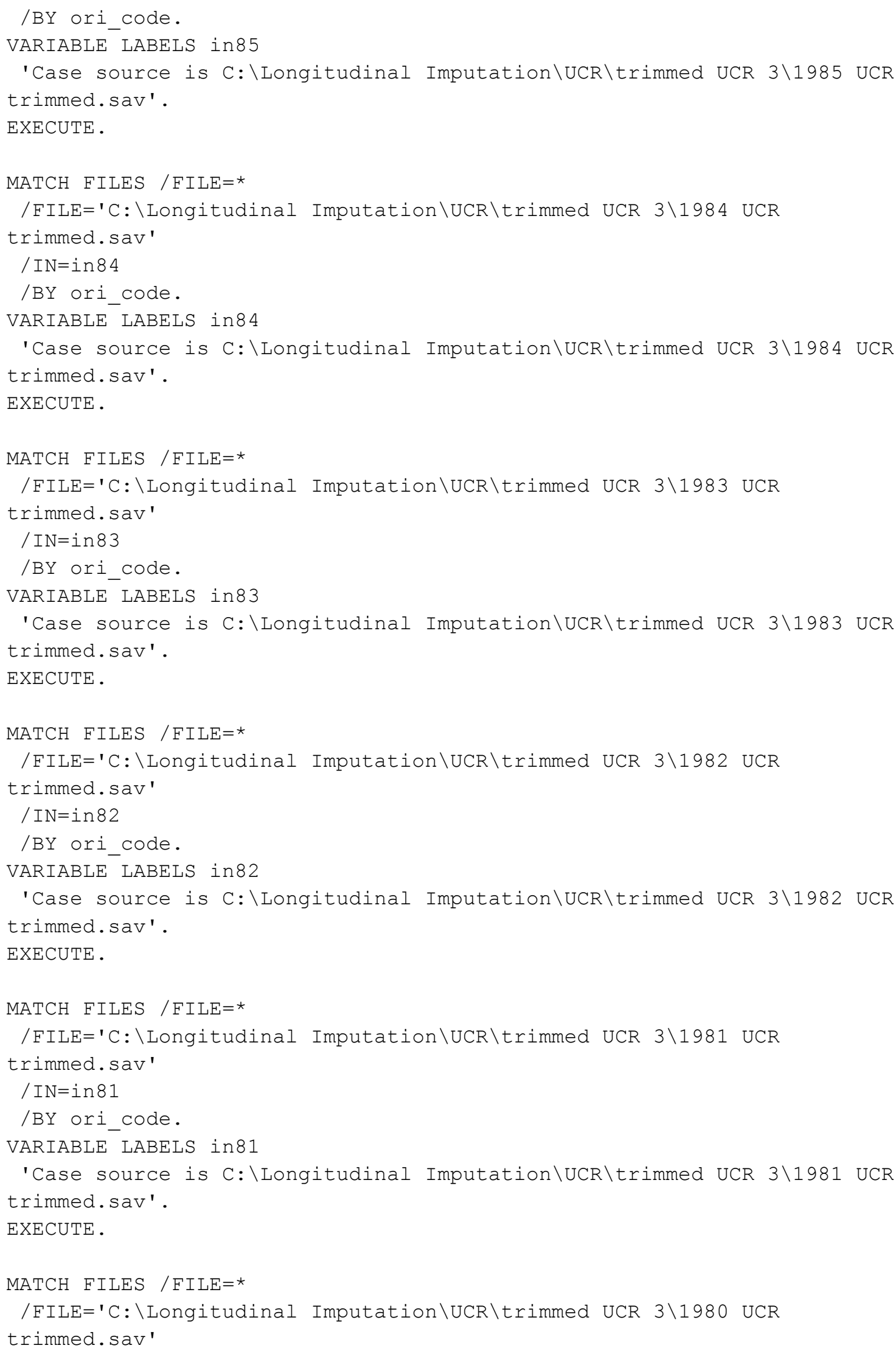




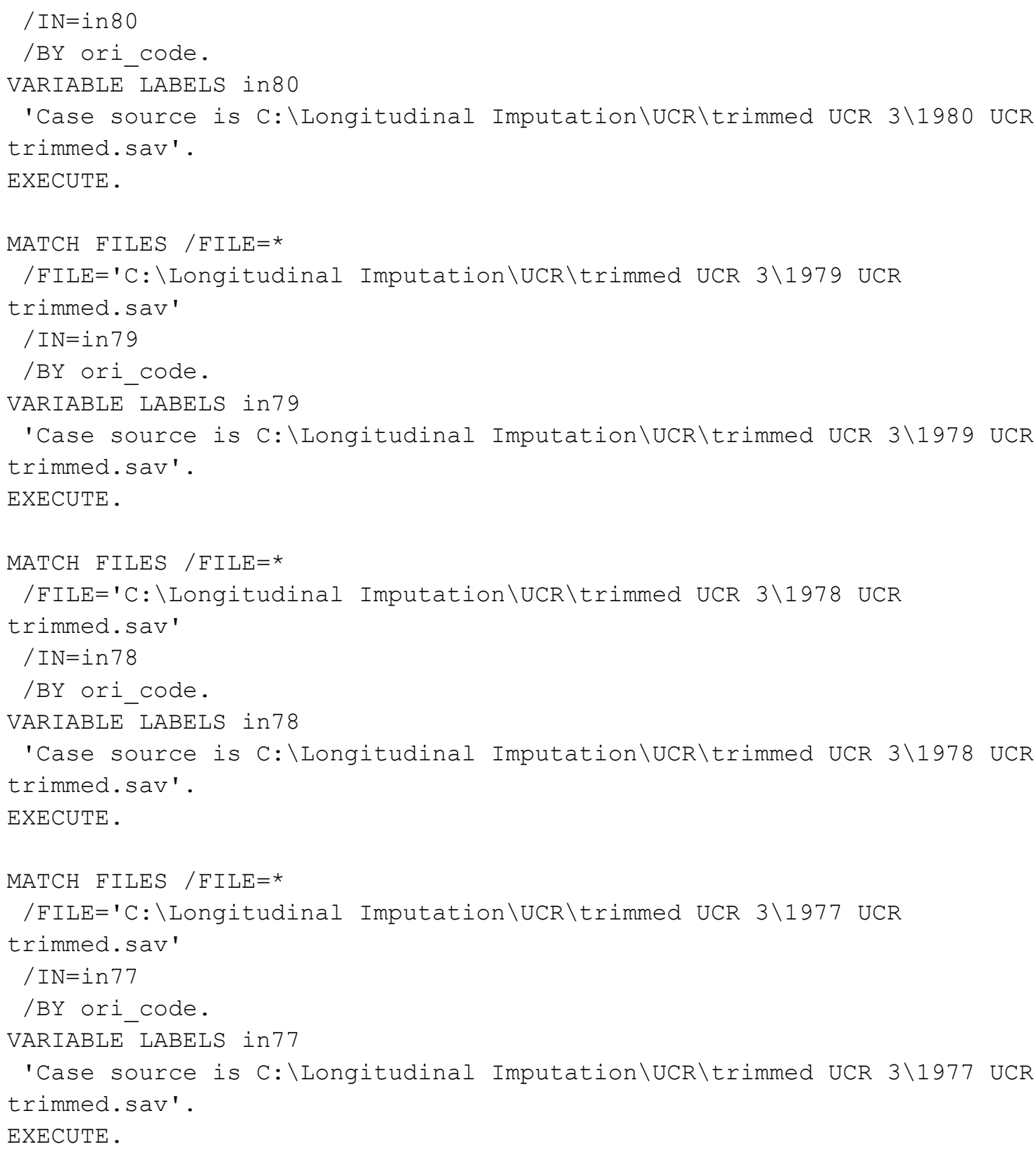




\section{APPENDIX C: VISUAL BASIC CODE FOR IMPUTATION}

\section{Determine the missing patterns and run lengths}

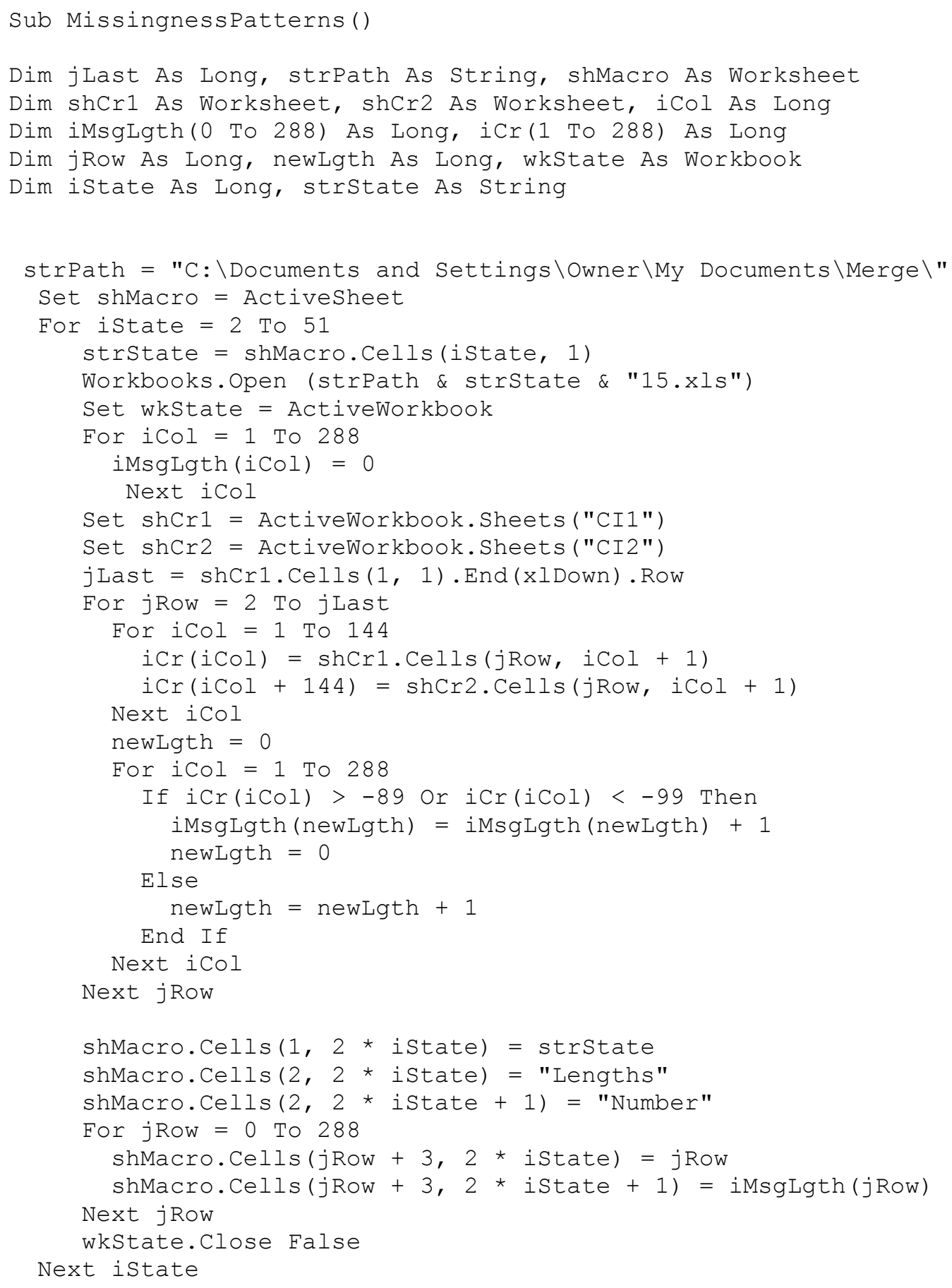

End Sub 


\section{For each state and year, this creates the group crime rate index for each group. A separate worksheet is created for each group.}

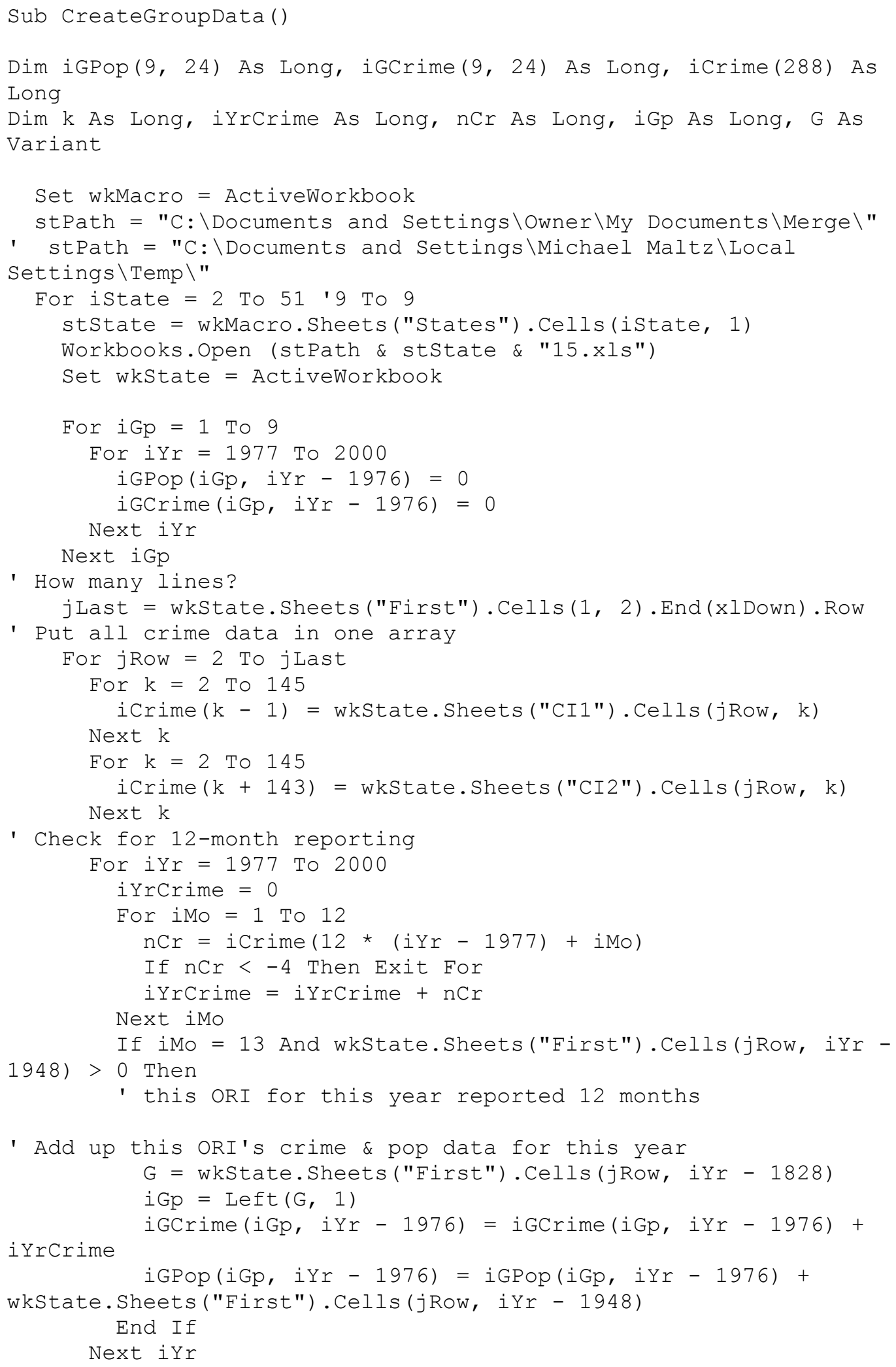




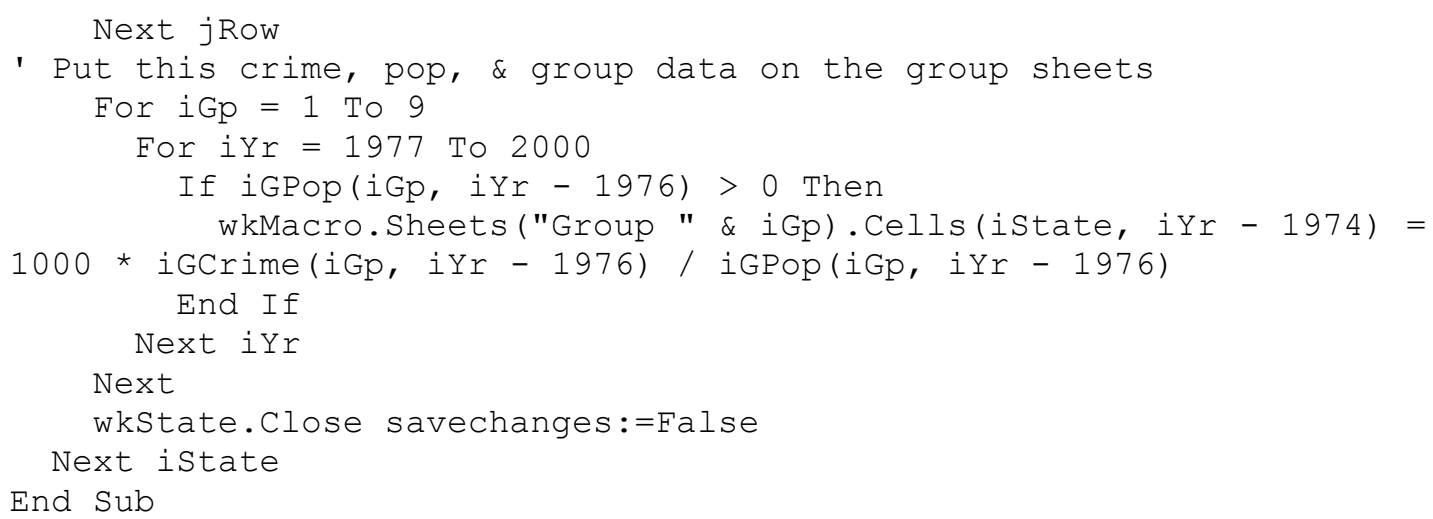

\section{Create simulation data set}

\section{3a. Select only ORIs with full reporting history for 1989-2000}

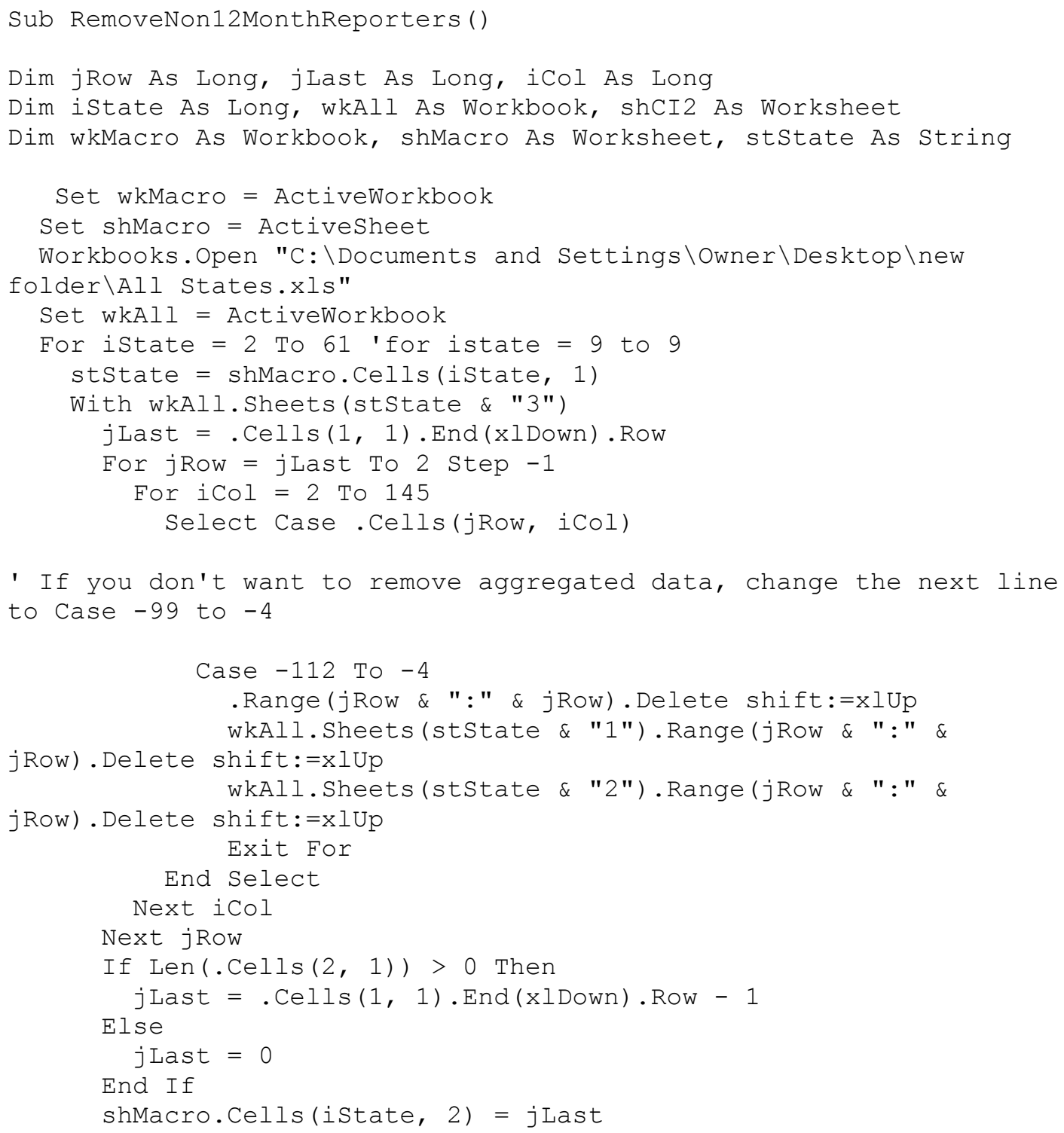




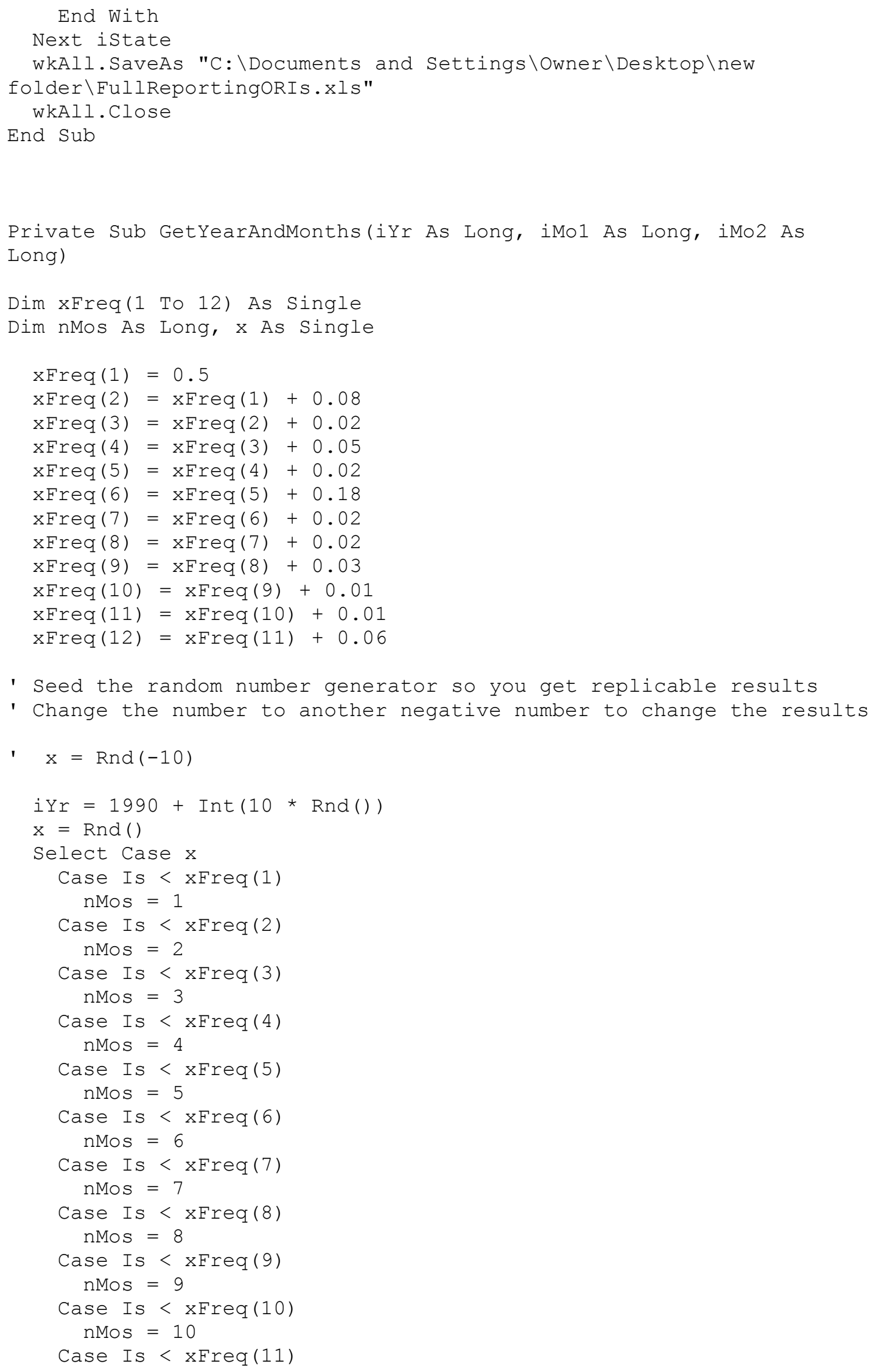




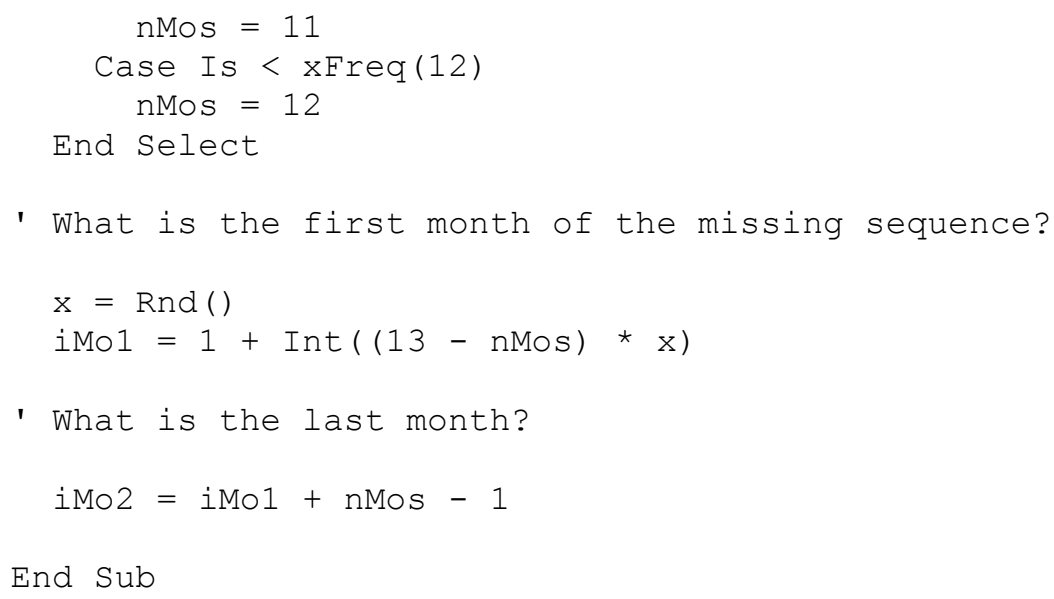

\section{3b. Using the new full reporter data set, select data to be deleted based on the missingness patterns from step 1.}

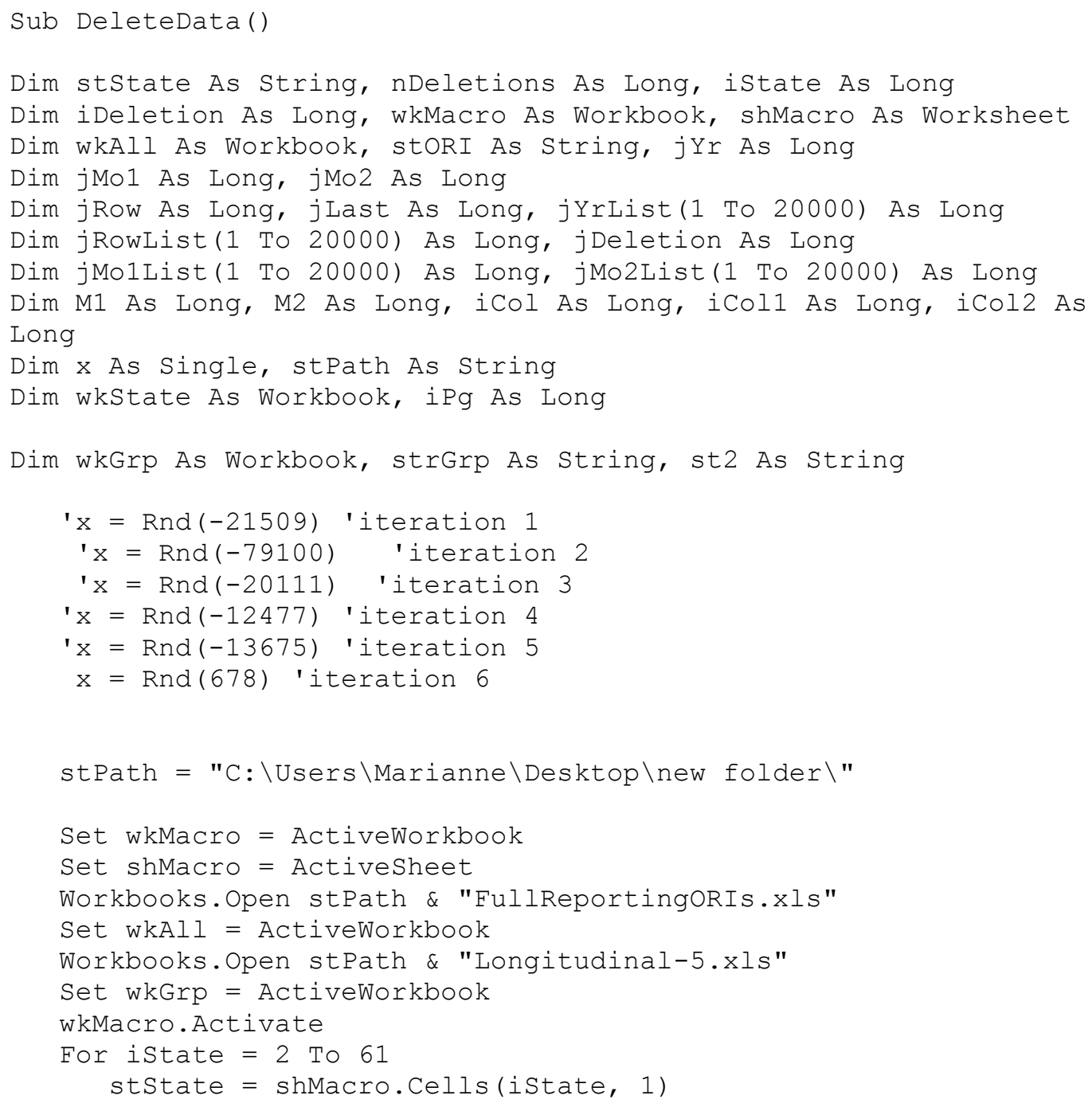


With wkAll. Sheets (stState \& "3")

If .Cells $(2,1)="$ " Then GoTo Nextstate

jLast $=\cdot \operatorname{Cells}(1,1) \cdot$ End $(x l$ Down $)$. Row

nDeletions $=3 *($ jLast -1$)$

For iDeletion $=1$ To nDeletions

ReDo:

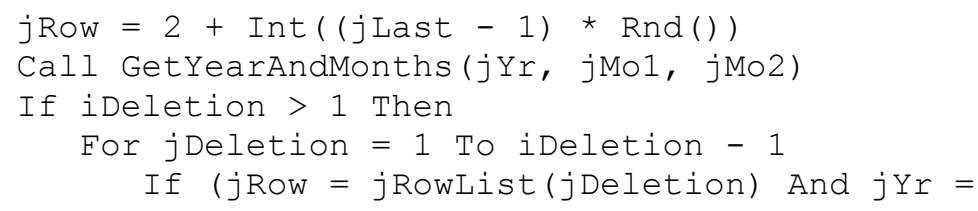

jYrList(jDeletion)) Then

M1 $=$ jMolList $(j$ Deletion $)-1$

M2 $=$ jMo2List (jDeletion) +1

If $((j M O 1-M 1)$ * $(M 2-j M o 1)>=0$ Or $(j M o 2-$

M1) * (M2 - jMo2) >= 0) Then

GoTo ReDo

ElseIf $((j \mathrm{MO1}-\mathrm{M} 1) *(\mathrm{M} 1-j \mathrm{Mo})>=0$ Or $(j \mathrm{Mo1}$

- M2) * (M2 - jMO2) >= 0) Then

GoTo ReDo

End If

End If

jRowList(iDeletion) $=$ jRow

jYrList(iDeletion) $=$ jYr

jMolList(iDeletion) $=$ jMo1

jMo2List(iDeletion) $=j$ Mo2

Else

Next jDeletion

jRowList(iDeletion) $=$ jRow

jYrList(iDeletion) $=$ jYr

jMolList(iDeletion) $=$ jMo1

jMo2List (iDeletion) $=$ jMo2

End If

Next iDeletion

End With

' Now to create a new file with the undeleted and deleted data

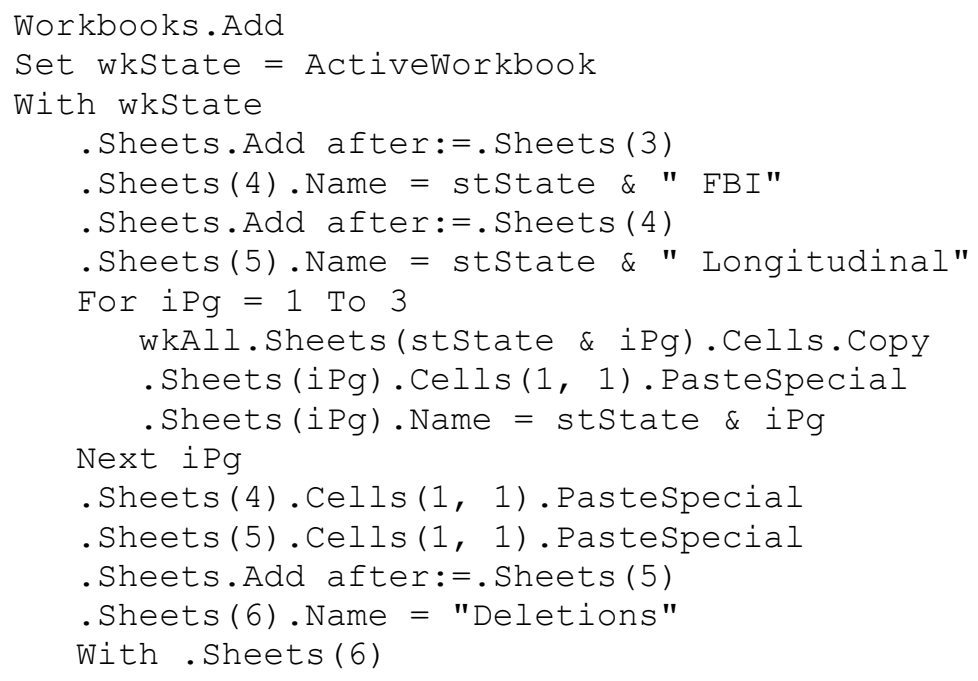




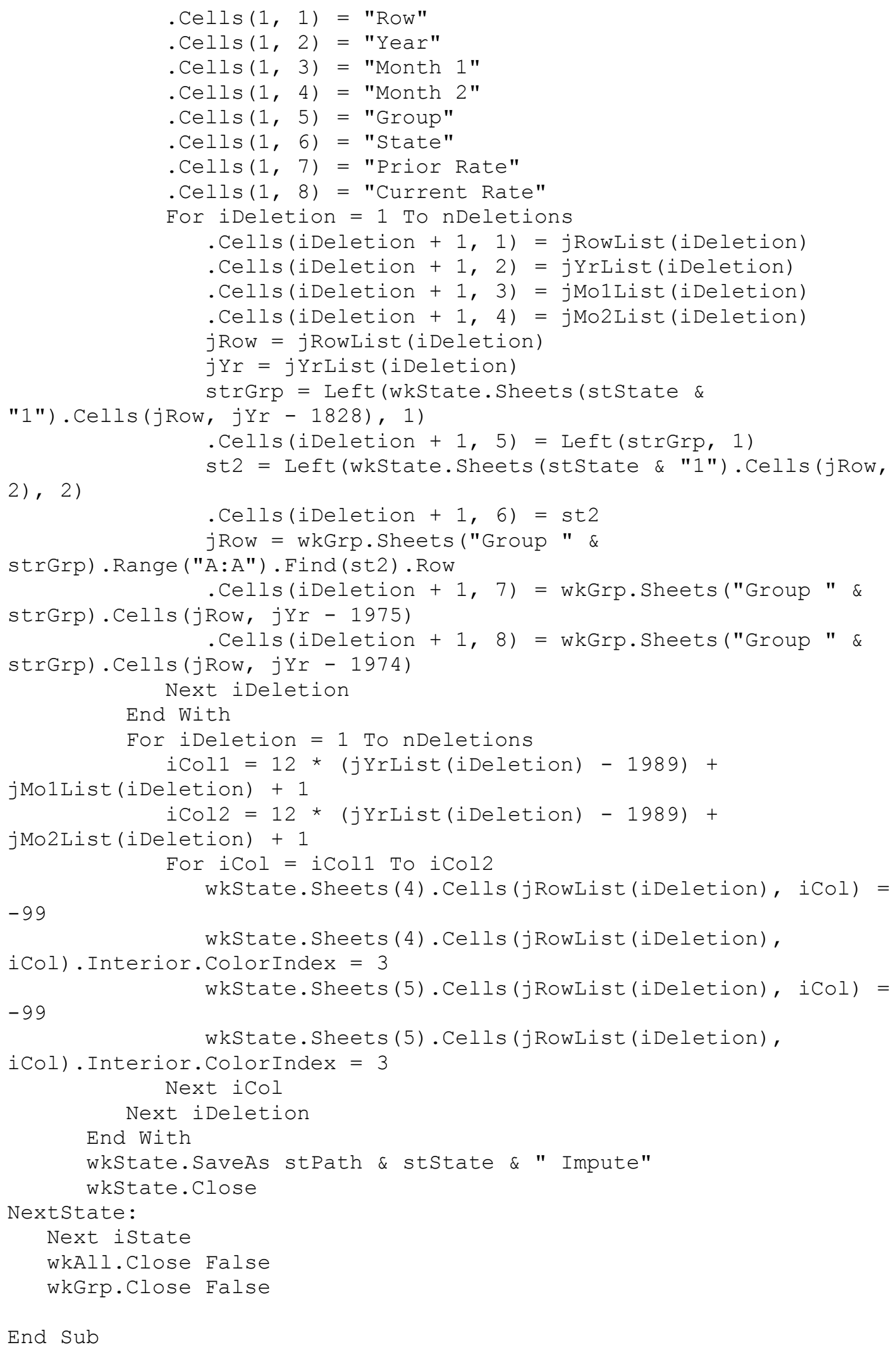

End Sub

\section{3c. Apply the each imputation method to the simulation data set.}


Sub ApplyImputations ()

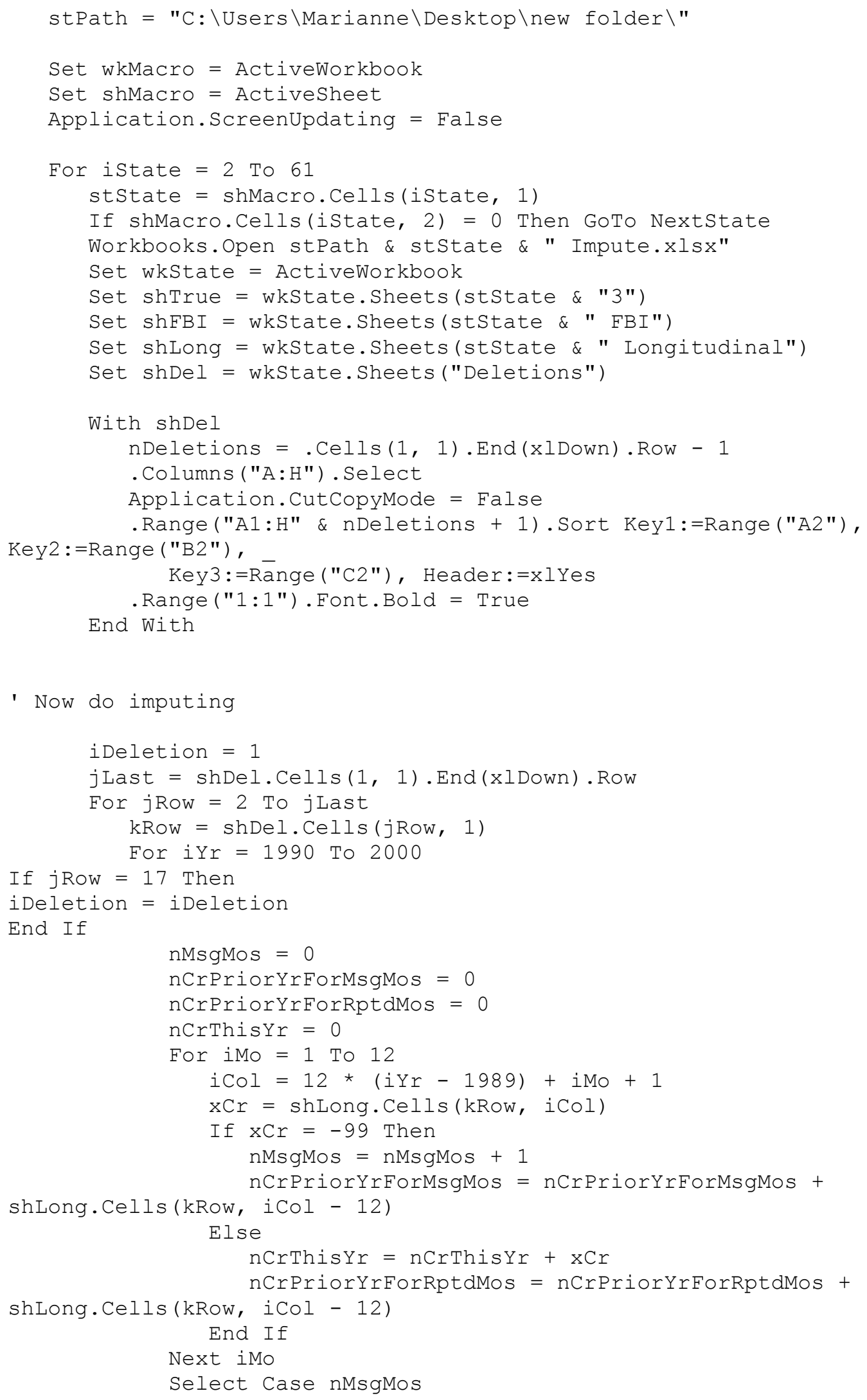




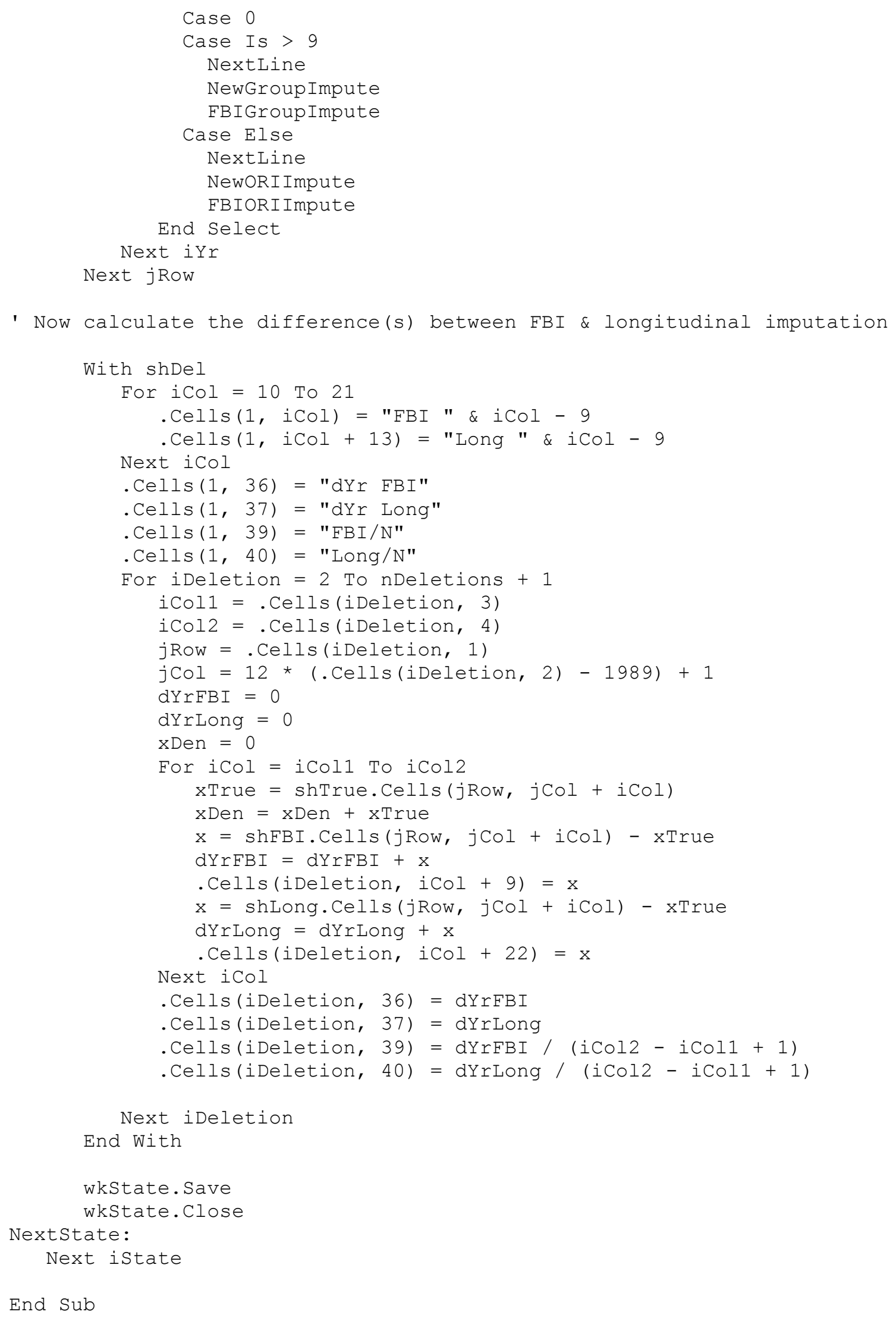




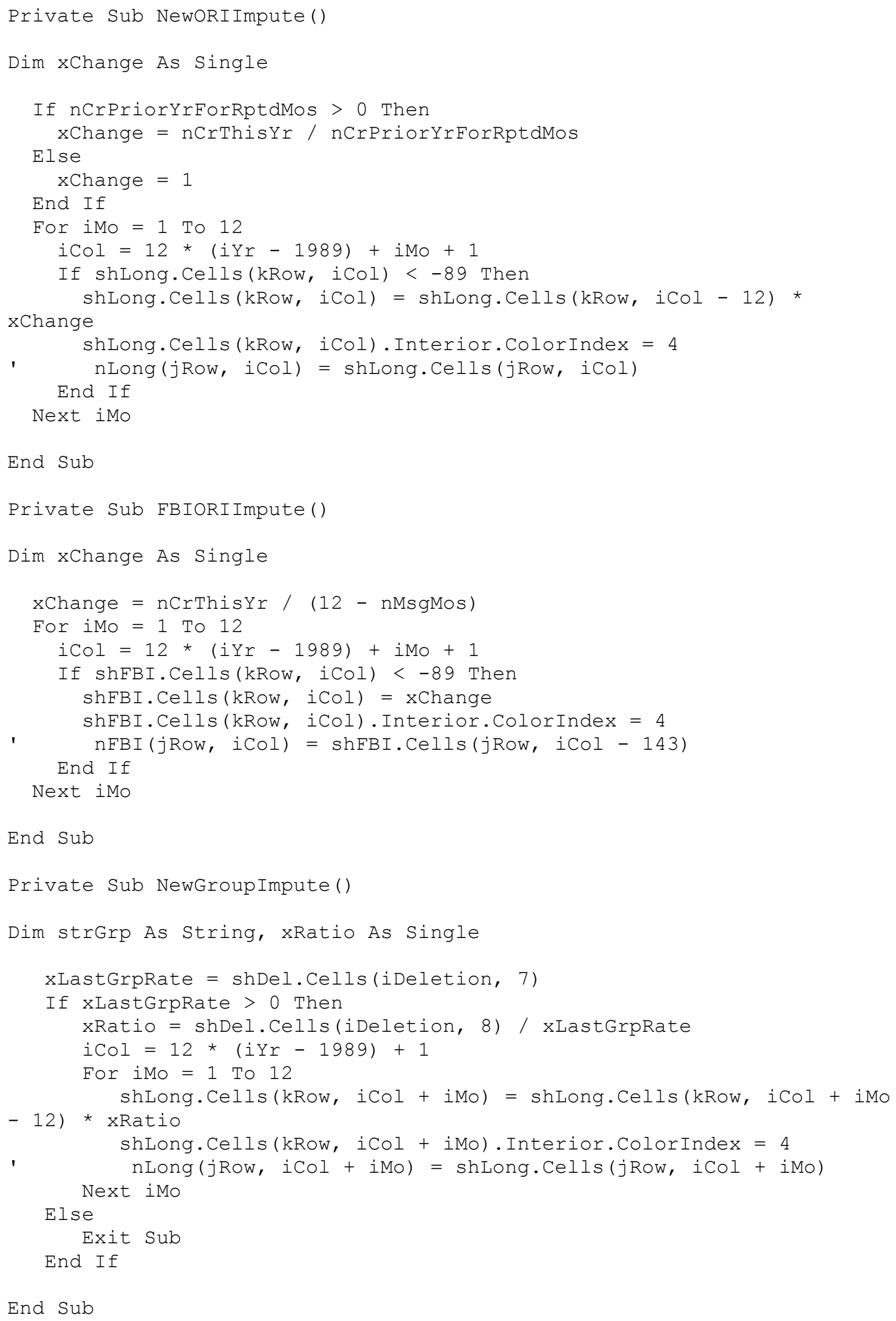




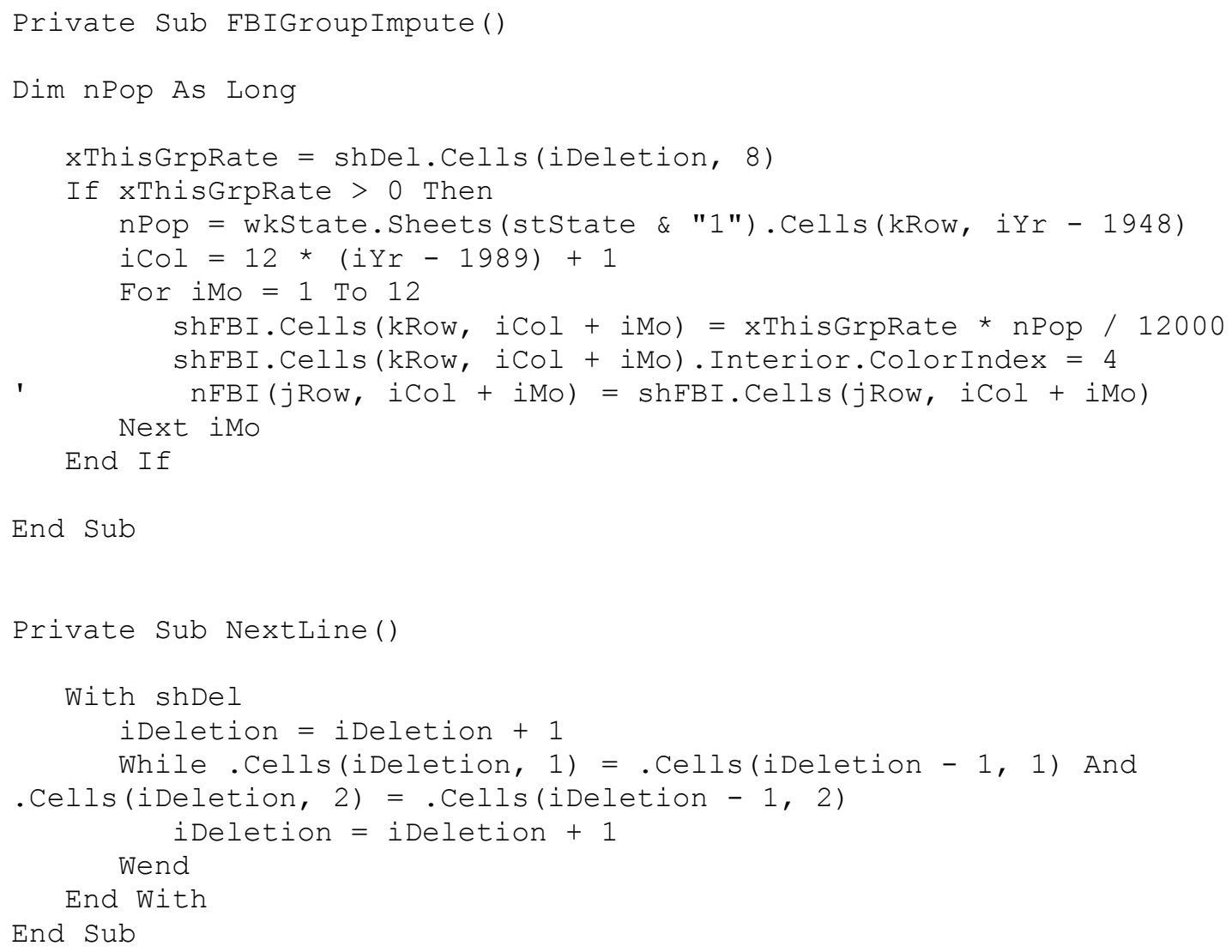




\section{APPENDIX D: STATE LEVEL MISSING DATA CHARTS}
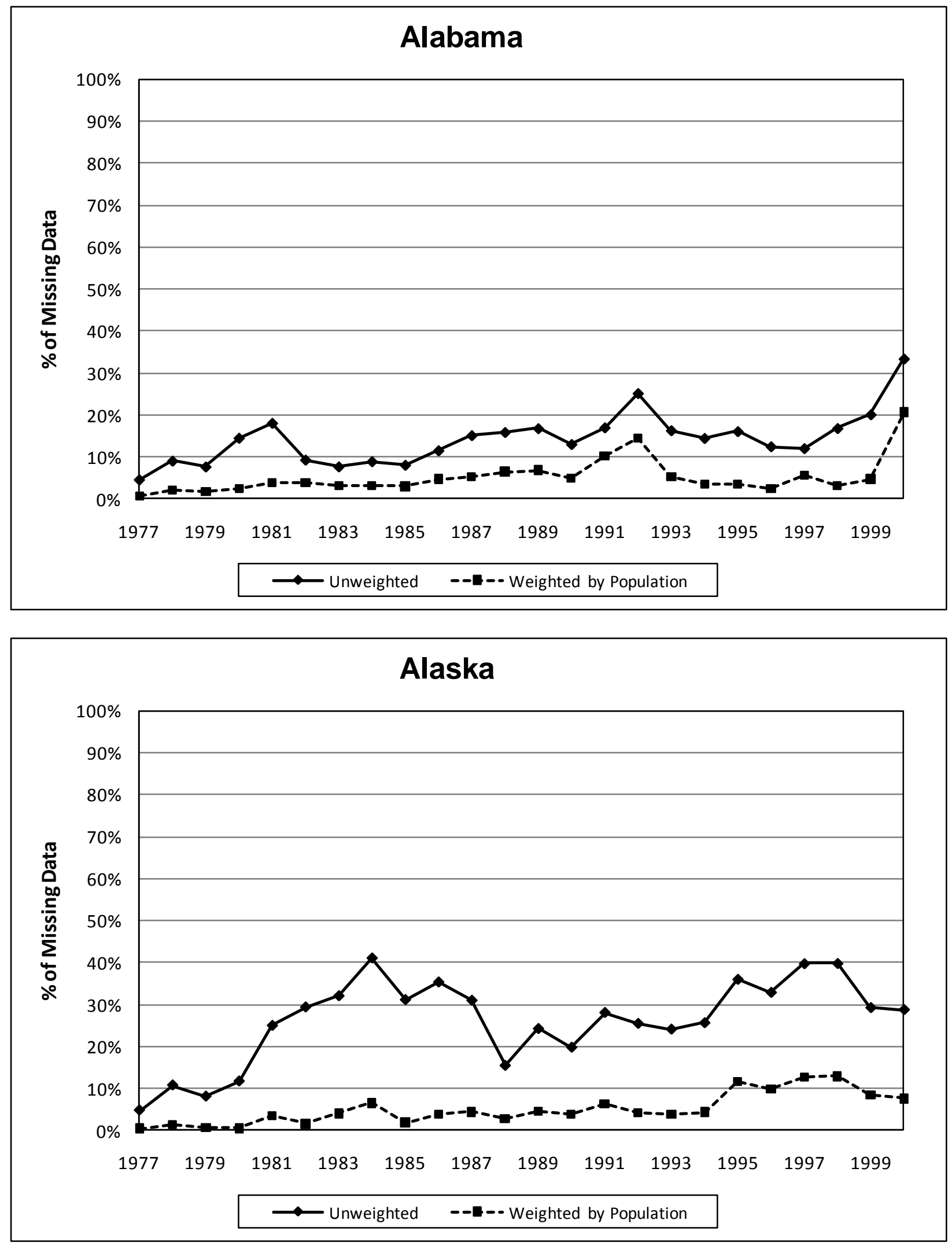

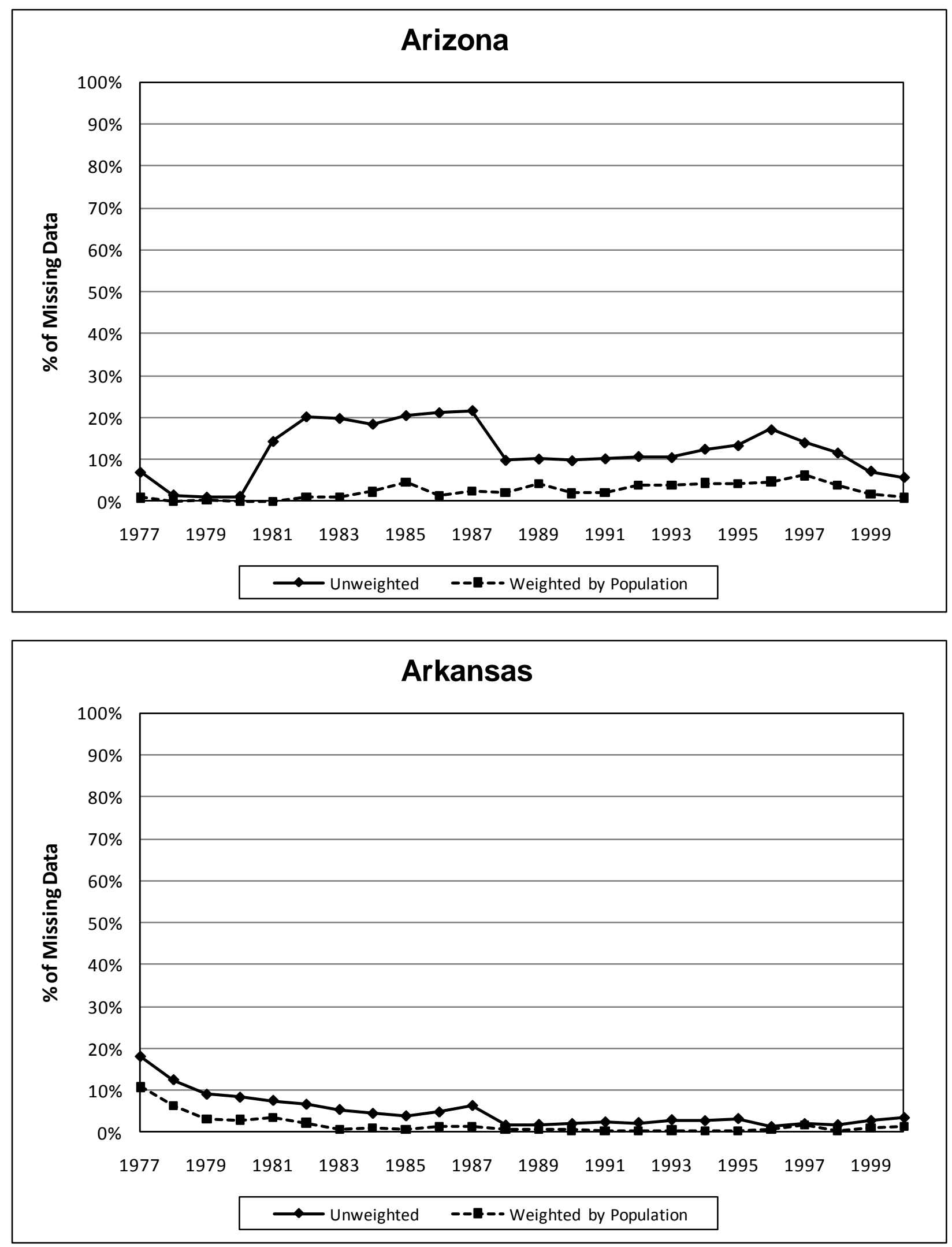

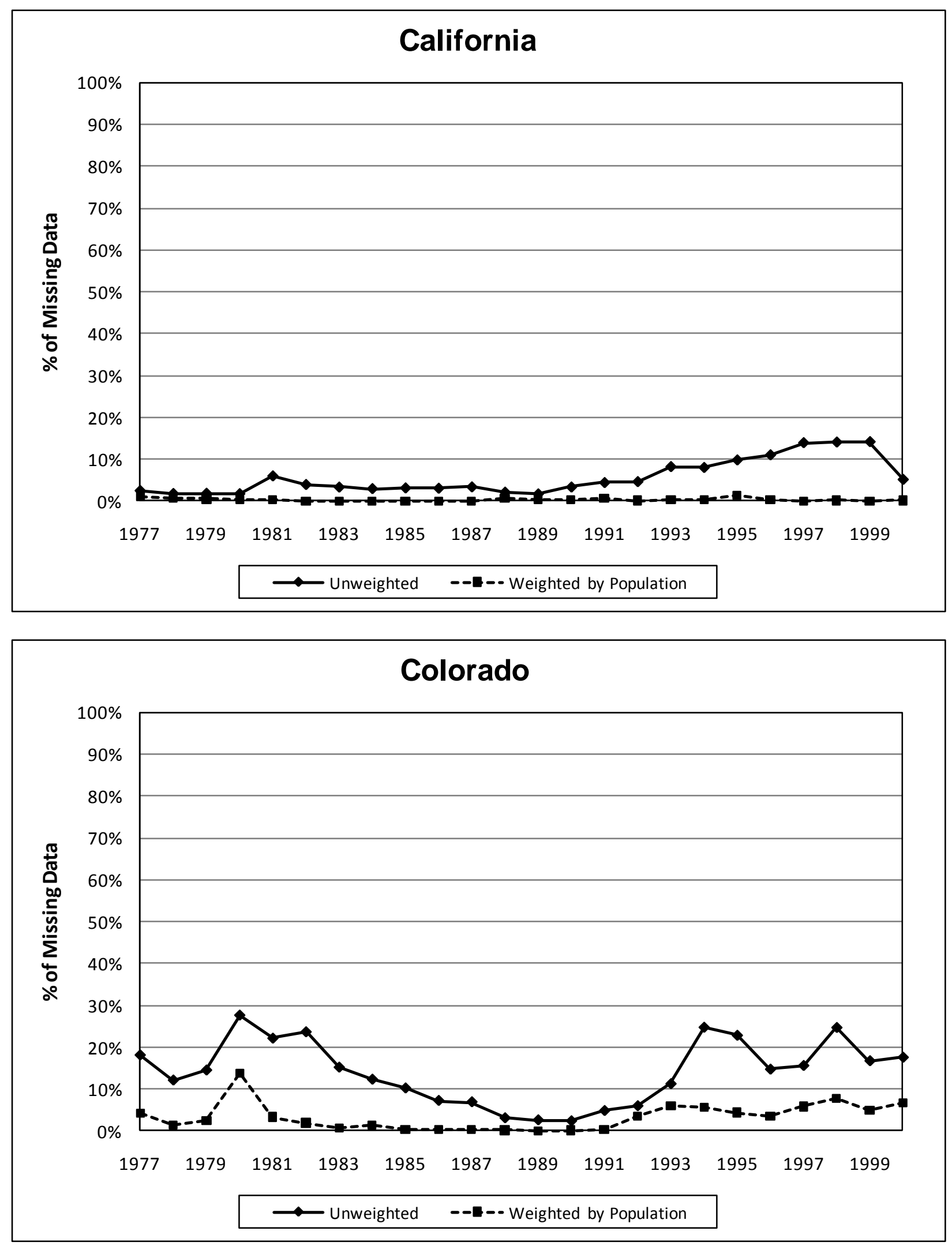

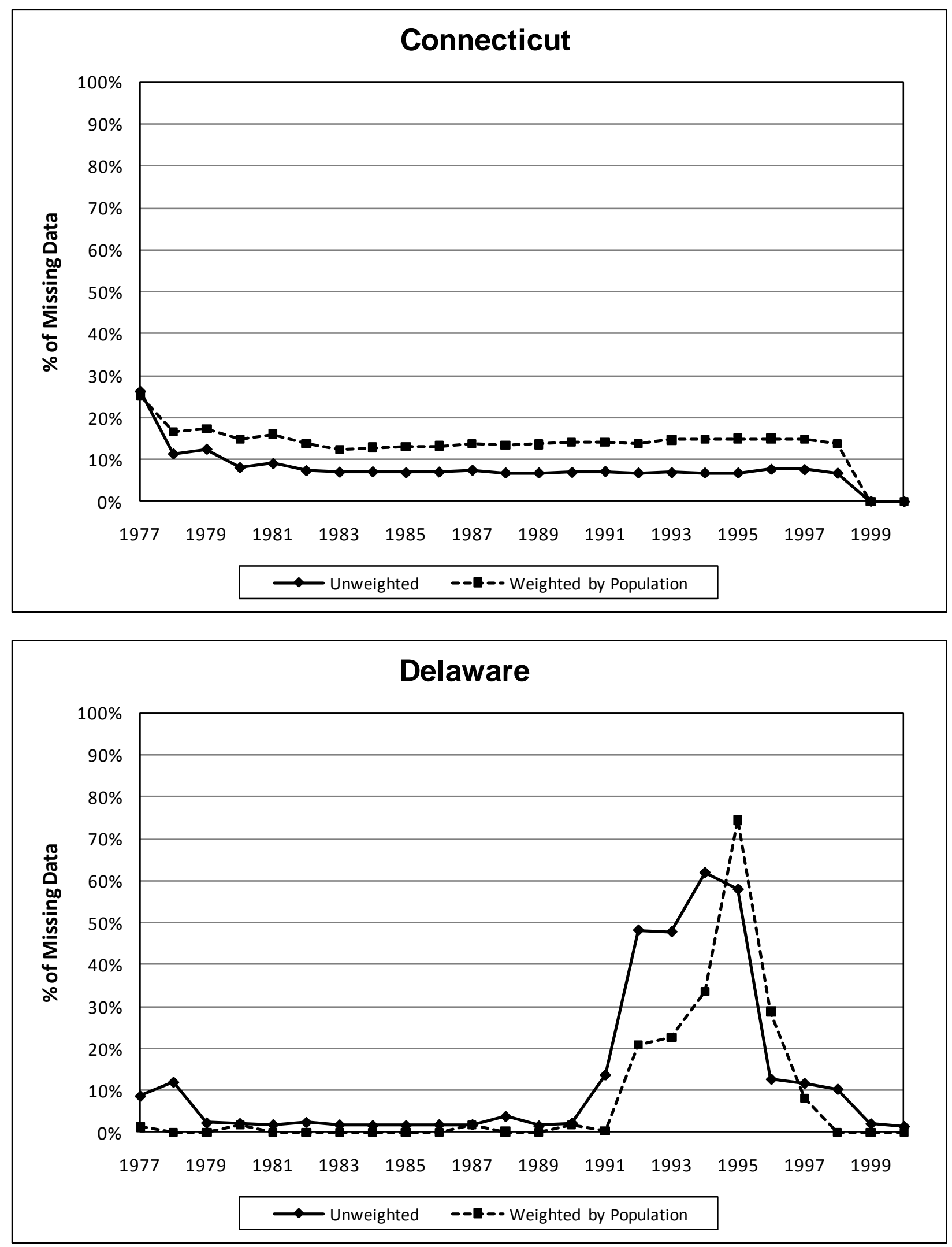

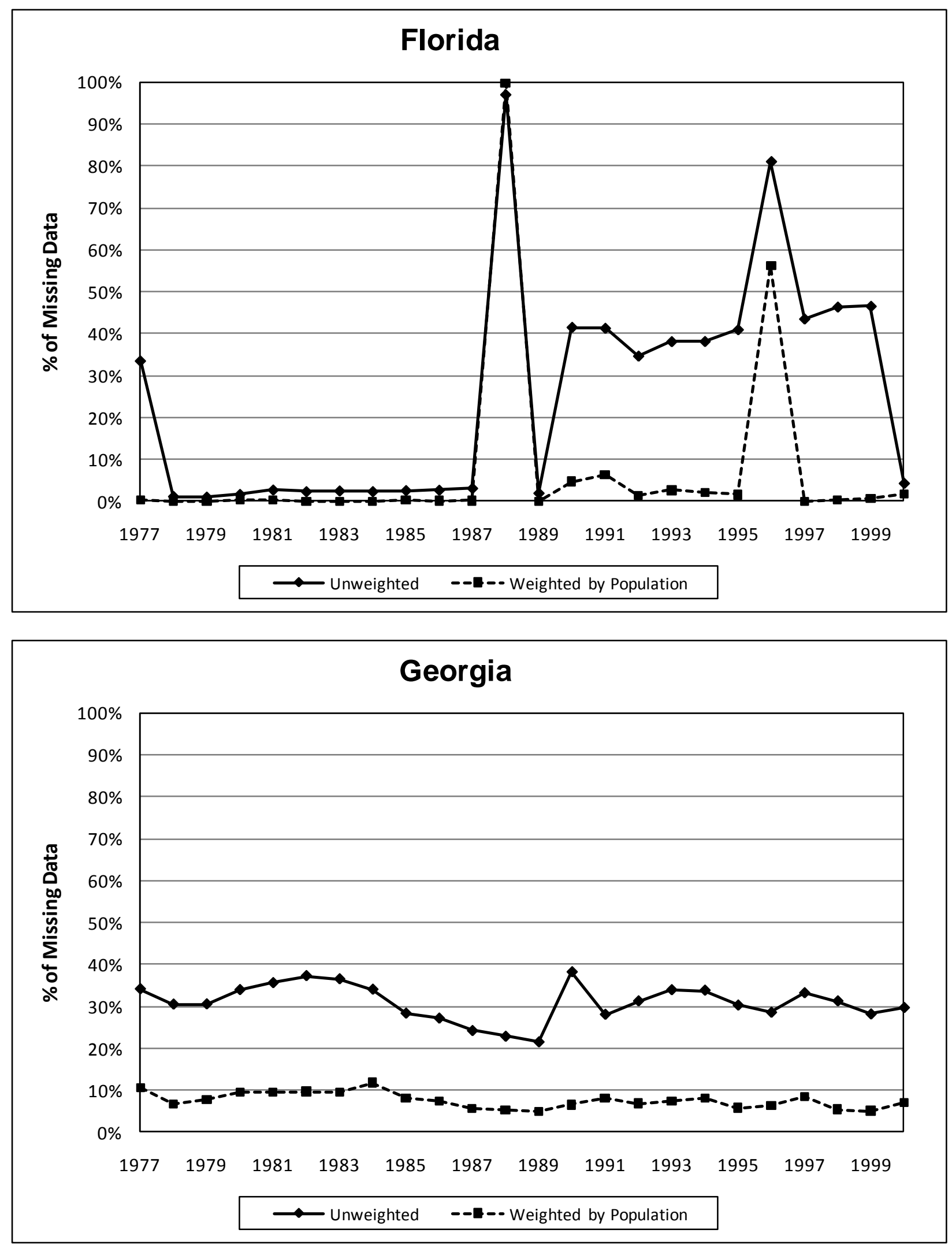

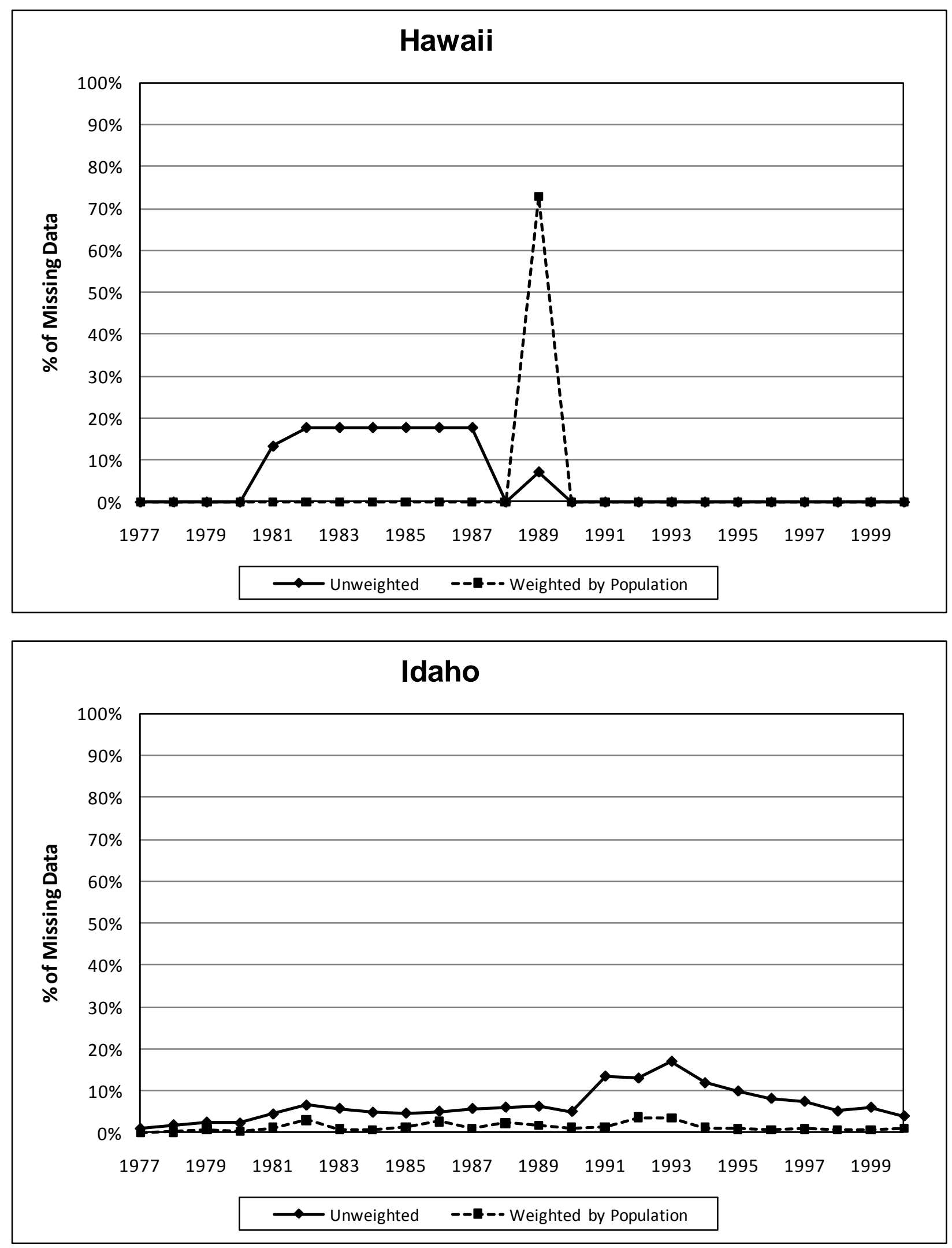

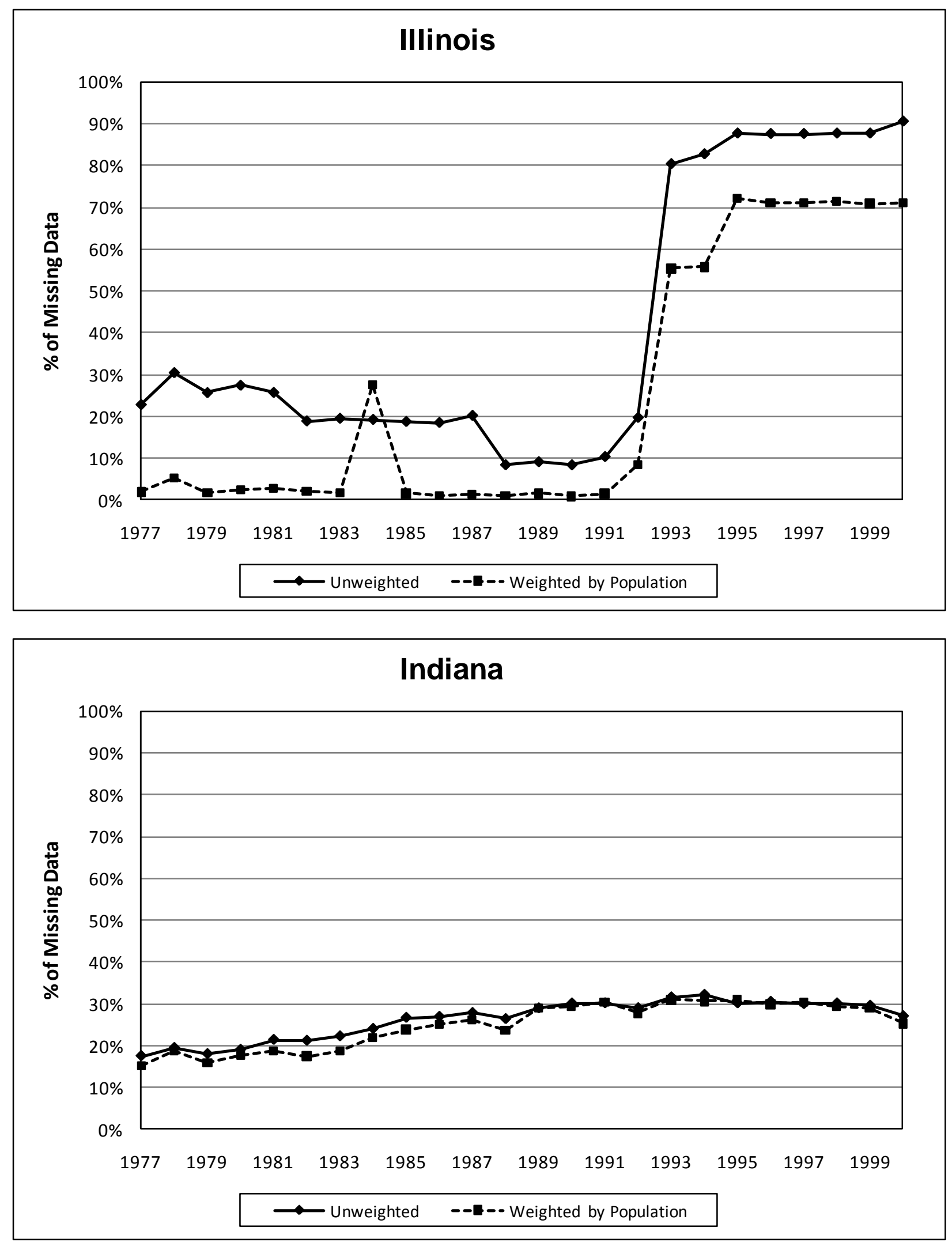

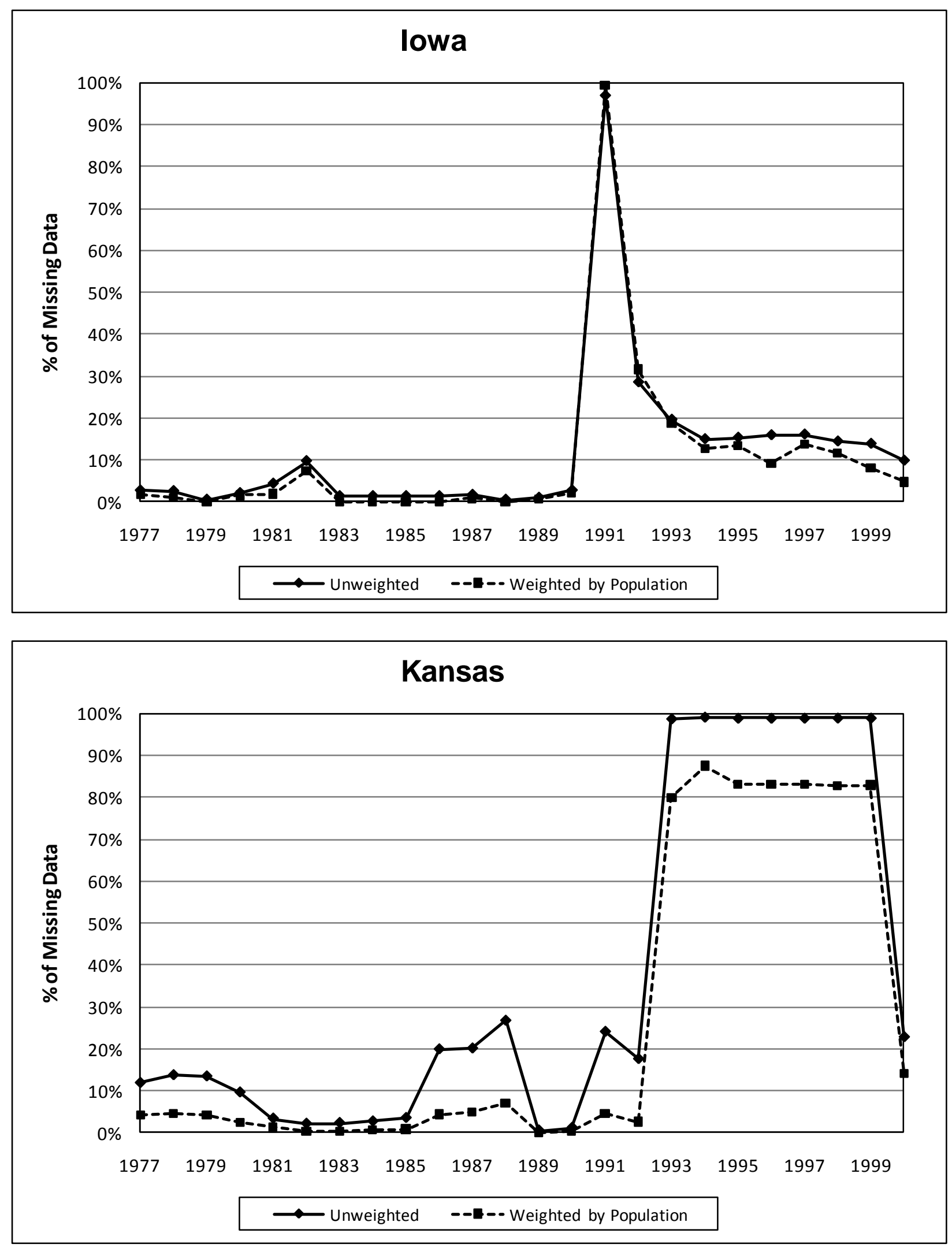

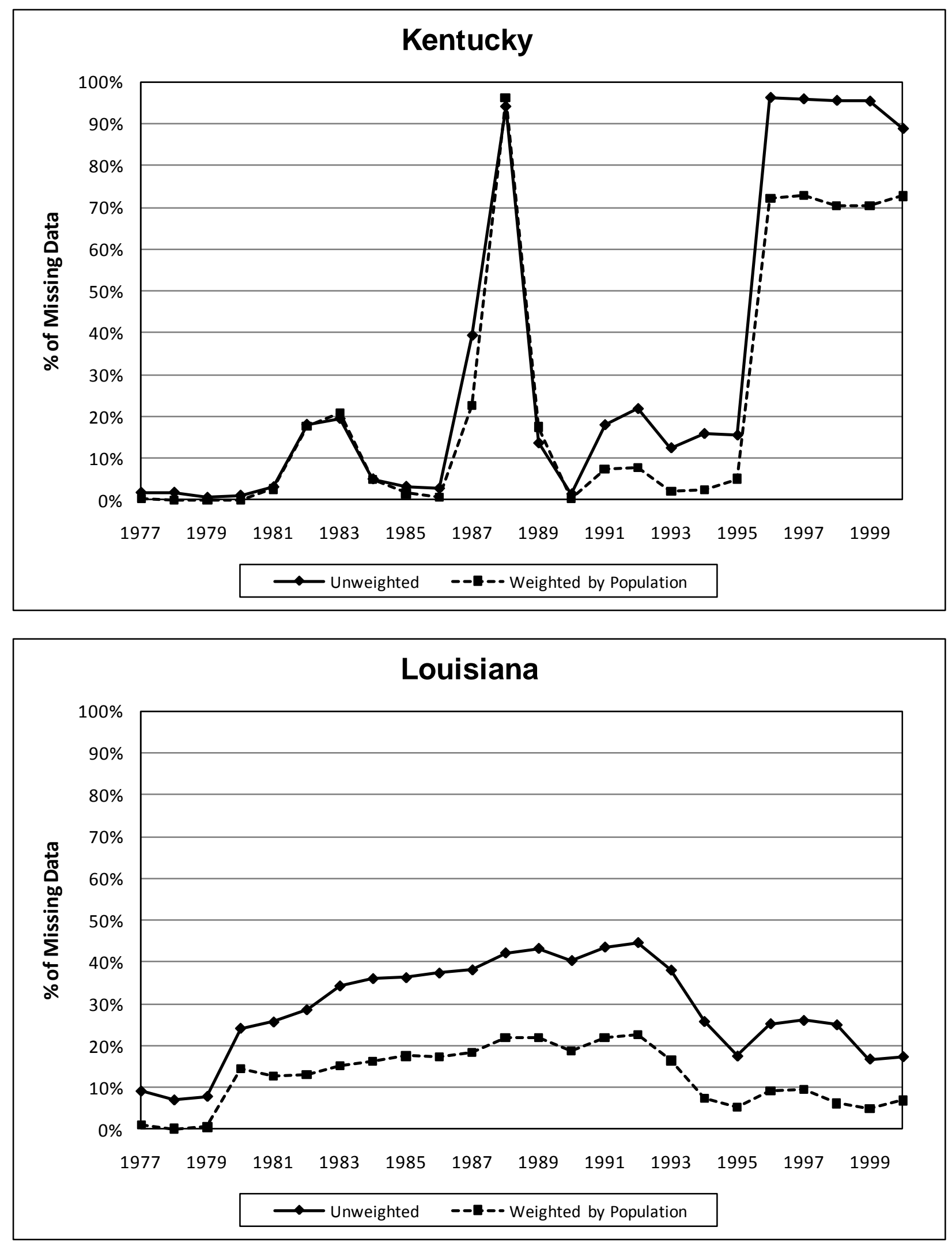

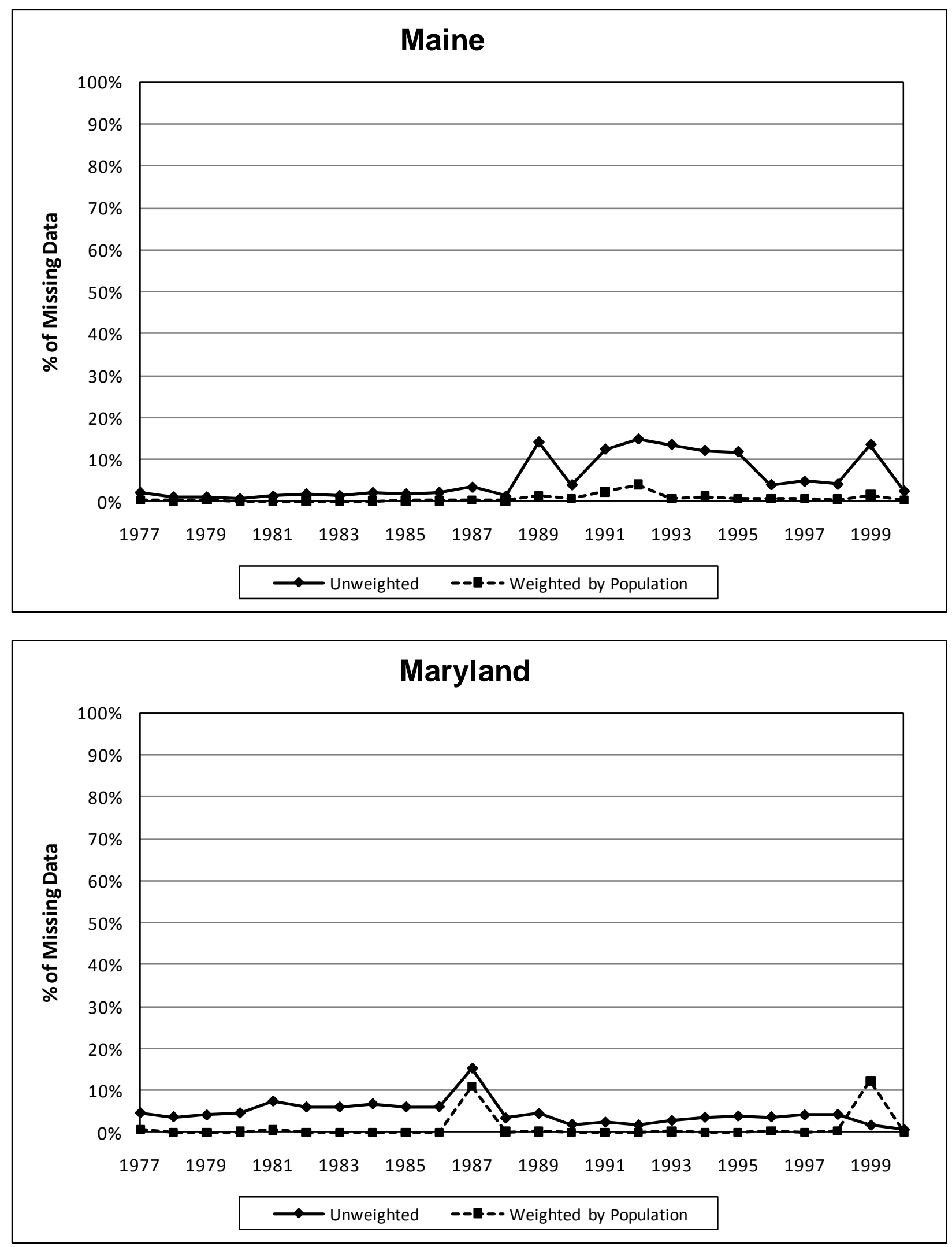

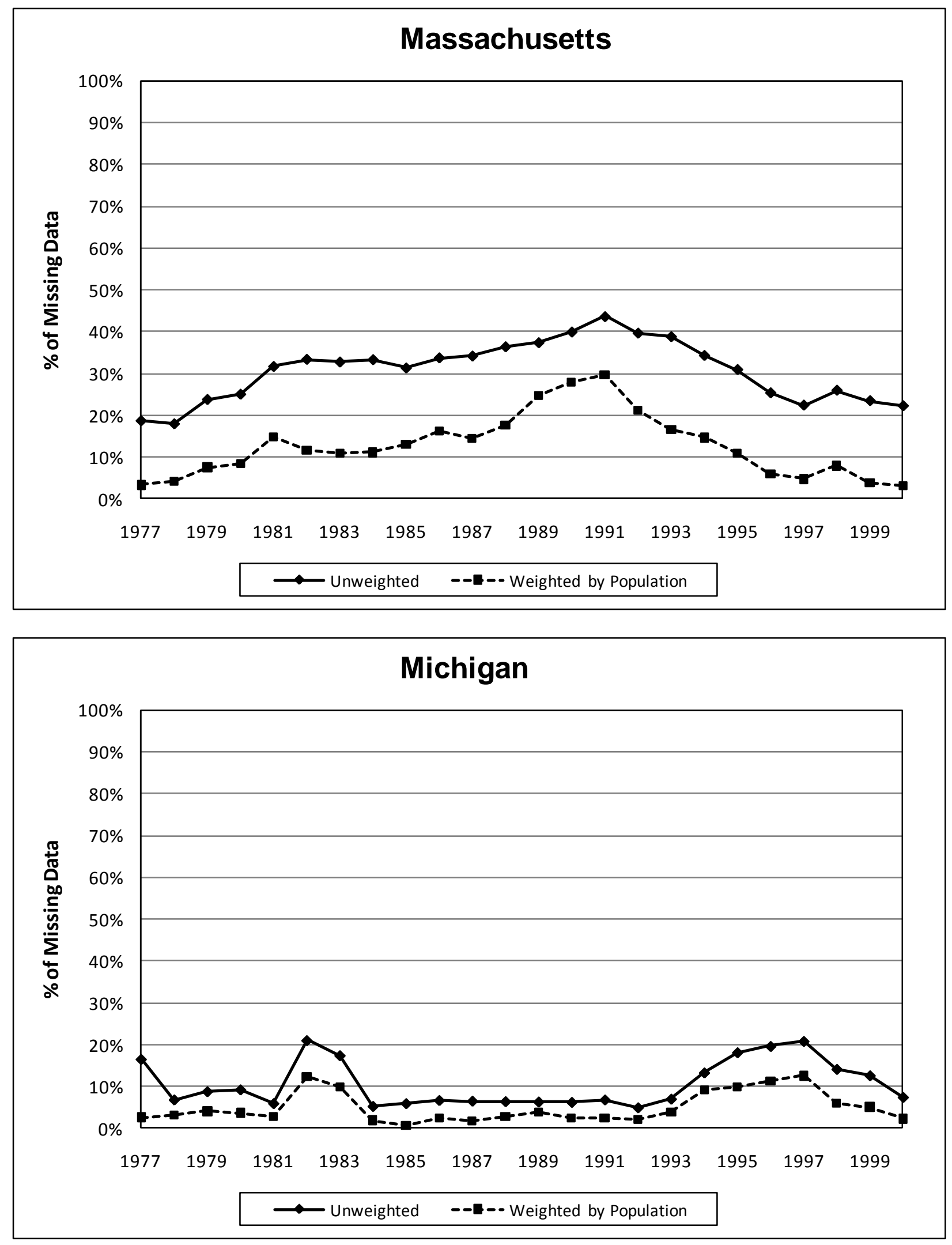

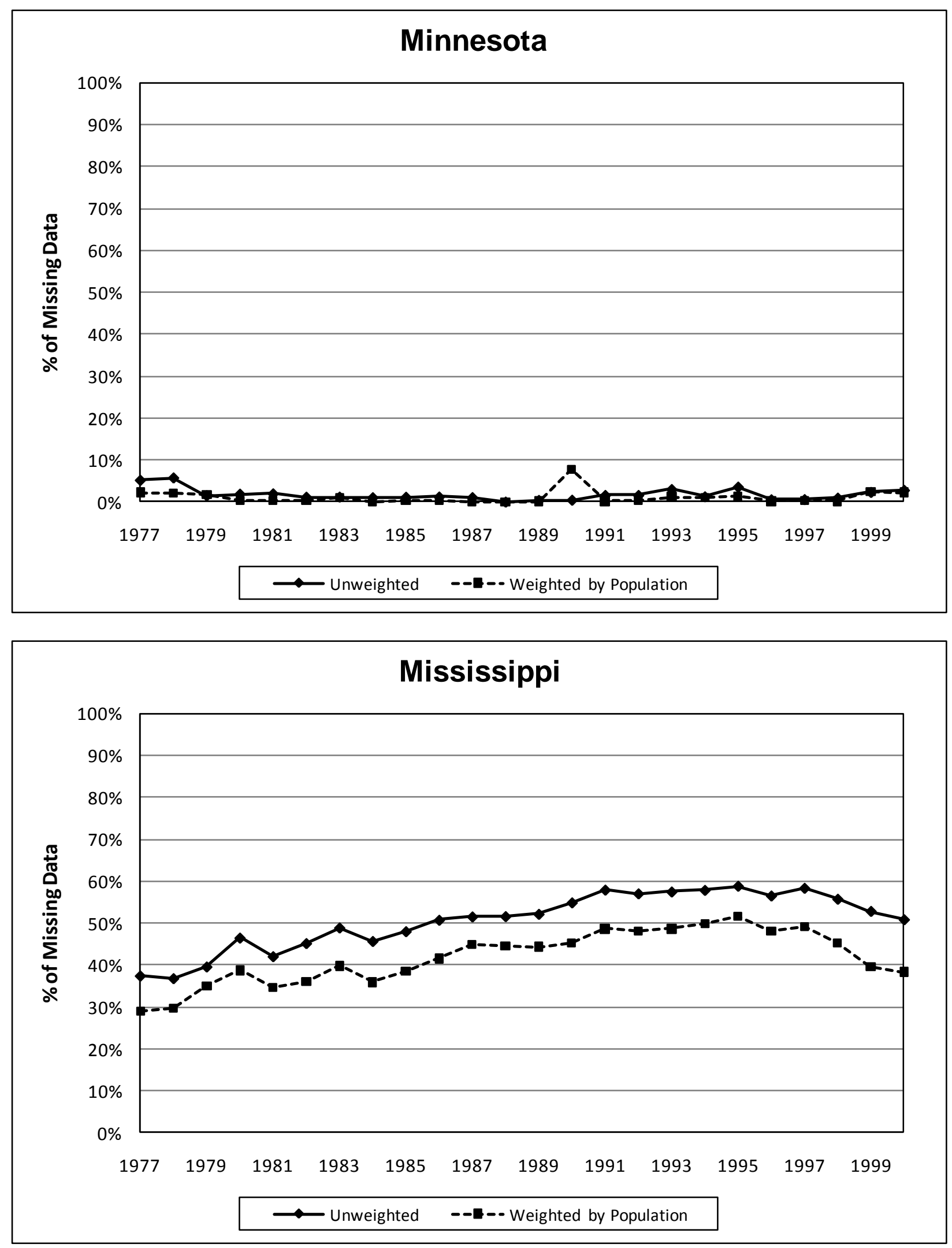

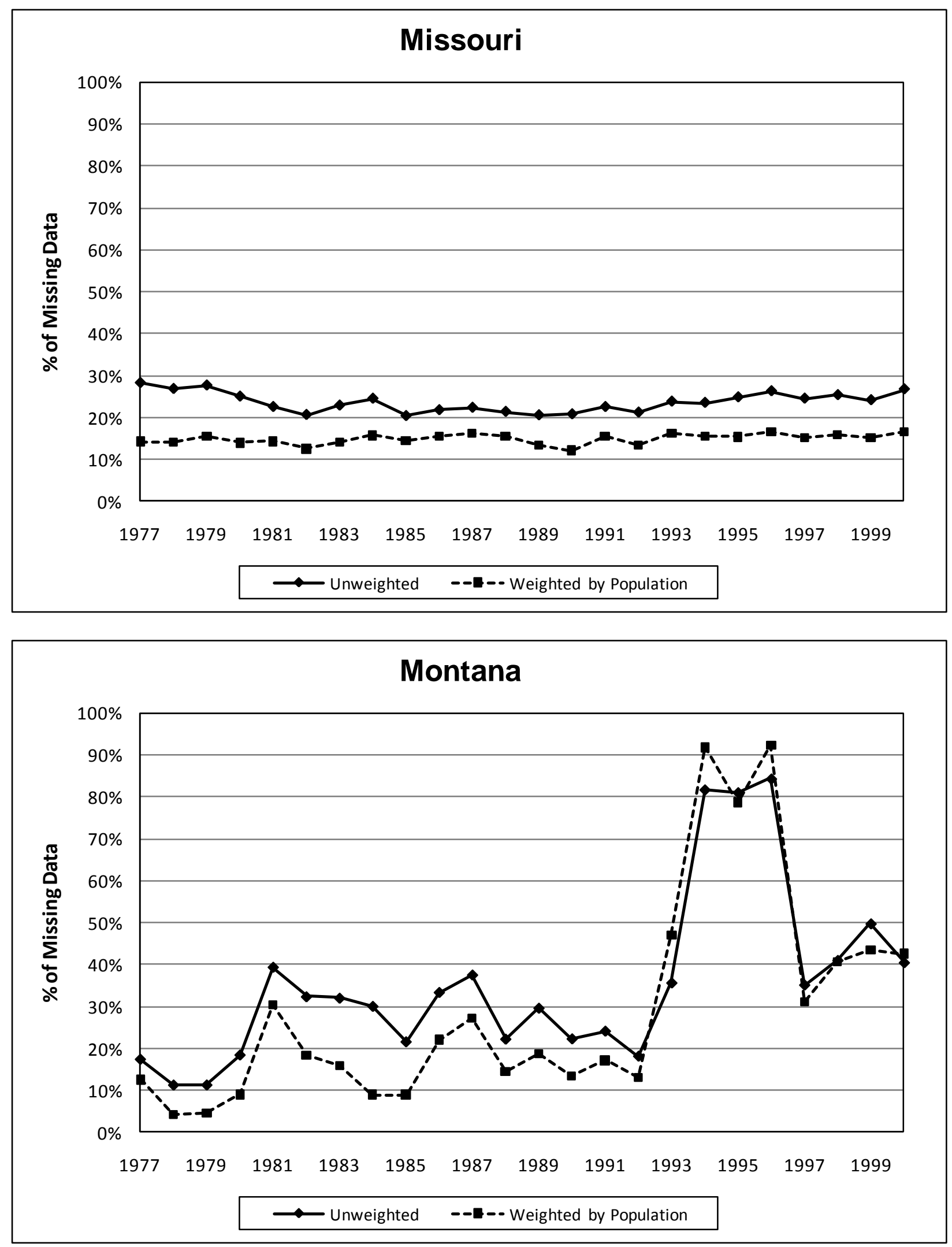

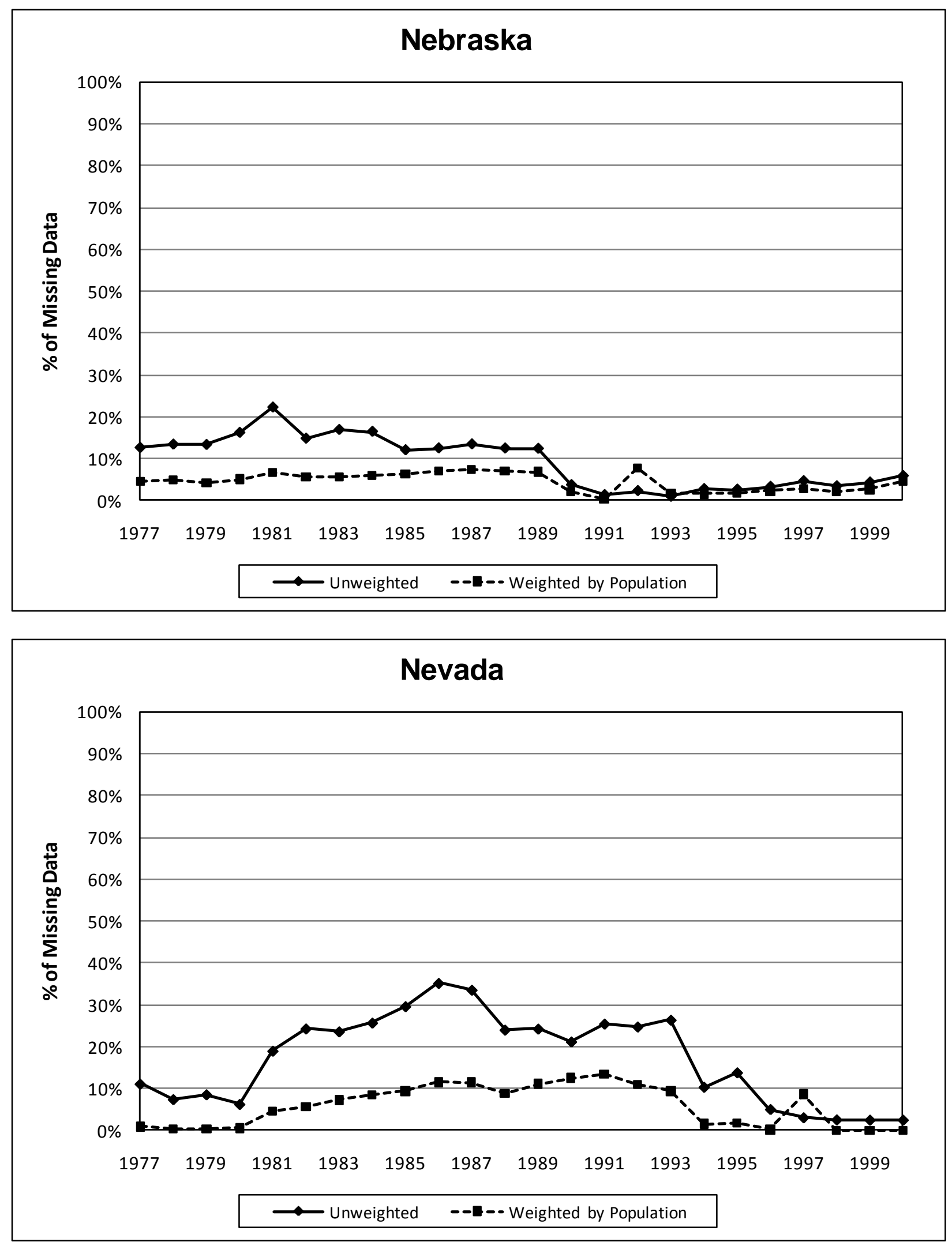

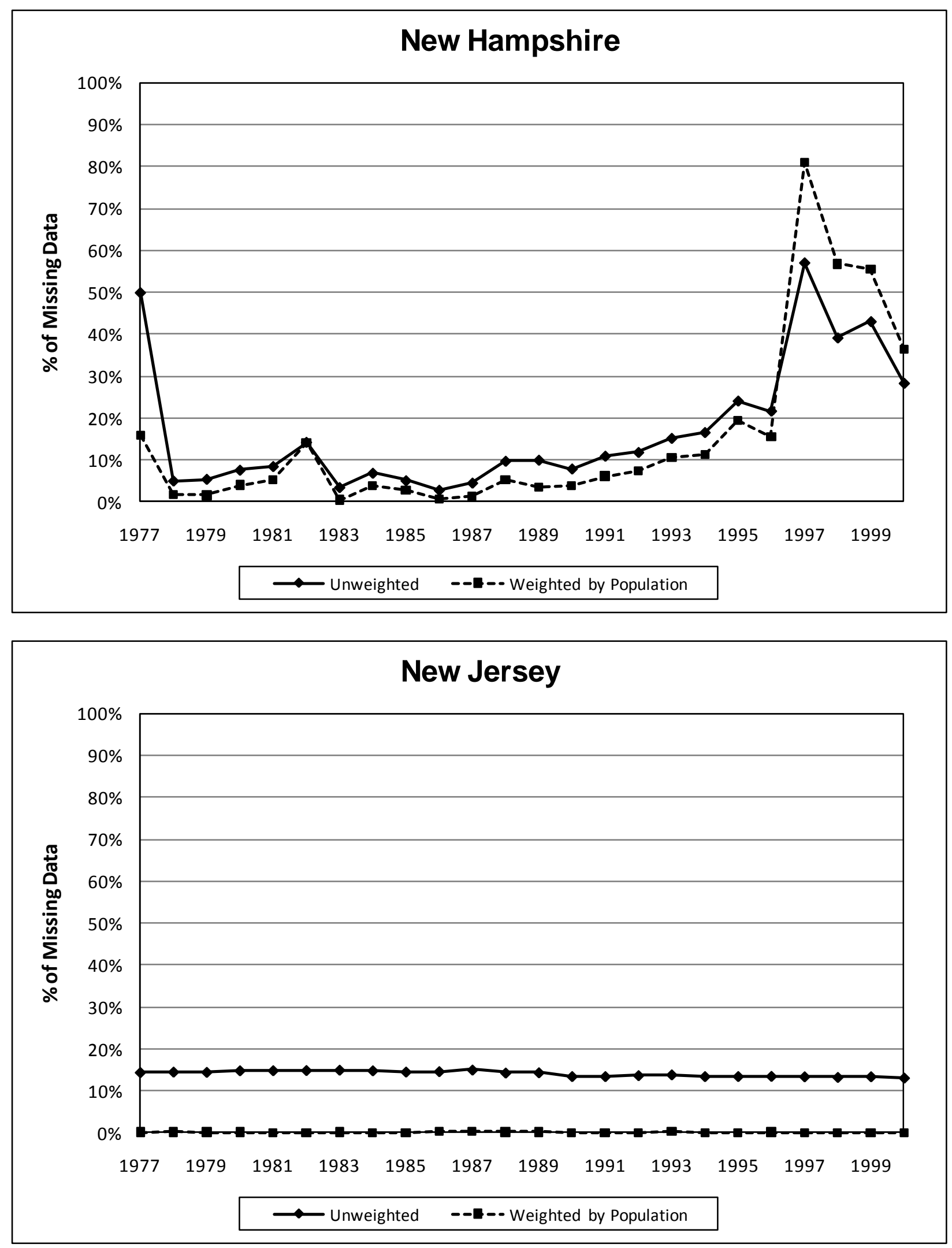

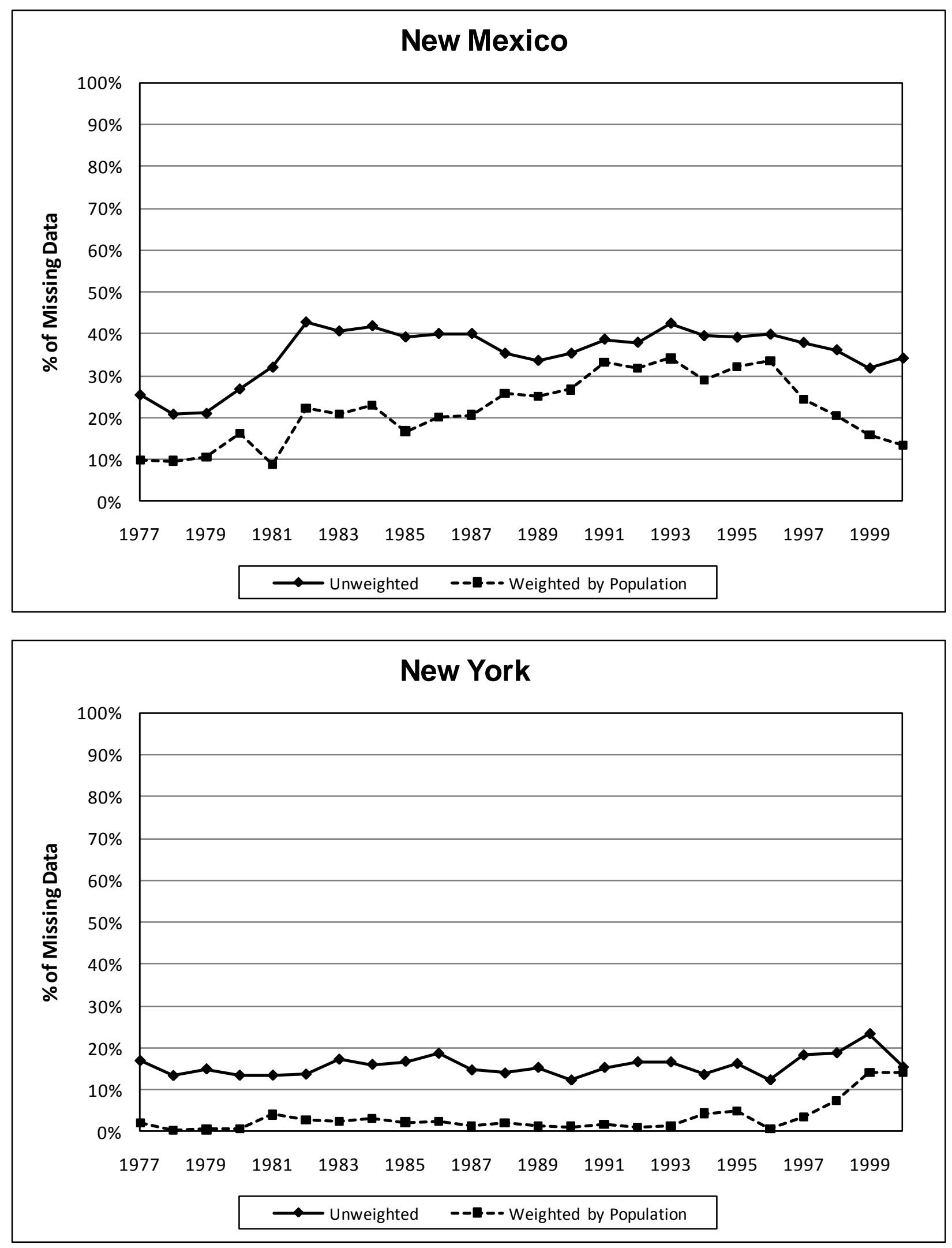

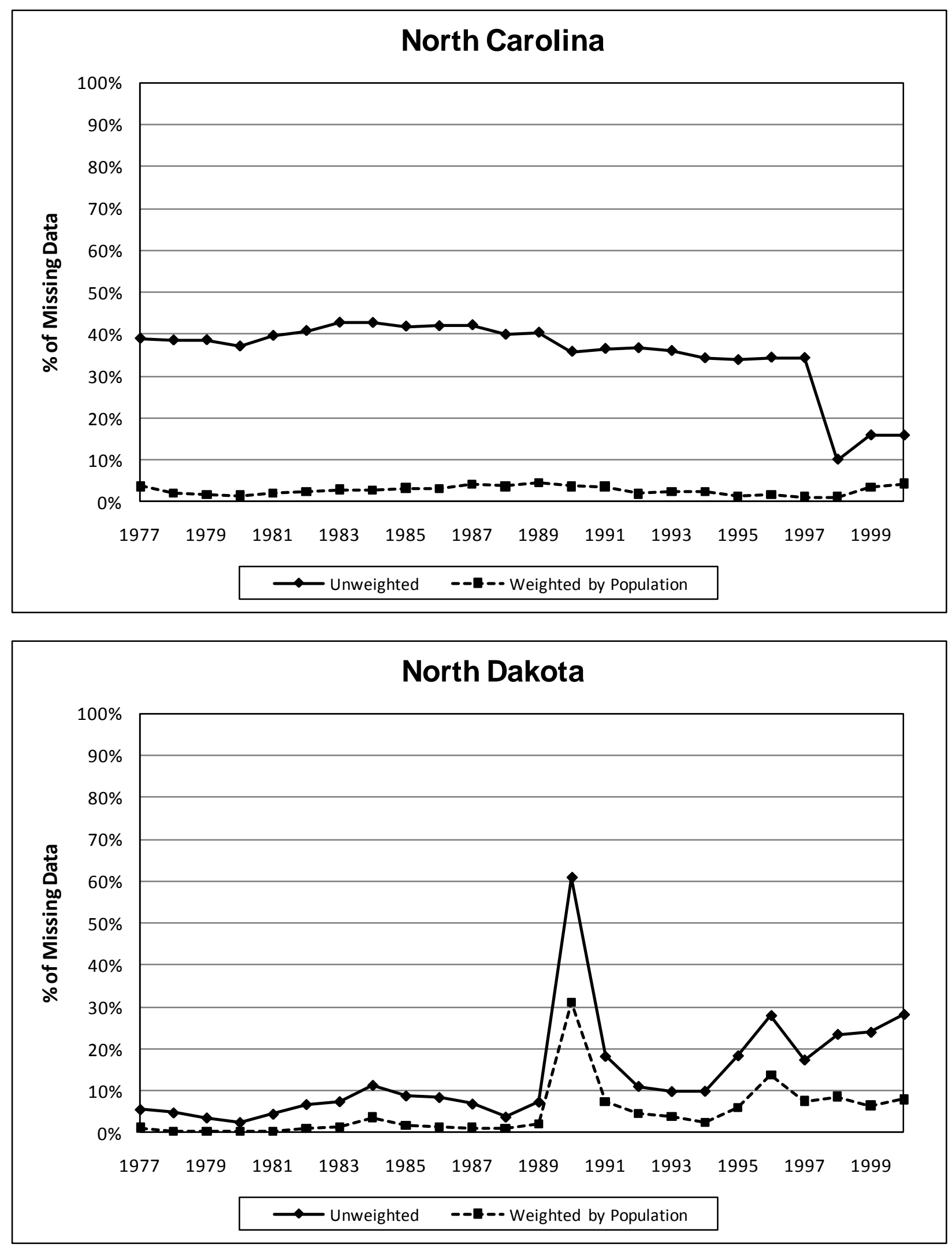

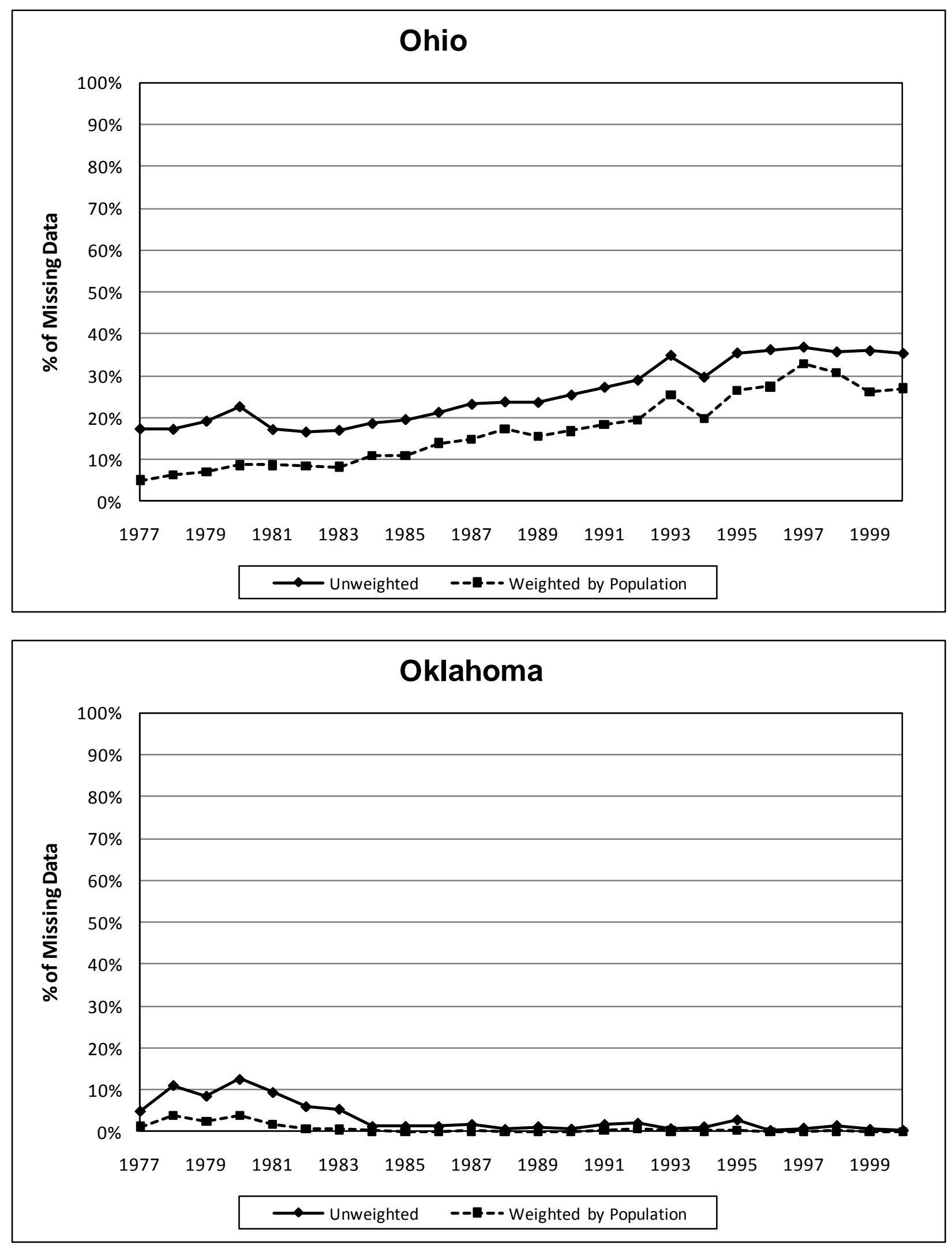

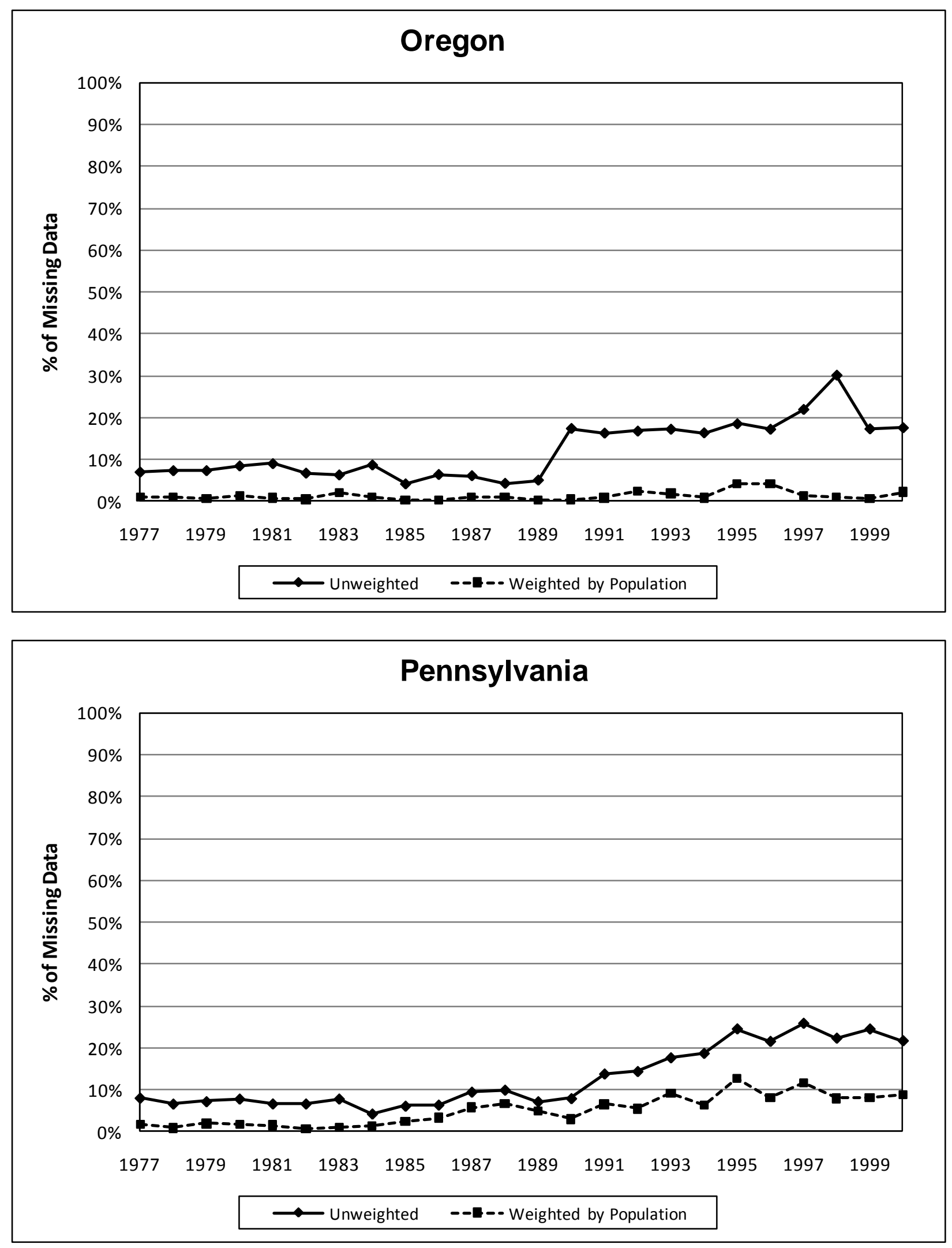

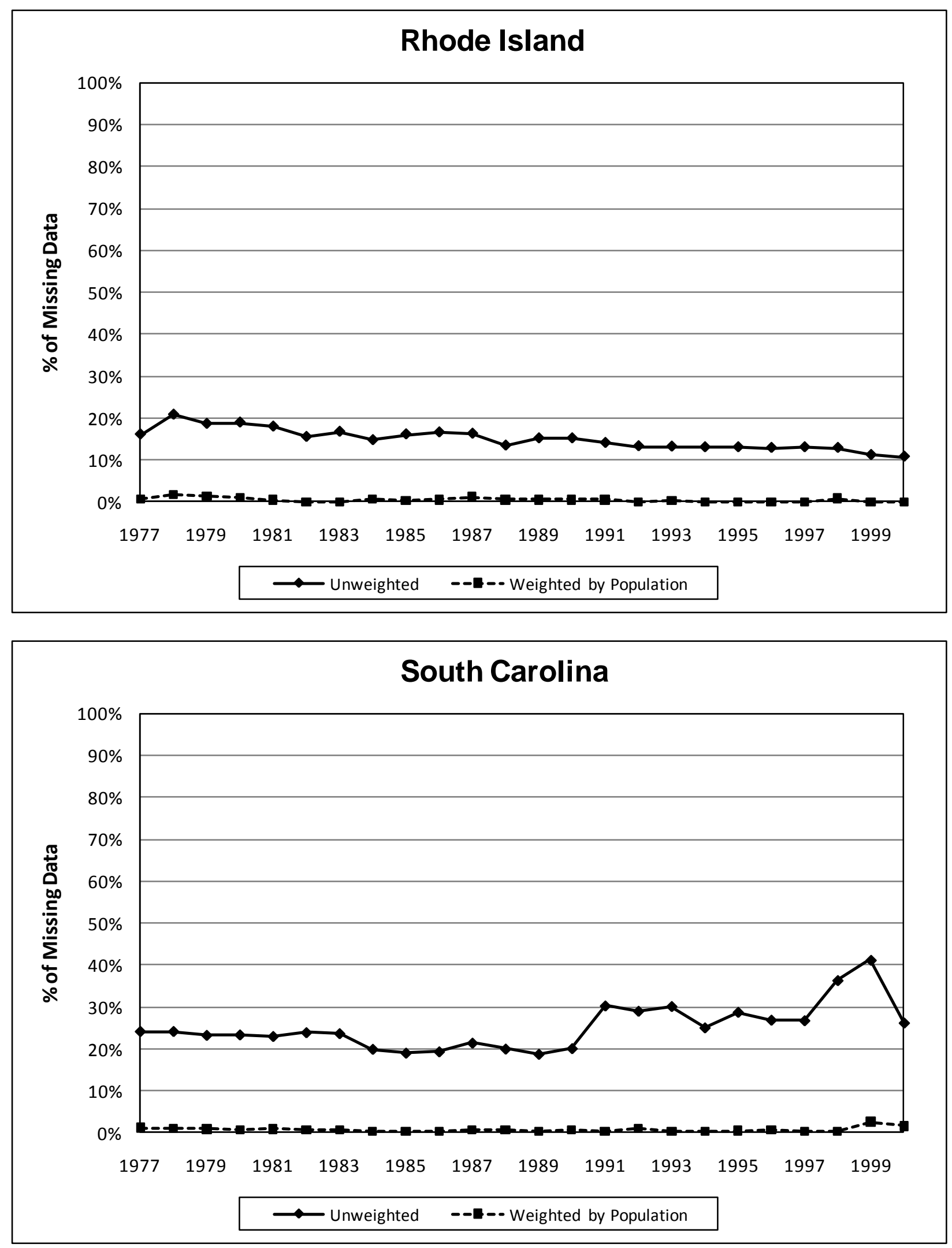

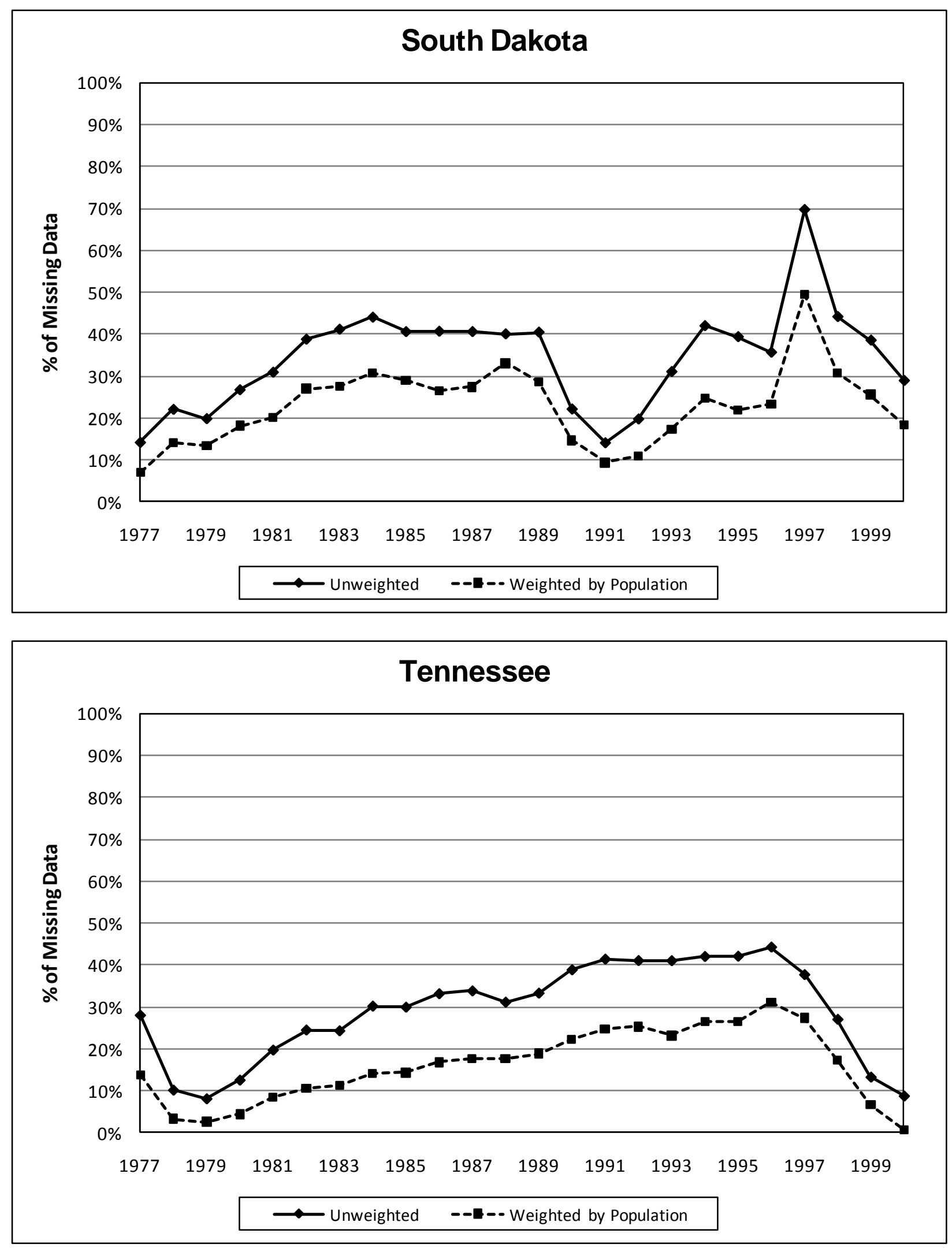

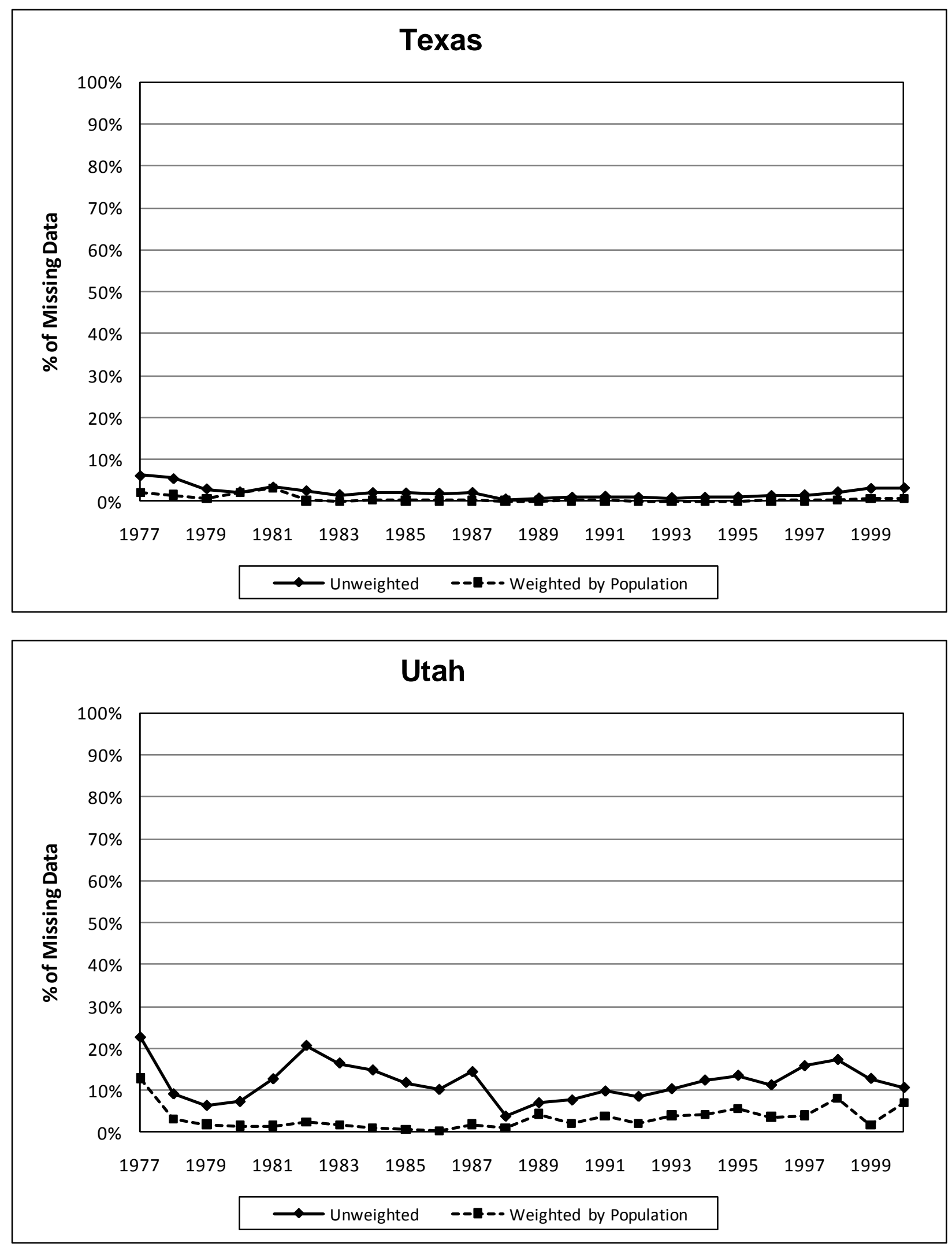

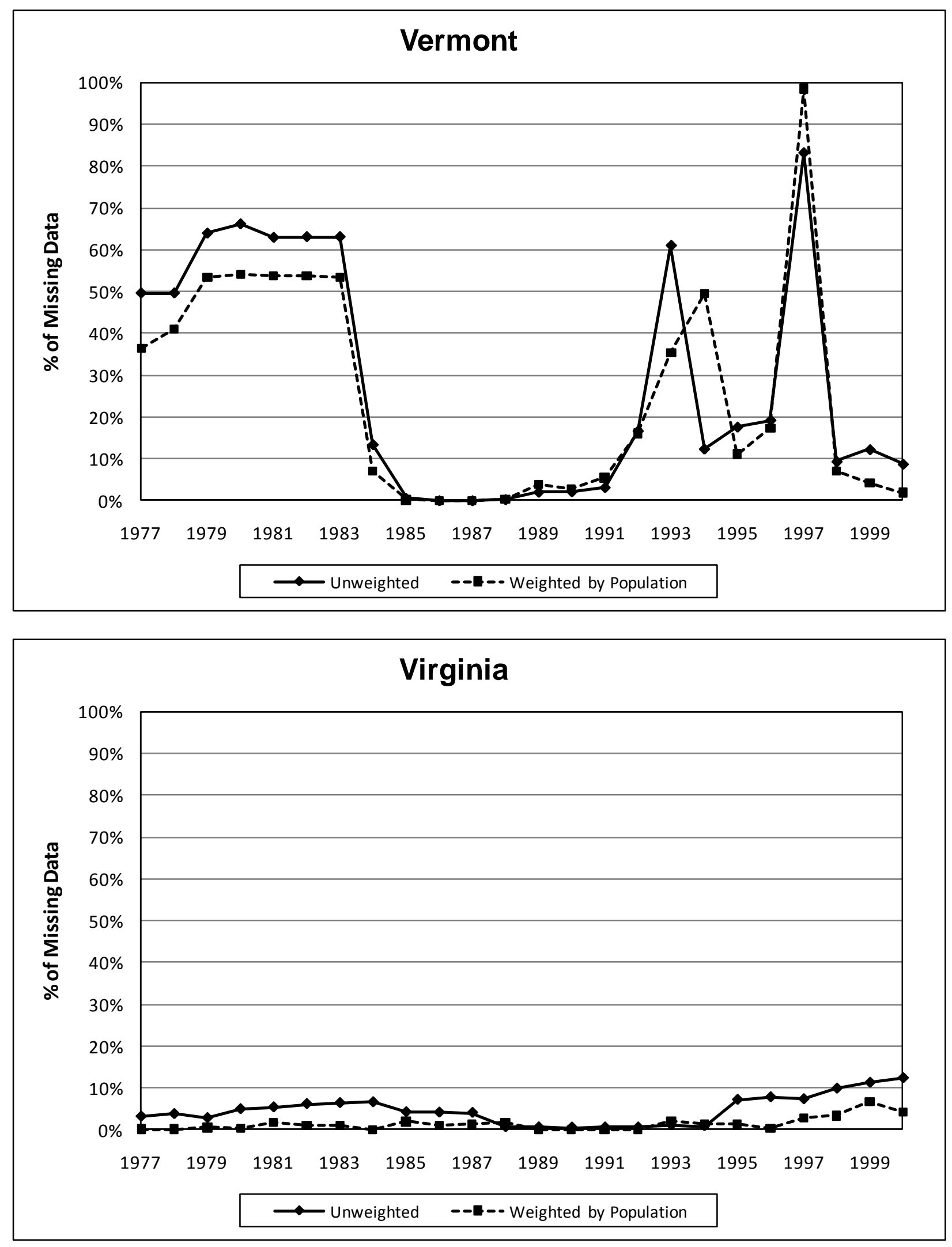

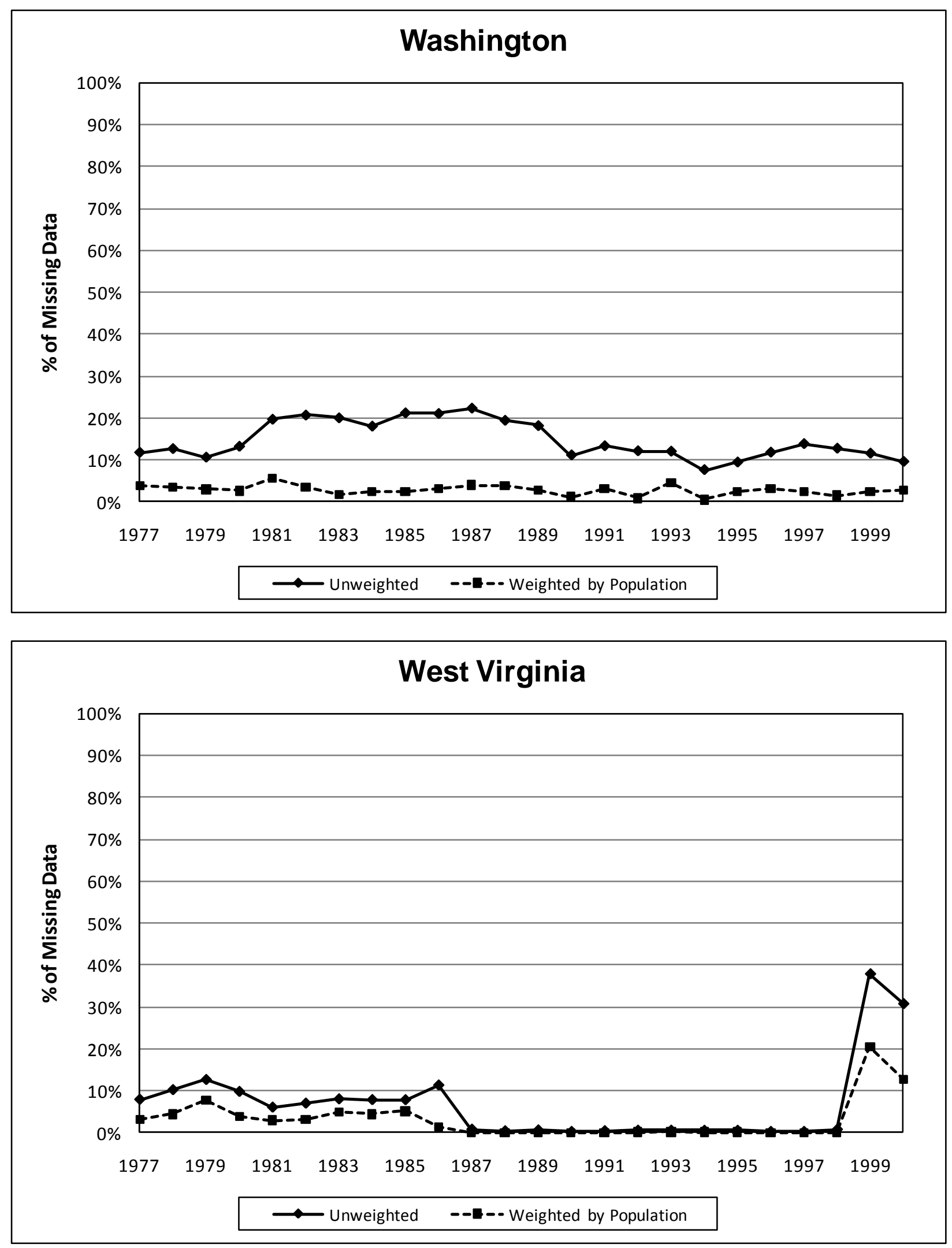

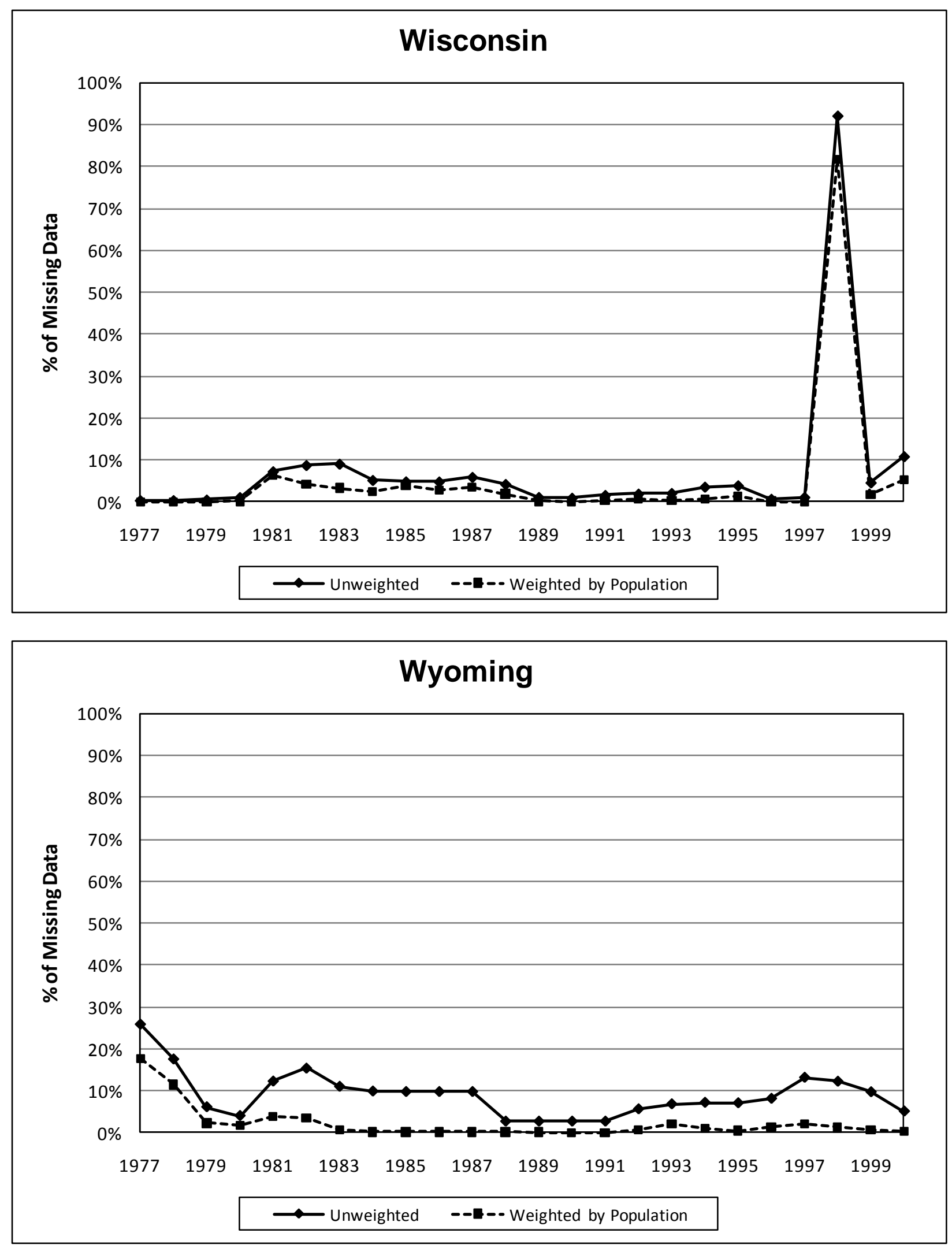


\section{CITED LITERATURE}

Addington, L. (2004). "The Effect of NIBRS Reporting on Item Missing Data in Murder Cases." Homicide Studies 8(3): 193-213.

Akiyama, Y. and S. K. Propheter (2005). Methods of Data Quality Contol: For Uniform Crime Reporting Programs. Clarksburg, WV, Criminal Justice Informaiton Services Division, Federal Bureau of Investigation.

Black, D. J. (1970). "Production of Crime Rates." American Sociological Review 35: 733-758.

Blumstein, A., J. Cohen, et al. (1992). "The UCR-NCS Relationship Revisitied: A Reply to Menard." Criminology 30(1): 115-124.

Brame, R. and R. Paternoster (2003). "Missind Data Problems in Criminological Research: Two Case Studies." Journal of Quantitative Criminology 19(1): 55-78.

Brownstein, H. H. (2000). "The Social Production of Crime Statistics." Justice Research and Policy 2(2): 73-89.

Cleveland, W. S. (1993). Visualizing Data. Murray Hill, NJ, AT\&T Bell Laboratories.

Cleveland, W. S. (1994). The Elements of Graphing Data. Murray Hill, NJ, AT\&T Bell Laboratories.

Conaway, M. R. and S. L. Lohr (1994). "A Longitudinal Analysis of Factors Associated with Reporting Violence Crimes to the Police." Journal of Quantitative Criminology 10(1): 23-39.

Dorinski, S. M. (1998). "Imputation Methods in the Sample Survey of Law Enforcement Agencies." American Statistical Association Proceedings on Survey Research: 302-307.

FBI (1966). Uniform Crime Reporting Handbook. Washington, D.C., U.S. Department of Justice.

FBI (1984). Uniform Crime Reporting Handbook. Washington, D.C., U.S. Department of Justice.

FBI (1999). Hate Crime Data Collection Guidelines. Washington, D.C., U.S. Department of Justice.

FBI (2000). National Incident-Based Reporting System, Volume 1, Data Collection Guidelines. Washington, DC, US Department of Justice.

FBI (2002). Uniform Crime Reporting Program Data [United States]: 1977-2000 [Computer file]. ICPSR09028, Inter-university Consortium for Political and Social Research [distributor], Ann Arbor, MI. 
FBI (2007). Crime in the United States. Washington, DC, US Department of Justice.

FBI (2011). "NIBRS General FAQs." Retreived from http://www.fbi.gov/aboutus/cjis/ucr/frequently-asked-questions/nibrs_faqs\#agencyparticipation on 4/15/2011.

Flewelling, R. L. (2004). "A Nonparametric Imputation Approach for Dealing With Missing Variables in SHR Data." Homicide Studies 8(3): 255-266.

Fox, J. A. (2000). Demographics and U.S. Homicide. The Crime Drop in America. A. Blumstein and J. Wallman. New York, Cambridge University Press.

Fox, J. A. (2004). "Missing Data Problems in the SHR." Homicide Studies 8(3): 214-254.

Jacobs, J. and K. Potter (1998). Hate Crimes: Criminal Law and Identity Politics. New York, NY, Oxford University Press.

Kituse, J. L. and A. V. Cicourel (1963). "A Note on the Uses of Official Statistics." Social Problems 11: 131-139.

Kposowa, A. J., K. D. Breault, et al. (1995). "Reassessing the structural covariates of violent and property crimes in the USA: A county level analysis." British Journal of Sociology 46: 79-105.

LaFree, G. (1989). Rape and Criminal Justice: The Social Construction of Sexual Assault. Belmont, CA, Wadsworth, Inc.

Lillard, L., J. P. Smith, et al. (1986). "What Do We Really Know About Wages? The Importance of Nonreporting and Census Imputation." Journal of Political Economy 94(3): 489-506.

Little, R. J. A. (1988). "Missing-Data Adjustments in Large Surveys." Journal of Business \& Economic Statistics 6(3): 287-296.

Little, R. J. A. and D. B. Rubin (1987). Statitical Analysis of Missing Data. New York, John Wiley \& Sons.

Little, R. J. A. and D. B. Rubin (1989). "The Analysis of Social Science Data with Missing Values." Sociological Methods and Research 18(2\&3): 292-326.

Little, R. J. A. and H.-L. Su (1989). Item Nonresponse in Panel Surveys. Panel Surveys. D. Kasprzyk, G. Duncan, G. Kalton and M. P. Singh. New York, John Wiley \& Sons.

Loftin, C. (1986). "The Validity of Robbery-Murder Classifications in Baltimore." Violence and Victims 1(3): 191-205.

Loftin, C., D. McDowall, et al. (2008). "A Comparison of SHR and Vital Statistics Homicide." Journal of Contemporary Criminal Justice 24(1): 4-17. 
Lott, J. R. (1998). More Guns, Less Crime. Chicago, IL, University of Chicago Press.

Lott, J. R. (2000). More Guns, Less Crime. Chicago, IL, University of Chicago Press.

Lott, J. R. and D. B. Mustard (1997). "Crime, Deterrence, and Right-to-Carry Concealed Handguns." Journal of Legal Studies 26: 1-68.

Lynch, J. P. and L. A. Addington (2007). Understanding Crime Statistics: Revisiting the Divergence of the NCVS and UCR. Cambridge, MA, Cambridge University Press.

Lynch, J. P. and J. P. Jarvis (2008). "Missing Data and Imputation in Uniform Crime Reports and the Effects on National Estimates." Journal of Contemporary Criminal Justice 24(1): 69-85.

Maisel, R. and C. H. Persell (1996). How Sampling Works. Thousand Oaks, CA, Pine Forge Press.

Maltz, M. D. (1977). "Crime Statistics: A Historical Perspective." Crime and Delinquency 23(1): $32-40$.

Maltz, M. D. (1998). "Visualizing Homicide: A Research Note." Journal of Quantitative Criminology 15(4): 397-410.

Maltz, M. D. (1998). "Which Homicides Decreased? Why?" Journal of Criminal Law and Criminology 88(4): 1479-1486.

Maltz, M. D. (1999). Bridging Gaps in Police Crime Data. Washington D.C., Bureau of Justice Statistics.

Maltz, M. D. (2006). Missing UCR Data and Divergence of the NCVS and UCR Trends. J. P. a. A. Lynch, Lynn.

Maltz, M. D. (2007). Missing UCR Data and Divergence of the NCVS and UCR Trends. Understanding Crime Statistics: Revisting the Divergence of the NCVS and UCR. J. P. Lynch and L. A. Addington. New York, NY, Cambridge University Press: 269-298.

Maltz, M. D., Ed. (2009). Look Before You Analyze: Visualizing Data in Criminal Justice. Handbook of Quantiative Criminology. New York, NY, Springer.

Maltz, M. D. and J. Targonski (2002). "A Note on the Use of County-Level Data." Journal of Quantitative Criminology 18(3): 297-318.

Maltz, M. D. and J. Targonski (2003). "Measurement and Other Errors in County-Level UCR Data: A Reply to Lott and Whitley." Journal of Quantitative Criminology 19(2): 199-206. 
Maxfield, M. G. (1989). "Circumstances in Supplementary Homicide Reports: Variety and Validity." Criminology 27(4): 671-695.

McCleary, R., B. C. Nienstedt, et al. (1982). "Uniform Crime Reports as Organizational Outcomes: Three Time Series Experiments." Social Problems 29(4): 361-372.

Menard, S. (1991). "Encouraging News for Criminologists (In the Year 2050)?: A Comment on O'Brien (1990)." Journal of Criminal Justice 19: 563-567.

Menard, S. (1992). "Residual Gains, Reliability, and the UCR-NCS Relationship: A Comment on Blumstein, Cohen, and Rosenfeld (1991)." Criminology 30(1): 105-113.

Mosher, C. J., T. D. Miethe, et al. (2002). The Mismeasure of Crime. Thousand Oaks, CA, Sage.

Nolan, J., S. M. Hass, et al. (2006). "Establishing the "Statistical Accuracy" of Uniform Crime Reports (UCR) in West Virginia." State of West Virginia, Division of Criminal Justice.

O'Brien, R. M. (1990). "Comparing Detrended UCR and NCS Crime Rates Over Time: 19731986." Journal of Criminal Justice 18: 229-238.

O'Brien, R. M. (1991). "Detrended UCR and NCS Crime Rates: Their Utility and Meaning." Journal of Criminal Justice 19: 569-574.

Petee, T. A. and G. S. Kowalski (1993). "Modeling Rural Violent Crime Rates: A Test of Social Disorganization Theory." Sociological Focus 28(1): 87-89.

Petee, T. A., G. S. Kowalski, et al. (1994). "Crime, social disorganization, and social structure: A research note on the use of interurban ecological models." American Journal of Criminal Justice 19: $117-127$.

Poggio, E. C., Kennedy, Stephen D., Chaiken, Jan M., Carlson, Kenneth E. (1985). "Blueprint for the Future of the Uniform Crime Reporting Program." US Department of Justice: FBI.

Pridemore, W. A. (2005). "A Cautionary Note on Using County-Level Crime and Homicide Data." Homicide Studies 9(3): 256-268.

Queally, J. and D. Giambusso (2010). "More than 200 Newark police officers may face layoffs due to $\$ 16.7 \mathrm{M}$ budget shortfall." Retrieved from

http://www.nj.com/news/index.ssf/2010/07/more_than_200_newark_police_of.html on $3 / 15 / 2011$.

Riedel, M. (1990). Nationwide Homicide Data Sets: An Evaluation of the Uniform Crime Reports and the National Center for Health Statistics Data. Measuring Crime: Large-Scale, Long-Range Efforts. D. L. MacKenzie, P. J. Baunach and R. R. Roberg. Albany, NY, State University of New York Press. 
Riedel, M. and W. C. Regoeczi (2004). "Missing Data In Homicide Research." Homicide Studies 8(3): 163-192.

Ringel, C. (1997). Criminal Victimization 1996. Washington, D.C., U.S. Department of Justice.

Rosenbaum, D. P. (1987). "Coping with Victimization: The Effects of Police Intervention On Victim's Psychological Readjustment." Crime and Delinquency 33(4): 502-519.

Rubin, D. B. (1987). Multiple Imputation for Nonresponse in Surveys. New York, John Wiley \& Sons.

Rubin, D. B. (1996). "Multiple Imputation After 18+ Years." Journal of the American Statistical Association 91(434): 473-489.

Schafer, J. L. and J. W. Graham (2002). "Missing Data: Our View of the State of the Art." Psychological Methods 7(2): 144-177.

Schneider, V. W. and B. Wiersema (1990). Limits and Use of the Uniform Crime Reports. Measuring Crime: Large-Scale, Long-Range Efforts. D. L. MacKenzie, P. J. Baunach and R. R. Roberg. Albany, NY, State University of New York Press.

Seidman, D. and M. Couzens (1974). "Getting the Crime Rate Down: Political Pressure and Crime Reporting." Law and Society Review 8: 457-493.

Sherman, L. W., D. Gottfredson, et al. (1997). Preventing Crime: What Works, What Doesn't, What's Promosing. College Park, MD, Department of Criminology and Criminal Justice, Univerisy of Maryland.

Shon, P. and J. Targonski (2003). "Declining Trends in U.S. Parricides, 1976-1998." International Journal of Law and Psychiatry 387: 1-16.

Skogan, W. G. (1974). "The Validity of Official Crime Statistics: An Empirical Investigation." Social Science Quarterly 55: 25-38.

Skogan, W. G. (1975). "Measurement Problems in Official and Survey Crime Rates." Journal of Criminal Justice 3: 17-32.

Skogan, W. G. (1977). "Dimensions of the Dark Figure of Unreported Crime." Delinquency 23(1): 41-50.

Tremblay, A. (1994). Longitudinal Imputation of SIPP Food Stamp Benefits. Washington, DC, U.S. Bureau of the Census.

Tufte, E. R. (1983). The Visual Display of Quantitative Information. Cheshire, CT, Graphics Press. 
Tufte, E. R. (1990). Envisioning Information. Cheshire, CT, Graphics Press.

Tufte, E. R. (1997). Visual Explanations. Cheshire, CT, Graphics Press.

Ullman, S. E. and J. M. Siegel (1994). "Predictors of Exposure to Traumatic Events and Posttraumatic Stress Sequelae." Journal of Community Psychology 22: 328-338.

User Technology Associates, I., Ed. (1999). CJIS Crime Reporting (CCR) Project: Refined Quality Control, Imputation and Estimation Algorithms and Detailed, Tutorial Documentation of Algorithms for Oversight Committees. Arlington, VA.

Van Court, J. and R. B. Trent (2004). "Why Didn't We Get Them All?" Homicide Studies 8(3): 311-321.

Wadsworth, T., J. M. Roberts, et al. (2008). "When Missing Data are Not Missing: A New Approach to Evaluating Supplemental Homicide Report Imputation Strategies." Criminology 46(4): 841-870.

Wilkinson, K. P. (1984). "Rurality and Patterns of Social Disruption." Rural Sociology 49(1): 23-36.

Williams, T. R. and L. Bailey (1996). "Compensating for Missing Wave Data in the Survey of Income and Program Participation (SIPP)." American Statistical Association Proceedings on Survey Research: 305-310.

Yansaneh, I. S., L. S. Wallace, et al. (1998). "Imputation Methods for Large Complex Datasets: An Application to the NEHIS." American Statistical Association Proceedings on Survey Research: 314-319.

Ybarra, L. M. R. and S. L. Lohr (2002). "Estimates of repeat victimization using the National Crime Victimization Survey." Journal of Quantitative Criminology 18: 1-22. 


\section{VITA}

\section{Joseph Robert Targonski}

University of Illinois at Chicago

Department of Criminology, Law and Justice

1007 West Harrison (M/C 141)

Chicago, IL 60607-7140

(312) 413-5893

E-mail: jtargo1@uic.edu

\section{Research Interests:}

Crime measurement, UCR Data, Imputation, gun violence.

\section{Education:}

Doctor of Philosophy in Criminology, Law, and Justice (Expected 8/2011)

University of Illinois at Chicago

- Dissertation: "A Comparison of Imputation Methodologies in the OffensesKnown Uniform Crime Reports"

Chair: Dr. Michael D. Maltz

Master of Arts in Criminal Justice, 5/2001

University of Illinois at Chicago

Bachelor of Arts in Sociology, 5/1999

University of Colorado at Boulder

- Thesis: "Fear of Crime: Examining Gender Differences in the Context of Other Independent Variables,"

Chair: Dr. Joanne Belknap

- Cumulative GPA: 3.25/4.0

- Major GPA: 3.76/4.0

\section{Experience:}

Data Investigation Manager 3/2007-Present Information Resources, Inc. Chicago, IL

Promotion Analyst, 5/2006-3/2007

NCH Marketing Services, Inc. Deerfield, IL

Data Investigation Analyst, 6/2003-5/2006

Information Resources, Inc. Chicago, IL 
Research Assistant, 1/2000-6/2003

Dr. Michael D. Maltz, University of Illinois-Chicago

- Co-Principal Investigator for NIJ Grant, "Enhancing Imputation Methodologies for County-Level UCR Data"

- Examine patterns of missing UCR data to develop longitudinal imputation procedures

Teaching Assistant, 8/2001-12/2001

Criminal Justice 262, Statistics, University of Illinois-Chicago

Dr. Michael D. Maltz

Research Assistant, 11/1999-7/2000

Dr. Mindie Lazarus-Black, University of Illinois-Chicago

- Entered court record data for domestic violence cases in the Caribbean

- Maintained the quality of database and coordinated project efforts with principal investigators

Research Assistant, 1/1997-5/1999

Center for the Prevention of Adverse Life Outcomes, Boulder, CO.

- Trained and supervised approximately 15 lab staff

- Developed and maintained a database for juvenile arrest records

- Collected and analyzed interview data from juvenile offenders

\section{Honors and}

\section{Activities:}

Recipient of the \$20,000 2004 National Institute of Justice Graduate Research Fellowship

$\$ 15,000$ University Fellowship, University of Illinois at Chicago, 8/2002-8/2003

Member of American Statistical Association's Crime and Justice UCR Subcommittee, 4/2002-Present

\$2,500 award from Bureau of Justice Statistics to attend ICPSR workshop, "Quantitative Analysis of Crime and Criminal Justice," 6/2001, University of Michigan at Ann Arbor.

"Missing Data: Statistical Analysis of Data with Incomplete Observations," 7/2002, ICPSR summer course, University of Michigan at Ann Arbor.

\$350 Graduate Student Council Travel Award, 11/2001

\$200 Graduate College Travel Award, 10/2001

\$175 Graduate College Travel Award, 4/2001 
\$250 Graduate Student Council Travel Award, 11/2000

Chicago Bar Association Entertainment Committee Criminal Justice Graduate Award Recipient, 4/2000 and 4/2002

Graduated Cum Laude, University of Colorado at Boulder

Dean's List, Spring 1998, Fall 1998, and Spring 1999

University of Colorado at Boulder

Psi Chi, The National Honor Society in Psychology, 2/1997-Present

Alpha Kappa Delta, The National Honor Society in Sociology,

10/1998-Present

\section{Professional \\ Societies:}

American Society of Criminology

Academy of Criminal Justice Sciences

Justice Research and Statistics Association

Homicide Research Working Group

American Statistical Association

\section{Publications:}

Shon, Phillip C.H., Sudipto Roy, and Joseph Targonski (2007) "Female Offender Parricides: The Asymmetrical Distribution of Homicide for Parents ad Stepparents," Criminology and Social Integration, 14 (2): 13-23.

Shon, Phillip and Joseph Targonski (2003). "Declining Trends in U.S. Parricides, 19761998," International Journal of Law and Psychiatry, 387: 1-16.

Maltz, Michael D. and Joseph Targonski (2003) "Measurement and Other Errors in County-Level UCR Data: A Reply to Lott and Whitley," Journal of Quantitative Criminology 19(2): 199-206.

Maltz, Michael D. and Joseph Targonski (2002) "A Note on the Use of County-Level UCR Data” Journal of Quantitative Criminology, 18(3): 297-318.

Chaiken, Marcia R., Boland, Barbara, Maltz, Michael, Martin, Susan, and Joseph Targonski (2001). "State and Local Change and the Violence Against Women Act," NIJ Research Report, NCJ 191186, Washington, D.C. 


\section{Presentations:}

"Missing in Action: Handling Agency Nonresponse in the UCR." (with Michael Maltz). 2003 Annual Meeting of the American Society of Criminology, Denver, CO.

"Normal Beginnings: John Hinckley and Timothy McVeigh." (with Jeffery Frost). Presidential Panel on "Visualizing Life Course Trajectories," 2002 Annual Meeting of the American Society of Criminology, Chicago, IL.

"Life Course Visualization methodology," (with Sharon Shipinski, and Marianne Ring), 2001 Annual Meeting of the Homicide Research Working Group, St. Louis, MO.

"Fear of Crime and Social Control: A Community-Level Analysis Across 100 Neighborhoods," (with Dennis Rosenbaum), 2001 Annual Meeting of the American Society of Criminology, Atlanta, GA.

"Dealing with Missing Data in the UCR," (with Michael Maltz), 2001 Annual Meeting of the Justice Research and Statistics Association, New Orleans, LA.

"Trends in U.S. Parricides, 1976-1998," (with Phillip Shon), 2001 Annual Meeting of the Academy of Criminal Justice Sciences, Washington, D.C.

"Imputation Issues in UCR Data," (with Michael D. Maltz), 2000 Annual Meeting of the American Society of Criminology, San Francisco, CA.

"Gender and Fear of Crime: Explaining the Discrepancy in Relation to Victimization Rates," 1999 Annual Meeting of the Midwest Sociological Society, Minneapolis, MN. 